Michelly Arjona Maciel

\title{
EFEITOS DA REABILITAÇÃO VIRTUAL EM PACIENTES COM DOENÇA DE PARKINSON E SUAS CORRELAÇÕES COM O METABOLISMO CEREBRAL IN VIVO
}

\author{
Dissertação apresentada à Faculdade \\ Israelita de Ciências da Saúde Albert \\ Einstein para obtenção do Título de Mestre \\ em Ciências da Saúde.
}


Michelly Arjona Maciel

\title{
EFEITOS DA REABILITAÇÃO VIRTUAL EM PACIENTES COM DOENÇA DE PARKINSON E SUAS CORRELAÇÕES COM O METABOLISMO CEREBRAL IN VIVO
}

\author{
Dissertação apresentada à Faculdade \\ Israelita de Ciências da Saúde Albert \\ Einstein para obtenção do Título de Mestre \\ em Ciências da Saúde.
}

Orientador: Dr. André Carvalho Felício

São Paulo

2018 
M152e

Maciel, Michelly Arjona

Efeitos da reabilitação virtual em pacientes com doença de

Parkinson e suas correlações com o metabolismo cerebral in vivo /

Michelly Arjona Maciel. -- São Paulo, 2018.

$\mathrm{xv}, 62 \mathrm{f}$.

Dissertação (Mestrado) - Faculdade Israelita de Ciências da Saúde Albert Einstein. Instituto Israelita de Ensino e Pesquisa Albert Einstein. Programa de Pós-Graduação em Ciências da Saúde.

Título em inglês: Effects of virtual rehabilitation in patients with Parkison's diseases and correlations with in vivo cerebral metabolism.

1. Doença de Parkinson. 2. Realidade virtual. 3. Cognição. 4. Qualidade de vida. 5. Neuroimagem.

NLM - WL 359

Elaborada pelo Sistema Einstein Integrado de Bibliotecas 
FACULDADE ISRAELITA DE CIÊNCIAS DA SAÚDE ALBERT EINSTEIN

Coordenador do Curso de Pós-Graduação: Prof. Dr. Luiz Vicente Rizzo 
Michelly Arjona Maciel

\section{EFEITOS DA REABILITAÇÃO VIRTUAL EM PACIENTES COM DOENÇA DE PARKINSON E SUAS CORRELAÇÕES COM O METABOLISMO CEREBRAL IN VIVO}

Presidente da banca: Prof. Dr. André Carvalho Felício

BANCA EXAMINADORA

Membros titulares:

Prof. Dr. Luís Otávio Caboclo

Profa. Dra. Lilian Yuri Itaya Yamaga

Prof. Dr. Marcelo Pinto Ferreira

Membros suplentes:

Profa. Dra. Alexandra Passos Gaspar

Prof. Dr. Clécio de Oliveira Godeiro Junior

Aprovada em: 26/11/2018. 


\section{Agradecimentos}

Nesse momento tão importante só devo agradecer.

Agradecer a minha querida mãe por todo o incentivo de sempre e por ter certeza que tudo daria certo.

A minha família e esposo por acreditarem que eu seria capaz e por sempre me apoiarem em todas as conquistas entendendo minha ausência em alguns momentos.

A minha amiga e companheira de projeto, Juliana, sem ela certamente seria mais difícil chegar até aqui.

Agradeço especialmente ao meu orientador, Dr. André, pela confiança, por apostar nesse projeto de grande responsabilidade e por todo o auxílio e ensinamentos para que tudo se concretizasse.

Não posso esquecer-me de agradecer aos voluntários da pesquisa, pacientes com disfunções motoras e dificuldades de locomoção que participaram fielmente do estudo, sempre felizes por estarem contribuindo para a pesquisa. Vocês foram essenciais.

Agradeço a toda equipe da Pós-Graduação em Ciências da Saúde IIEP, por todo o auxílio durante o projeto. Ao setor de imagem que colaborou muito, em especial a Taise e Karine que foram ótimas em todo o momento, as enfermeiras Alda, Karina e Rose por trabalharem para que tudo desse certo e ao Dr. Guilherme de Carvalho pelo auxilio nos momentos de desespero durante as análises dos resultados. Obrigada também ao setor do NAP pela auxilio com a parte burocrática e administrativa que envolveu o projeto.

Muito obrigada à banca avaliadora que mostrou novas possibilidades e agregou muito conteúdo ao trabalho.

Obrigada a todos, que juntos, me proporcionaram mais que a busca de conhecimento técnico e científico, mas sim uma lição de vida. 
Agradeço a Fundação de Amparo à Pesquisa do Estado de São Paulo FAPESP pelo apoio financeiro para realização deste estudo, assim como pela bolsa de mestrado concedida.

Número do processo de pesquisa: 2015/07088-6

Número processo de bolsa de mestrado: 2016/10795-9. 


\section{Sumário}

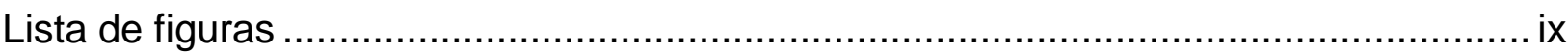

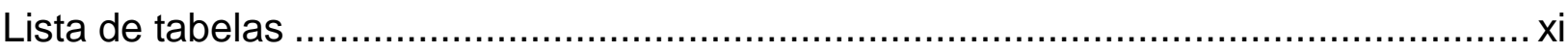

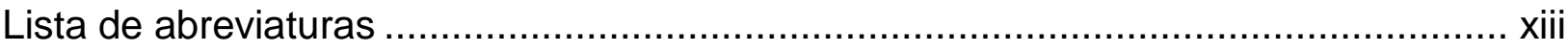

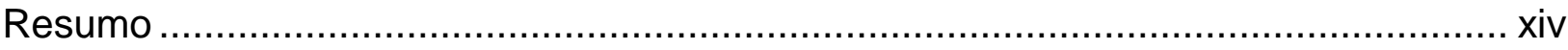

1 INTRODUÇÃO

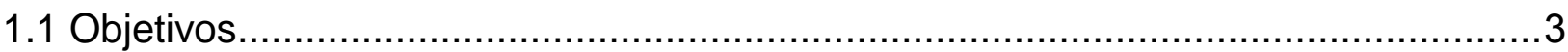

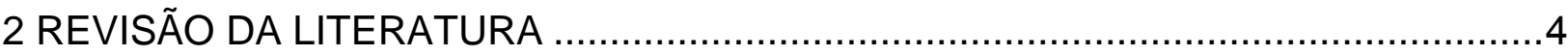

2.1 Doença de Parkinson ........................................................ 4

2.1.1 Fisiopatologia: fatores ambientais e genéticos .............................................

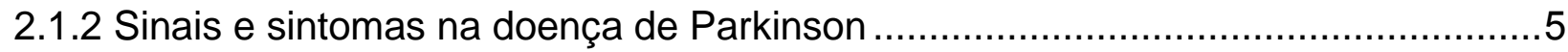

2.1.3 Sinais e sintomas não motores na doença de Parkinson ...................................6

2.2 Reabilitação virtual ............................................................ 8

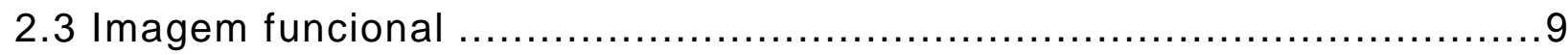

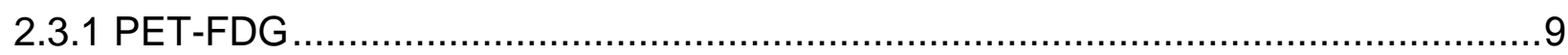

2.3.2 PET-FDG na doença de Parkinson sem comprometimento cognitivo ................... 10

2.3.3 PET-FDG na doença de Parkinson com comprometimento cognitivo ...................10

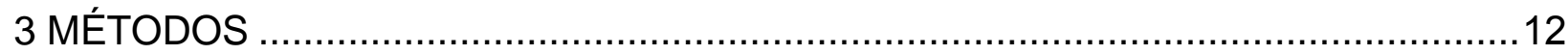

3.1 Seleção de pacientes ............................................................ 12

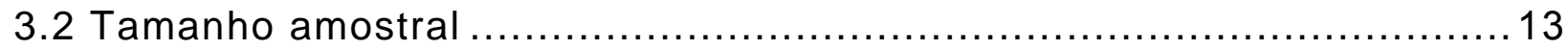

3.3 Local de avaliação e protocolo clínico ........................................ 13

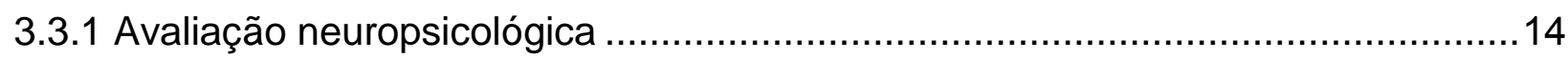

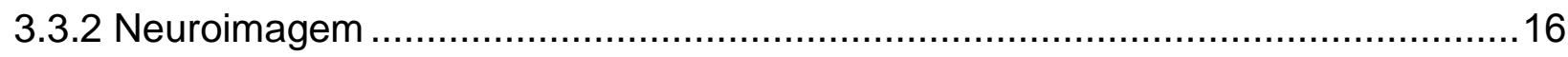

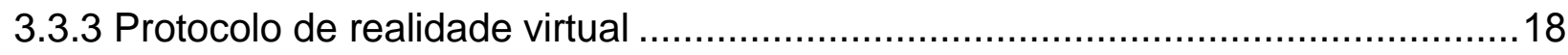

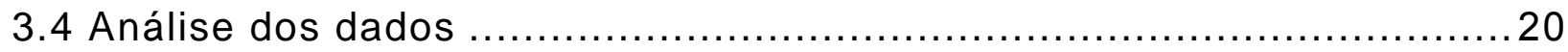

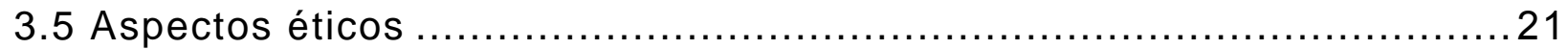

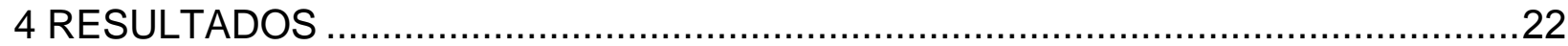

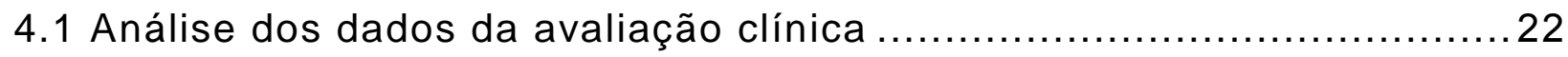

4.1.1 Perfil dos pacientes: dados demográficos e características da doença de

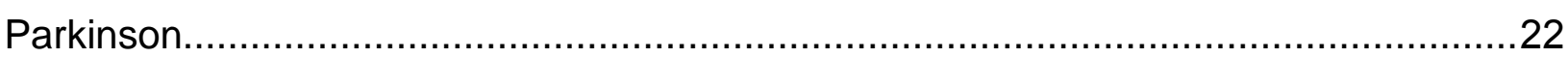

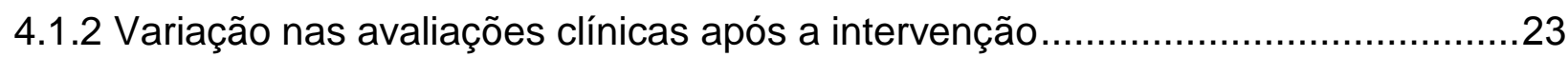

4.1.3 Variação nos escores dos testes de avaliação neuropsicológica após a intervenção..... 
4.1.4 Variação nas medidas de neuroimagem funcional obtidas através de PET-RM

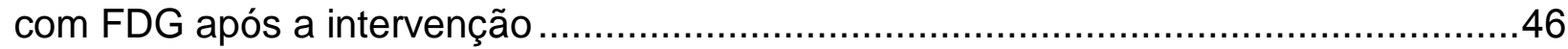

5 DISCUSSÃO

6 CONCLUSÕES

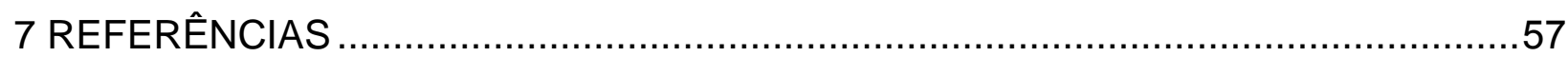

Abstract

Apêndices 


\section{Lista de figuras}

Figura 1. Seleção dos voluntários 12

Figura 2. Escore na Parte II. Atividades da Vida Diária do instrumento UPDRS nas avaliações pré e pós-intervenção .28

Figura 3. Escore na Parte III. Exame Motor do instrumento UPDRS nas avaliações pré e pós-intervenção. .29

Figura 4. Escore total do instrumento UPDRS nas avaliações pré e pós-intervenção .29 Figura 5. Escore no domínio Mobilidade do questionário PDQ-39 nas avaliações pré e pós-intervenção 36

Figura 6. Escore no domínio Atividade de Vida Diária do questionário PDQ-39 nas avaliações pré e pós-intervenção 36

Figura 7. Escore no domínio Estigma do questionário PDQ-39 nas avaliações pré e pós-intervenção .37

Figura 8. Escore no domínio Comunicação do questionário PDQ-39 nas avaliações pré e pós-intervenção 37

Figura 9. Escore no domínio Desconforto Corporal do questionário PDQ-39 nas avaliações pré e pós-intervenção 38

Figura 10. Escore total do questionário PDQ-39 nas avaliações pré e pós-intervenção .38

Figura 11. Escore no domínio Capacidade Funcional do instrumento SF-36 nas avaliações pré e pós-intervenção .39

Figura 12. Escore no domínio Dor do instrumento SF-36 nas avaliações pré e pósintervenção.

Figura 13. Escore no domínio Saúde Mental do instrumento SF-36 nas avaliações pré e pós-intervenção. 40

Figura 14. Escore total do instrumento Escala de Equilíbrio Funcional de Berg nas avaliações pré e pós-intervenção

Figura 15. Escore do Teste de Aprendizagem Auditivo-Verbal de Rey - Lista A 5 nas avaliações pré e pós-intervenção

Figura 16. Escore do Teste de Nomeação de Boston nas avaliações pré e pósintervenção 
Figura 17. Escore do Inventário Neuropsiquiátrico - Intensidade dos Sintomas nas avaliações pré e pós-intervenção

Figura 18. Escore do Inventário Neuropsiquiátrico - Total nas avaliações pré e pósintervenção.

Figura 19. PET-RM Desvio Padrão Lobo frontal no lado contralateral ao lado mais afetado nas avaliações pré e pós-intervenção 48

Figura 20. PET-RM Desvio Padrão Giro medial frontal no lado contralateral ao lado mais afetado nas avaliações pré e pós-intervenção .48

Figura 21. PET-RM Desvio Padrão Giro frontal superior, dorsolateral no lado contralateral ao lado mais afetado nas avaliações pré e pós-intervenção 49

Figura 22. PET-RM Desvio Padrão Área motora suplementar no lado contralateral ao lado mais afetado nas avaliações pré e pós-intervenção.

Figura 23. PET-RM Desvio Padrão Cuneus no lado ipsilateral ao lado mais afetado nas avaliações pré e pós-intervenção .50

Figura 24. PET-RM Desvio Padrão Giro frontal superior, dorsolateral no lado ipsilateral ao lado mais afetado nas avaliações pré e pós-intervenção .50

Figura 25. PET-RM Desvio Padrão Área motora suplementar no lado ipsilateral ao lado mais afetado nas avaliações pré e pós-intervenção. .50 


\section{Lista de tabelas}

Tabela 1. Características demográficas e da DP dos participantes do estudo 22

Tabela 2. Escores nos itens da UPDRS dos participantes do estudo nas avaliações pré e pós-intervenção.

Tabela 3. Escores total e das partes II e III da UPDRS dos participantes do estudo nas avaliações pré e pós-intervenção 28

Tabela 4. Escores nos itens da UPDRS no lado mais afetado dos participantes do estudo nas avaliações pré e pós-intervenção. 30

Tabela 5. Escores nos itens do questionário PDQ-39 dos participantes do estudo nas avaliações pré e pós-intervenção

Tabela 6. Escores total da escala PDQ-39 dos participantes do estudo nas avaliações pré e pós-intervenção. .35

Tabela 7. Escores dos instrumentos de avaliação SF-36 antes e após oito semanas de treinamento.

Tabela 8. Escores nos itens do instrumento Escala de Equilíbrio Funcional de Berg dos participantes do estudo nas avaliações pré e pós-intervenção

Tabela 9. Escores total da Escala de Equilíbrio Funcional de Berg dos participantes do estudo nas avaliações pré e pós-intervenção.

Tabela 10. Escores nos subtestes WAIS-III (vocabulário, semelhanças, cubos e dígitos) dos participantes do estudo nas avaliações pré e pós-intervenção.

Tabela 11. Escores nas tarefas do Teste de Aprendizagem Auditivo-Verbal de Rey (RAVLT) dos participantes do estudo nas avaliações pré e pós-intervenção.

Tabela 12. Escores no Teste de Nomeação de Boston, Teste do Desenho do Relógio e Subteste de Letras Fragmentadas e Análise de Cubos da bateria de Percepção Visual de Objetos e Espeço (VOSP) dos participantes do estudo nas avaliações pré e pósintervenção

Tabela 13. Inventário neuropsiquiátrico dos participantes do estudo nas avaliações pré e pós-intervenção.

Tabela 14. Medidas de Desvio-Padrão do exame de neuroimagem funcional através do PET-RM com FDG no lado contralateral ao lado mais afetado dos participantes do estudo nas avaliações pré e pós-intervenção. 
Tabela 15. Medidas de Desvio-Padrão do exame de neuroimagem funcional através do PET-RM com FDG no lado ipsilateral ao lado mais afetado dos participantes do estudo nas avaliações pré e pós-intervenção .48 


\section{Lista de abreviaturas}

DP

FDG

IAMSPE

PDQ-39

PET

$\mathrm{PET} / \mathrm{CT}$

PET-FDG

PET-RM

$\mathrm{RM}$

RV

SF-36

SUV

SNC

TCLE

UNIFESP

UPDRS
Doença de Parkinson

18F-fluorodeoxiglucose

Instituto de Assistência Médica ao Servidor Público

Questionário da Doença de Parkinson (Parkinson's Disease Questionnaire)

Tomografia por Emissão de Pósitrons (Positron Emission Tomography)

Tomografia Computadorizada com Tomografia por Emissão de Pósitrons (Positron Emission Tomography/Computed Tomography) Tomografia por Emissão de Pósitrons -18F-fluorodeoxiglucose PET-Ressonância Magnética

Ressonância Magnética

Realidade Virtual

Short-Form Health Status Survey

Standard Value Uptake

Sistema Nervoso Central

Termo de Consentimento Livre e Esclarecido

Universidade Federal de São Paulo

Escala Unificada de Avaliação da Doença de Parkinson (Unified Parkinsons' disease Rating Scale) 


\section{Resumo}

Introdução: A doença de Parkinson é a segunda doença neurodegenerativa mais comum e, em países como o Brasil, sua prevalência deverá aumentar ainda mais com o envelhecimento da população. A terapia padrão da doença de Parkinson consiste em medicações que aumentam a dopamina (levodopa) associado à fisioterapia convencional. A realidade virtual, entretanto, pode oferecer um ambiente mais dinâmico e interativo de reabilitação que a fisioterapia convencional, com possibilidade de aprendizado motor (feedback) e fornecimento de pistas sensoriais para o tratamento desses pacientes. De acordo com a literatura, a realidade virtual melhora sintomas motores da doença de Parkinson, incluindo aqueles resistentes à terapia com levodopa, como o equilíbrio, além de funções cognitivas como atenção, memória e planejamento. Entretanto, existe pouca informação na literatura sobre os mecanismos cerebrais in vivo pelos quais estes benefícios ocorreriam. Objetivos: Avaliar os efeitos de um protocolo de realidade virtual sobre sintomas motores, qualidade de vida e cognição de pacientes com doença de Parkinson, correlacionando estes dados com o metabolismo cerebral de glicose através de Tomografia Computadorizada por Emissão de Pósitrons com 18F-fluorodeoxiglucose. Métodos: Foram selecionados 20 pacientes com doença de Parkinson, sem demência, depressão e/ou alterações clínicas descompensadas. Os voluntários realizaram um protocolo de realidade virtual através do console Xbox $360 \mathrm{~S}^{\circledR}$ e sensor Kinect ${ }^{\circledR}$, com os jogos do Kinect ${ }^{\circledR}$ Adventures, durante 8 semanas de treinamento supervisionado, 2 sessões por semana. Os desfechos motores e não motores foram avaliados antes e depois da intervenção, por meio das seguintes escalas: Unified Parkinson's disease rating scale parte III, escala de equilíbrio de Berg, Parkinson's disease questionnaire, Short-Form Health Status Survey e avaliação neuropsicológica estruturada. As imagens cerebrais foram realizadas através de Tomografia por Emissão de Pósitrons -18F-fluorodeoxiglucose e quantificadas em regiões estriatais e extra-estriatais. Resultados: Avaliando-se os períodos pré e pós-protocolo de realidade virtual, foram observadas alterações estatisticamente significantes com melhora motora, equilíbrio, qualidade de vida e algumas funções cognitivas: teste de vocabulário $(p=0,047)$, teste de aprendizagem auditivo-verbal de Rey/RAVLT( $p=0,049)$, teste de nomeação de Boston $(p=0,014)$ e redução no escore de intensidade dos sintomas $(p=0,012)$ e escore total $(p=0,043)$ do 
teste Inventário Neuropsiquiátrico. Além disto, identificamos algumas alterações no metabolismo cerebral de glicose em regiões frontais: nas regiões de lobo frontal $(p=0,014)$, giro frontal medial $(p=0,031)$, giro frontal superior dorsolateral $(p=0,004)$ e área motora suplementar $(p=0,031)$ contralateral ao hemicorpo clinicamente mais afetado. Em relação às regiões ipsilaterais ao hemicorpo mais afetado observamos variações nas regiões do cuneus $(p=0,036)$, giro frontal superior dorsolateral $(p=0,010)$ e área motora suplementar $(p=0,012)$. Conclusões: Observamos que a realidade virtual melhorou sinais motores e qualidade de vida dos pacientes com doença de Parkinson, além de algumas funções cognitivas. Paralelamente, houve possível atividade compensatória no metabolismo cerebral de glicose. 


\section{INTRODUÇÃO}

A doença de Parkinson (DP) é uma das doenças neurodegenerativas mais frequentes que afetam os idosos. Dados da Organização Mundial de Saúde mostram que aproximadamente $1 \%$ da população mundial com idade superior a 65 anos tem a doença. Só no Brasil, estima-se que cerca de 200 mil pessoas sofram com o problema. ${ }^{(1)}$

A DP é causada pela degeneração dos neurônios dopaminérgicos da substância negra dos núcleos da base, que traz como consequência a diminuição progressiva da produção de dopamina. Este comprometimento leva aos sinais da tétrade clássica em portadores de DP: bradicinesia, tremor de repouso, rigidez e instabilidade postural, denominados sinais motores; e os não motores, depressão, alterações do sono, diminuição do olfato, constipação intestinal e urgência urinária, entre outros. O pilar do tratamento está em minimizar o impacto dos sinais motores, seja com levodopa ou agonistas dopaminérgicos, ${ }^{(2)}$ ou seja através do tratamento cirúrgico com estimulação cerebral profunda, ${ }^{(3)}$

A levodopa é, sem dúvidas, a medicação com mais eficácia para tratar os sinais motores da DP. Sua indicação depende de uma série de fatores que levam em conta a gravidade dos sintomas, a idade do paciente e seu status funcional. ${ }^{(4)}$ Entretanto, virtualmente todos os portadores de DP irão apresentar complicações do uso crônico da levodopa, por exemplo, flutuações motoras e discinesias. ${ }^{(5)}$

Infelizmente, apesar de todo avanço nas pesquisas, existem sinais motores que normalmente não respondem ou respondem pobremente a levodopa, por exemplo, a instabilidade postural (desequilíbrio) e o congelamento de marcha, do inglês, freezing. ${ }^{(6,7)}$ A estes sinais associa-se a terminologia dopa-resistente, justamente para denotar sua pobre resposta ao tratamento farmacológico com levodopa ou agonistas dopaminérgicos.

A fisioterapia tem um papel fundamental na reabilitação de pacientes com DP maximizando a independência funcional e sua forma física geral. Segundo a Diretriz Europeia de Fisioterapia para DP, ${ }^{(8)}$ as cinco áreas centrais da fisioterapia direcionadas a portadores da DP são: capacidade física, transferências, atividades manuais, equilíbrio e marcha. 
A Realidade Virtual (RV) é uma técnica pela qual uma pessoa interage com uma realidade artificial, que pode ser totalmente controlada pelo experimentador, de modo que as respostas do sujeito possam ser perfeitamente monitoradas e avaliadas. A RV pode ajudar a superar algumas das limitações de espaço e recursos encontradas nas clínicas tradicionais, ao mesmo tempo em que permite aos pacientes repetir a prática de habilidades. ${ }^{(9)}$

No contexto de uma doença neurodegenerativa, com envolvimento de vários sistemas como a DP, as técnicas de imagem molecular têm o objetivo de avaliar qualitativa e quantitativamente ${ }^{(10)}$ a neurodegeneração cerebral e extra-cerebral associada à presença de corpos de Lewy, por exemplo, com radiotraçadores que se ligam no terminal pré-sináptico dopaminérgico. ${ }^{(11)} \mathrm{O}$ momento da demência em relação ao parkinsonismo é a principal distinção clínica entre demência por corpúsculos de Lewy e DP, com demência surgindo no cenário da DP idiopática bem estabelecida (após pelo menos 1 ano de sintomas motores) denotando DP, enquanto comprometimento cognitivo anterior em relação ao parkinsonismo denota demência por corpúsculos de Lewy. ${ }^{(12)}$

Outra possibilidade de estudo não invasivo de regiões estriatais, mas principalmente corticais do encéfalo é através da tomografia por emissão de pósitrons (PET - Positron Emission Tomography), utilizando-se 0 ligante Fluorodeoxiglicose (FDG) marcada com flúor-18, uma molécula similar em estrutura à glicose, de modo que pode ser usado para conseguir imagens de partes do cérebro que estão usando mais ou menos glicose do que outros, inferindo-se sobre o metabolismo cerebral. ${ }^{(13)}$ Embora de acesso limitado em nosso país, este exame está disponível comercialmente. Entre as vantagens de utilizar o PET-FDG para o estudo do metabolismo cerebral destaca-se a melhor resolução das imagens, quando comparadas às de tomografia computadorizada por emissão de fóton único (SPECT Single Photon Emission Computed Tomography), assim como a possibilidade de avaliar estruturas corticais envolvidas na DP com comprometimento cognitivo e motor. ${ }^{(14-16)}$

Portanto, a hipótese desse estudo, considerando o mesmo como proof of concept, é que a RV poderia alterar o metabolismo cerebral de glicose em pacientes com DP, normalizando as áreas de hiper ou hipoatividade em regiões corticais e subcorticais. 


\subsection{Objetivos}

1. Verificar o efeito da realidade virtual no metabolismo cerebral de glicose em indivíduos com doença de Parkinson;

2. Verificar a influência da reabilitação virtual nos sinais motores, qualidade de vida e função cognitiva em pacientes com doença de Parkinson. 


\section{REVISÃO DA LITERATURA}

\subsection{Doença de Parkinson}

A DP é uma doença neurodegenerativa crônica e progressiva com maior prevalência em idosos. Essa patologia representa um distúrbio complexo influenciado por anormalidades genéticas e celulares, fatores ambientais e idade. ${ }^{(17)}$

A DP é a segunda doença neurodegenerativa mais comum no mundo. ${ }^{(18)}$ Segundo um estudo recente, o Brasil está passando por uma mudança demográfica, na qual o número de idosos está aumentando exponencialmente, invertendo a pirâmide etária de nosso país. ${ }^{(19)}$ Isto, por sua vez, acarreta em número cada vez maior de pacientes com DP, dado a correlação desta doença com a idade (envelhecimento). ${ }^{(20)}$ Naturalmente, o aumento do número de casos de DP traz consigo um grande desafio para as contas públicas em nosso país, particularmente com os frequentes cortes no orçamento para saúde, que foi em torno US\$19 bilhões em 2016, quase US $\$ 4,680$ bilhões a menos que o de $2015 .^{(20)}$

\subsubsection{Fisiopatologia: fatores ambientais e genéticos}

Embora a etiologia específica da DP não seja clara, o processo patológico é bem conhecido. A característica mais notável é a perda de neurônios dopaminérgicos da substância negra. ${ }^{(21)}$

A DP decorre da destruição generalizada da parte da substância negra, a pars compacta, que envia fibras nervosas secretoras de dopamina para o núcleo caudado e para o putâmen. Com a degeneração desses neurônios dopaminérgicos, o caudado e o putâmen ficam excessivamente ativos, causando assim, saída contínua de sinais excitatórios para o sistema de controle motor corticoespinhal. $^{(22)}$

Embora a etiologia especifica da DP seja desconhecida, acredita-se que fatores ambientais e genéticos poderiam interagir em conjunto com outros processos patológicos (disfunção mitocondrial) e contribuir para o processo de neurodegeneração na DP. ${ }^{(23)}$ 
Dentre os fatores ambientais interligados ao aparecimento da DP, destacam-se os indivíduos que vivem em zona rural, que fazem uso de água de poço e que estão mais expostos a pesticidas e herbicidas. Além disto, a exposição ambiental a produtos químicos industriais, como manganês, mercúrio e solventes também está ligada ao surgimento da DP. Esta exposição a fatores ambientais poderia levar, em parte, a um estresse oxidativo, por um desequilíbrio entre os fatores que promovem a formação de radicais livres e os mecanismos de defesa antioxidativos. ${ }^{(24)}$ Por outro lado, mutações dos principais genes que levam à DP (PARK1, 2, 6, 7, 8) estão, via de regra, relacionadas a disfunções mitocondriais ou destruição de sistemas de reparação celular, levando a uma cascata de eventos que culmina com morte celular programada. ${ }^{(25)}$

O diagnóstico de DP é frequentemente realizado vários anos após o início do processo de neurodegeneração, conforme demonstram estudos patológicos e de neuroimagem funcional. ${ }^{(18)}$ Desta forma, existe um período chamado "subclínico" ou "pré-motor" em que os sintomas motores típicos ainda não se desenvolveram. Estudos post-mortem baseados na contagem de células nigrais e na avaliação dos níveis de dopamina nos estriados, e estudos de imagem avaliando a via nigrostriatal in vivo, estimaram que este período poderia durar de 3 a 6 anos. Neste período subclínico, os pacientes com DP apresentam sintomas não motores como hiposmia, transtorno comportamental do sono REM, depressão ou constipação intestinal. ${ }^{(18,26)}$ A fisiopatologia desses sintomas "pré-motores", embora ainda não esteja clara, é atualmente considerada relacionada ao envolvimento precoce pelo processo patológico subjacente à DP de estruturas do tronco cerebral não dopaminérgico inferior ou plexos autonômicos.

\subsubsection{Sinais e sintomas na doença de Parkinson}

Dentre os sinais clínicos que caracterizam a DP destacam-se a seguinte tétrade: bradicinesia, tremor de repouso, rigidez e instabilidade postural. ${ }^{(18)}$

A bradicinesia refere-se à lentidão do movimento, com fadiga precoce, decremento da amplitude do movimento e hesitações. Este é o sinal que define a DP, embora também possa ser visto em outras doenças, incluindo a depressão. A bradicinesia é uma marca de distúrbios dos núcleos da base, e está 
associada a outras dificuldades motoras que os pacientes apresentam como planejamento do movimento, iniciação e execução do movimento e realização de tarefas sequenciais e simultâneas. ${ }^{(27)}$

O tremor de repouso é o sintoma mais comum da DP e pode ser facilmente reconhecido. Os tremores são em geral unilaterais ou bilaterais assimétricos e, quase sempre, são mais proeminentes na parte distal do membro superior. ${ }^{(27)}$

A rigidez é caracterizada pelo aumento do tônus, com resistência passiva durante todo movimento de extensão e flexão do membro, geralmente acompanhada pelo fenômeno "roda denteada", particularmente quando associada a um tremor subjacente. ${ }^{(18,27)}$

A instabilidade postural devido à perda de reflexos posturais é geralmente uma manifestação de estágios mais tardios da DP e ocorre geralmente após o aparecimento dos outros sinais motores da doença. ${ }^{(27)}$ Dentre os sintomas motores mencionados, este é classicamente considerado como refratário ao tratamento de reposição dopaminérgica. ${ }^{(28)}$

\subsubsection{Sinais e sintomas não motores na doença de Parkinson}

Além de sintomas motores, existem ainda na DP sintomas não motores que afetam de maneira significativa a qualidade de vida dos pacientes. ${ }^{(28,29)}$ Por exemplo, o comprometimento cognitivo e a depressão podem influenciar os níveis de atividade física, independentemente da função motora. ${ }^{\left({ }^{30}\right)}$

Em pacientes com DP sem demência, os déficits cognitivos são tipicamente fronto-estriatais por natureza. Assim, habilidades executivas como planejamento, flexibilidade cognitiva, fluência verbal e controle inibitório, além de tarefas do tipo memória de trabalho, mostraram-se prejudicadas nesses pacientes. A velocidade de processamento é outro domínio cognitivo que é de vital importância para o funcionamento cotidiano, e tipicamente mostra declínios na PD. ${ }^{(31)}$

O declínio cognitivo na DP pode estar entre os sintomas mais debilitantes associados à progressão da doença. As estimativas de declínio cognitivo e demência na DP sugerem que, anualmente, $14 \%$ dos pacientes com mais de 65 anos com DP desenvolverão algum comprometimento cognitivo. ${ }^{(30,32)}$ Clinicamente, o declínio cognitivo na DP caracteriza-se por disfunção executiva, desatenção e 
alterações na percepção visuoespacial, semelhante ao que ocorre na demência com corpos de Lewy. ${ }^{(32)}$

$\mathrm{Na}$ DP os sintomas não motores tais como comprometimento cognitivo e depressão influenciam os níveis de atividade física. A depressão está relacionada ao bem-estar dos pacientes e à qualidade de vida relacionada à saúde, bem como ao comprometimento cognitivo e demência. Nos estágios avançados da DP, os déficits cognitivos e a demência aparecem cada vez mais nesses pacientes. ${ }^{(30)}$

Os distúrbios neurodegenerativos são caracterizados pela perda gradual de neurônios no sistema nervoso central. Eles têm várias manifestações, como deficiência cognitiva; e alterações de movimento. Esses distúrbios neurodegenerativos estão associados a um espectro diversificado de manifestações clínicas que podem ter grande impacto em diferentes dimensões da qualidade de vida. ${ }^{(33)}$

Medicações dopaminérgicas como, por exemplo, a levodopa, também podem ter um efeito deletério sobre a função cognitiva. A evidência indica que o estado dopaminérgico necessário para controlar os sintomas motores tem o potencial de alterar certas funções cognitivas e pode até levar a uma síndrome de desregulação da dopamina. ${ }^{(34)}$ Outros estudos, por outro lado, sugerem que a hiperativação ou a estimulação anormal de receptores de dopamina pós-sinápticos por agonistas de dopamina de segunda geração possam desempenhar um papel no prejuízo de funções cognitivas em pacientes com DP. ${ }^{(35)}$

Os domínios cognitivos mais afetados na DP são as funções executivas, visuoespaciais, de atenção e de memória. O diagnóstico de demência na DP requer avaliação objetiva, no entanto, para se alcançar a sensibilidade diagnóstica deve-se avaliar o declínio cognitivo com pelo menos dois testes neuropsicológicos investigando cada um dos quatro domínios cognitivos mencionados acima, mais o domínio da linguagem. ${ }^{(36)}$

Acredita-se que os aspectos da aprendizagem e da motivação dependem da função da dopamina do estriado e que múltiplos mecanismos neurobiológicos sustentam tais efeitos na aprendizagem e na motivação. ${ }^{(37)}$ 


\subsection{Reabilitação virtual}

A RV é uma ferramenta de reabilitação promissora com uma ampla possibilidade de aplicações. No contexto da fisioterapia, a RV é recomendada para otimizar o aprendizado motor em um ambiente seguro, além de ser uma abordagem eficiente que oferece feedback aumentado sobre o desempenho, estimulando simultaneamente os processos motores e cognitivos. ${ }^{(38)}$

Acredita-se que exercícios com terapia de RV podem ser uma ferramenta útil devido à estimulação de músculos voluntários; ativação do sistema somatossensorial por várias posições dos segmentos do corpo em diferentes amplitudes de movimentos; e um conjunto envolvente de tarefas e feedback em tempo real. Além disso, os aspectos lúdicos e dinâmicos da terapia virtual também podem contribuir para melhorar a motivação e a disposição para a atividade proposta e, ao mesmo tempo, podem levar à redução da apatia dos pacientes. A RV oferece oportunidades para aprender novas estratégias motoras e reaprender as habilidades motoras perdidas como resultado de uma lesão ou doença. ${ }^{(39)}$

$\mathrm{Na}$ DP além da fisioterapia convencional bem consolidada, essas novas estratégias terapêuticas, dentre elas o treinamento de RV através de videogames, mostraram efeitos positivos na DP. Estudo recente, por exemplo, demonstrou a viabilidade e segurança de um treino com RV em pacientes na fase moderada da DP. ${ }^{(40)}$

Em meio aos recentes avanços tecnológicos, o sensor Microsoft Kinect é um potencial recurso alternativo de baixo custo que pode auxiliar no tratamento de indivíduos com DP. ${ }^{(41)} \mathrm{O}$ aparelho se resume em um sensor baseado em câmera usado principalmente para controlar diretamente jogos de computador por meio do movimento do corpo. O Kinect rastreia a posição dos membros e do corpo sem a necessidade de controle portátil ou plataformas de força. O uso de um sensor de profundidade também permite que o Kinect capture padrões de movimento tridimensionais. ${ }^{(42)}$ Acredita-se que este sistema tenha potencial para avaliação remota de sintomas de transtornos movimento em pessoas com DP, especialmente sintomas hipocinéticos. ${ }^{(42)}$

Ao envolver o paciente por meio de múltiplas modalidades sensoriais, como jogos de RV semelhantes a funções do cotidiano, tem como benefício ao paciente a distração durante episódios de dor aguda na realização do movimento. A 
simulação baseada em RV foi estudada também como uma ferramenta no diagnóstico e tratamento de pacientes com comprometimento cognitivo leve e demência, com resultados promissores. ${ }^{(43)}$

\subsection{Imagem funcional}

Em termos gerais, a imagem funcional pode ser usada para estudar padrões de ativação para avaliar possíveis alterações neuroquímicas. A ativação de diferentes regiões pode ser estudada avaliando-se padrões de metabolismo de glicose cerebral ou fluxo sanguíneo cerebral usando PET, SPECT, ou ressonância magnética funcional. ${ }^{(18)}$

A imagem funcional pode fornecer informações úteis sobre a base da doença e complicações relacionadas ao tratamento da DP. ${ }^{(44)}$

\subsubsection{PET-FDG}

O PET representa uma valiosa ferramenta clínica e de pesquisa para visualizar mudanças patológicas em distúrbios do movimento. ${ }^{(45)}$ Dentre suas características, destaca-se o potencial de fornecer marcadores objetivos, quantificáveis e estáveis para o diagnóstico de síndromes parkinsonianas e para a avaliação da progressão e resposta ao tratamento desses distúrbios. Mais de uma década atrás, reconheceu-se pela primeira vez que as diferenças regionais no metabolismo da glicose medidas com o FDG poderiam ser utilizadas para distinguir diferentes formas de parkinsonismo. ${ }^{(45)}$

O PET-FDG é um procedimento de diagnóstico in vivo e minimamente invasivo usado para avaliar o metabolismo cerebral da glicose. A atividade metabólica da glicose cerebral é um índice de função sináptica e densidade, ${ }^{(46)}$ aumentos e diminuições da atividade sináptica no cérebro são acompanhados por mudanças na perfusão capilar e no consumo local de glicose. A perda de neurônios pode resultar em diminuição do consumo de glicose em regiões distais do cérebro, podendo também ocorrer um aumento regional de glicose por ativação dos neurônios vizinhos que assumem a função. ${ }^{(47)}$ 
A técnica de imagem funcional possui algumas desvantagens em relação à imagem estrutural convencional, principalmente em relação à resolução das imagens. Entretanto, hoje é possível realizar, simultaneamente PET-Ressonância Magnética (PET-RM), que possui vantagens em relação à resolução de imagem, qualidade de contraste e menor radiação ionizante quando comparado ao PET Scan (PET/CT - Positron Emission Tomography/Computed Tomography). ${ }^{(48)}$

Nos últimos anos, a imagem molecular na DP avançou substancialmente, melhorando a capacidade de melhor entendimento de sua patogênese, assim como permitindo um diagnóstico mais preciso e monitoramento de sua progressão. ${ }^{(49)}$

O metabolismo da glicose cerebral está intimamente associado à integridade e densidade neural local. ${ }^{(50)}$

\subsubsection{PET-FDG na doença de Parkinson sem comprometimento cognitivo}

Há décadas, foi primeiramente reconhecido que as diferenças regionais no metabolismo da glicose medido com PET-FDG poderiam ser usadas para distinguir entre diferentes formas de parkinsonismo. ${ }^{(47)}$

Segundo Meyer et al. ${ }^{(36)}$ a DP é caracterizada por um hipometabolismo temporoparietal posterior e occipital; e hipermetabolismo relativo do putâmen, globo pálido, córtex sensório-motor do tálamo, ponte e cerebelo.

\subsubsection{PET-FDG na doença de Parkinson com comprometimento cognitivo}

A neuroimagem molecular usando PET permite uma visualização quantitativa de processos funcionais e moleculares in vivo. O FDG é usado para a avaliação do metabolismo regional da glicose cerebral como marcador da função neuronal. Na virtude de revelar alterações específicas da doença devido à disfunção sináptica, degeneração neuronal e alterações de rede compensatórias associadas, 0 PET-FDG tornou-se uma parte essencial na investigação diagnóstica de pacientes com distúrbios neurodegenerativos, mais notavelmente a demência. 
O comprometimento cognitivo é frequente na DP, os resultados de vários estudos longitudinais investigando o declínio cognitivo e o metabolismo regional na DP tornaram-se disponíveis recentemente, Bohnen et al. ${ }^{(51)}$ demonstraram que a conversão de DP para DP com demência foi anunciada por hipometabolismo significativo em cingulado posterior, córtex occipital e núcleo caudado. $O$ hipometabolismo do córtex visual primário também foi observado em pacientes com DP cognitivamente estáveis. ${ }^{(36)}$

Estudos de PET em pacientes com DP com comprometimento cognitivo leve representam um estágio que antecede a demência na DP, especialmente naqueles com hipometabolismo cortical posterior. Pacientes com comprometimento cognitivo tipicamente leve exibem diminuição do metabolismo temporoparietal, occipital, precuneus e frontal quando comparados a controles saudáveis e, em menor grau, para pacientes com DP sem comprometimentos cognitivos. ${ }^{(36)}$ 


\section{MÉTODOS}

\subsection{Seleção de pacientes}

Foram recrutados para este estudo voluntários com DP naturais e procedentes do Brasil. De um total de 283 pacientes, foram selecionados 20 pacientes conforme os critérios de inclusão, porém 1 voluntário foi excluído porque não compareceu no primeiro dia do protocolo de $\mathrm{RV}$, restando 19 voluntários que completaram o estudo (Figura 1).

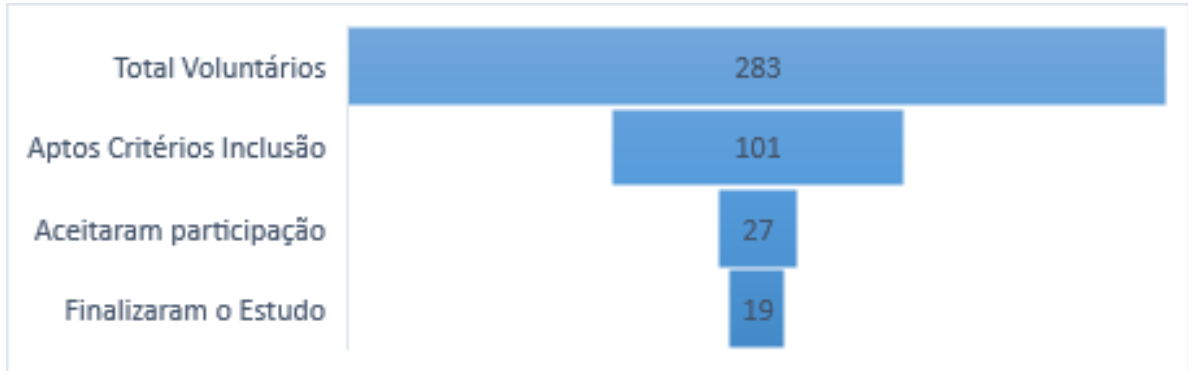

Figura 1. Seleção dos voluntários

Os voluntários foram recrutados a partir de divulgação em mídia impressa e virtual, além dos serviços específicos de atenção e cuidados aos portadores de DP no Instituto de Assistência Médica ao Servidor Público (IAMSPE) e na Universidade Federal de São Paulo (UNIFESP), pareados de acordo com idade e tempo de doença.

Os seguintes critérios de inclusão foram utilizados: voluntários com DP de qualquer sexo, preferencialmente entre 50 e 70 anos de idade, com ou sem alteração de equilíbrio e de marcha (freezing), Hoehn e Yahr scale ${ }^{(52)} 2$ à 3 e que não apresentassem alterações clínicas descompensadas e/ou ortopédicas que dificultassem a locomoção e/ou o protocolo de reabilitação virtual. Por outro lado, foram excluídos os voluntários que não concordassem com os termos do Termo de Consentimento Livre e Esclarecido (TCLE), aqueles com dificuldades de locomoção de sua residência para o centro de pesquisa, claustrofóbicos, com algum histórico de reação alérgica prévia a exames de medicina nuclear e os pacientes com depressão e/ou demência. 
Vale ressaltar que os voluntários faziam uso de suas medicações normalmente; não houve nenhuma alteração em suas medicações seja de dosagem e/ou uma nova medicação prescrita durante o período de coleta do estudo.

\subsection{Tamanho amostral}

O tamanho da amostra foi estimado com o objetivo de detectar diferença entre os momentos pré e pós, considerando erro do tipo I a $5 \%$. Os cálculos foram realizados pela ferramenta GLIMMPSE (http://glimmpse.samplesizeshop.org/\#/) e correlação de 0,5 entre as medidas dos momentos pré e pós. ${ }^{(53)}$ Baseado em um estudo $^{(54)}$ com medidas similares às que foram consideradas neste protocolo calculamos uma amostra de 16 pacientes com poder de 99,3\% para detectar uma diferença de 2 desvios padrão entre os momentos pré e pós, com erro do tipo I assumido $5 \%$.

Além disto, levamos em consideração a possibilidade de dropouts aumentando em $25 \%$ o tamanho de cada amostra, chegando ao resultado ideal de 20 sujeitos para esta pesquisa.

\subsection{Local de avaliação e protocolo clínico}

Após explicação, leitura e assinatura do TCLE, os voluntários foram submetidos ao protocolo clínico e exames nas instalações do Hospital Israelita Albert Einstein (São Paulo, SP).

Todos os casos foram submetidos a uma avaliação clínica composta por uma entrevista e exames físicos direcionados. O diagnóstico de DP foi definido pelos critérios da United Kingdom Parkinson's Disease Brain Bank, ${ }^{(55)}$ coletado idade, escolaridade, dominância manual, sexo, escolaridade, altura e peso, diagnóstico, comorbidades, lista de medicações, tempo de doença, lateralidade dos sintomas, assim como exames complementares relevantes.

Os portadores de DP foram avaliados por meio dos seguintes instrumentos: 
1. Hoehn e Yahr scale, ${ }^{(52)}$ e escala unificada de avaliação da DP (UPDRS - Unified Parkinson's Disease Rating Scale) parte III ${ }^{(56)}$ e para quantificar os sintomas motores como bradicinesia, rigidez, tremor de repouso e instabilidade postural. Estas 2 medidas foram utilizadas para avaliar os desfechos reabilitação virtual $\mathrm{X}$ sinais motores.

2. Percepção da qualidade de vida em indivíduos com $\operatorname{DP}^{(57)}$ e Questionário do estado de saúde (SF-36) ${ }^{(58)}$ para avaliar a qualidade de vida. Estas 2 medidas foram utilizadas para avaliar 0 desfecho reabilitação virtual $X$ qualidade de vida.

3. Inventário de depressão de Beck ${ }^{(59)}$ para avaliar e excluir candidatos com depressão.

4. Escala de equilíbrio de $\operatorname{Berg}^{(60)}$ que compreende uma escala de 14 tarefas ao dia-a-dia, que envolvem o equilíbrio estático e dinâmico.

Após aprovação do comitê de ética, os indivíduos foram agendados para os exames iniciais (pré-teste), treinamento com RV e exames finais (pós-testes).

\subsubsection{Avaliação neuropsicológica}

Para a avaliação neuropsicológica foi realizado um protocolo estruturado que consiste de 2 fases: Fase 1. Exclusão de demência, através do teste Montreal Cognitive Assessment (MoCA); Fase 2. Foram explorados campos cognitivos específicos como Atenção/ Funções Executivas (Dígitos - WAIS-III, Trail A e B, Stroop, Semelhanças - WAIS-III, Fluência Verbal - F.A.S. e Animais), Memória (RAVLT - Rey Auditory Verbal Learning Test), Linguagem (Boston e Vocabulário - WAIS-III), Funções Visuais (Letras Fragmentadas - VOSP, Análise de Cubos - VOSP, Desenho do Relógio, Cubos - WAIS-III) além de avaliação neuropsiquiátrica (NPI - Inventário Neuropsiquiátrico). Este protocolo de avaliação neuropsicológica serve para avaliar 0 desfecho secundário (reabilitação virtual $X$ metabolismo de glicose $X$ cognição).

Os testes utilizados, assim como os campos cognitivos testados em cada situação estão melhor detalhados abaixo.

Montreal Cognitive Assessment ${ }^{(61)}$ é um teste de rastreio cognitivo desenvolvido para auxiliar profissionais da saúde na detecção de Comprometimento Cognitivo Leve (CCL) e demência. O teste consiste de 12 tarefas divididas em 7 
domínios cognitivos (visuoespacial/executiva, nomeação, memória, atenção, linguagem, abstração e orientação). O escore máximo é 30 pontos e o ponto de corte é de 26 pontos.

Teste de Alcance de Dígitos/Digit Span, ${ }^{(62)}$ esta tarefa é composta de duas partes. Na primeira o sujeito é requerido a repetir uma sequência de números na mesma ordem que for apresentada e na segunda ele é requerido a repetir os números na ordem inversa à apresentada. O escore final é o número de sequências corretamente repetidas.

Teste de Semelhanças, ${ }^{(62)}$ nesta tarefa é apresentada uma série de pares de palavras as quais o sujeito deve explicar a semelhança entre os objetos ou conceitos comuns que são representados pelas palavras. São fornecidos pontos de acordo com o grau de abstração do examinando e a pontuação máxima é de 38 pontos.

Teste de Nomeação de Boston, ${ }^{(63)}$ consiste na apresentação de 60 figuras as quais o sujeito é solicitado a nomear. Caso o sujeito não reconheça a figura, pistas semânticas são oferecidas. Um ponto é dado para cada nomeação correta e o escore máximo é 60 pontos.

Teste de Vocabulário, ${ }^{(62)}$ neste subteste uma série de palavras é apresentada sob a forma oral e visual e o examinando é solicitado a definir oralmente o significado de cada palavra. As respostas são pontuadas o escore máximo é 66 pontos.

Teste do Desenho do Relógio, ${ }^{(64)}$ o sujeito é solicitado a desenhar em uma folha de papel a face de um relógio com todos os números e os ponteiros marcando 11 horas e 10 minutos. São fornecidos pontos para cada elemento presente no relógio e a pontuação máxima é 15 pontos.

Teste de Desenho com Cubos, ${ }^{(62)}$ nesta tarefa um conjunto de padrões geométricos bidimensionais impressos ou formados com cubos é apresentado ao sujeito que deve reproduzi-los usando cubos de duas cores. São fornecidas pontuações de acordo com o tempo que o sujeito gasta para executar corretamente a tarefe. O escore máximo é 68 pontos.

Teste das Trilhas parte $\mathrm{A}$ e $\mathrm{B},{ }^{(64)}$ a tarefa consiste na conexão, através de uma linha feita com lápis, de 25 números (Parte $A$ ) ou números e letras (Parte B) em ordem crescente alternada. O examinador marca o tempo gasto e o número de erros cometidos pelo examinando na realização de cada tarefa. 
Teste de Interferência de Stroop ${ }^{(64)}$ esta tarefa visa mensurar a atenção seletiva e a flexibilidade cognitiva conforme as mudanças de demandas e supressão de respostas habituais em favor de respostas não usuais. O sujeito deve nomear, o mais rápido possível, as cores de quatro retângulos impressos em verde, azul, preto e vermelho. O examinador marca o tempo gasto na execução de cada tarefa e o número de erros cometidos.

Fluência Verbal( ${ }^{(64)}$ é uma medida da habilidade de evocação de palavras restritas a categorias específicas. $O$ examinando é solicitado a evocar o maior número de palavras para cada uma das letras (F.A.S.) dentro de um tempo determinado e respeitando regras. Ao final, obtemos escores para cada uma das letras e um escore geral que é o número de palavras evocadas para as três letras.

Teste de Aprendizagem Auditivo-Verbal de Rey. ${ }^{(65,66)}$ O RAVLT é uma medida de lápis e papel que tem o objetivo de avaliar aspectos da memória verbal para informações pouco estruturadas (listas de palavras). Ao examinando é requerido prestar atenção enquanto uma lista $A$ de substantivos concretos não relacionados é apresentada e deve dizer quais palavras ele consegue recordar. Então a lista B é apresentada e recordada pelo avaliando. As respostas dadas pelo sujeito em cada etapa são anotadas pelo aplicador em formulário próprio e a pontuação é o número de palavras recordadas após cada apresentação.

Subteste de Letras Fragmentadas e Análise de Cubos da Bateria de Percepção Visual de Objetos e Espaço/VOSP(67) consiste em 2 subtestes para avaliação de habilidades da percepção visual de objetos e de espaço. $\mathrm{Na}$ tarefa de Letras Fragmentadas o sujeito é solicitado a identificar letras incompletas exibidas em um cartão. $\mathrm{O}$ escore total é 20 pontos. Na tarefa de Análise de Cubos é pedido ao examinando que conte quantos cubos são apresentados em um cartão. É necessária uma interpretação 3-D do espaço em uma representação em duas dimensões. A pontuação total é 10 pontos.

\subsubsection{Neuroimagem}

Os exames de neuroimagem funcional foram realizados através de PET-RM, utilizando-se o FDG marcado com flúor-18. O objetivo foi correlacionar os dados de reabilitação virtual $\mathrm{X}$ metabolismo de glicose. 
Os exames de PET-RM foram realizados em todos os voluntários da pesquisa com a injeção do ligante FDG, um análogo da glicose, que pode ser marcado com Flúor-18.

Os voluntários da pesquisa realizaram uma dieta pobre em carboidratos na véspera do exame e no dia do exame deviam chegar com jejum mínimo de 4 horas. Antes da administração do radiofármaco foi realizado um teste de glicemia capilar. A condição ideal para administração do radiofármaco é que a glicemia esteja abaixo de $150 \mathrm{mg} / \mathrm{dL}$. Para o exame utilizamos uma atividade de $3 \mathrm{a} 5 \mathrm{mCi}$ de FDG-18F, administrada por via intravenosa em uma veia periférica antecubital. Uma hora após da administração do radiotraçador, foi iniciada a aquisição de imagens no PET/RM.

Todos os exames de PET-RM foram realizados em equipamento de 3.0 T (Siemens ${ }^{\circledR}$ - Biograph $\mathrm{mMR}$ ) com gradientes de $45 \mathrm{mT} / \mathrm{m}$, razão de incremento $200 \mathrm{mT} / \mathrm{m} / \mathrm{s}$ e bobina de recepção dedicada de 12 elementos, no Departamento de Medicina Diagnóstica e Preventiva - Setor de Imagem do Hospital Israelita Albert Einstein.

Após reconstrução das imagens, foi realizada uma análise quantitativa através do software Database Comparison (Siemens Medical Solutions). Esse algoritmo permite a definição automática de regiões de interesse no sistema nervoso central e fornece a taxa média de concentração em cada uma dessas regiões, Standard Value Uptake (SUV), assim como um resultado comparativo com uma base de dados de indivíduos saudáveis (expresso pela diferença em desvios-padrão do resultado observado em relação ao valor médio da base de indivíduos saudáveis), pareados por idade e sexo.

O SUV é uma medida da atividade nas imagens PET. É um cálculo simples da taxa de captação da dose injetada (quanto da dose total injetada se concentrou em determinada área). Em resumo, SUV = Concentração na área de interesse / (Dose injetada/Kg).

Quanto ao Desvio-Padrão, o software compara o SUV médio em cada uma das regiões com um banco de imagens de indivíduos sabidamente normais, pareados para idade e sexo do paciente estudado.

As áreas cerebrais avaliadas foram o lobo frontal (giro pré-central, área motora suplementar, giros frontais, dorsolateral), tálamo, núcleo lentiforme (caudado e globo pálido), caudado, putâmen, outras estruturas dos núcleos da base e 
cerebelo. Estas regiões corticais e/ou subcorticais foram escolhidas porque apresentam uma relação intrínseca direta ou indireta com movimentos automáticos e/ou voluntários.

As avaliações das imagens foram realizadas por pesquisador cego, que desconhecia o paciente ou a que grupo o mesmo pertencia (pré ou pósintervenção).

\subsubsection{Protocolo de realidade virtual}

Após a realização dos exames pré-testes, os voluntários iniciaram o protocolo de treinamento de reabilitação virtual. De acordo com o protocolo do estudo, os voluntários tinham até 7 dias de intervalo para realizar os exames pré e pós-testes, a contar antes do início para o pré-teste, e após o término do protocolo de intervenção da reabilitação virtual para o pós-teste com o objetivo de diminuir qualquer tipo de influência durante esse intervalo de tempo.

O protocolo envolvia 16 sessões de terapia com RV e duração de 60 minutos; frequência de 2 sessões por semana, sempre no mesmo dia e horário; coleta realizada por duas fisioterapeutas e dois voluntários (1 terapeuta para cada voluntário); na $1^{\circ}$ sessão era realizada a familiarização com o ambiente virtual, os voluntários eram orientados a como realizar os jogos, posição que deviam ficar e conscientização de trabalho em dupla; durante a segunda à oitava sessão os voluntários jogavam todos os jogos em níveis básico, intermediário e avançado com auxilio verbal e motor das terapeutas conforme a necessidade de cada indivíduo e da nona à decima sexta sessão os voluntários jogavam todos os jogos em níveis básico, intermediário e avançado sem auxilio motor das terapeutas, somente verbal.

$O$ videogame $\mathrm{XBOX} 360 \mathrm{~S}^{\circledR}$ foi utilizado no treinamento (não imersivo). O sensor Kinect ${ }^{\circledR}$, peça acessória do console Xbox $360 \mathrm{~S}^{\circledR}$, é um sensor de movimento de alta tecnologia capaz de reconhecer 48 pontos distintos do corpo humano incluindo a face, e foi utilizado para identificar o movimento de cada paciente.

Os voluntários realizaram, em dupla, 60 minutos de treinamento por meio de jogos do videogame $\mathrm{XBOX} 360 \mathrm{~S}^{\circledR}$ com a assistência de um fisioterapeuta para cada voluntário. Os jogos foram selecionados de acordo um estudo semelhante ${ }^{(40)} \mathrm{com}$ a demanda motora e cognitiva dos voluntários, com o objetivo de estimular os ajustes posturais envolvidos na resolução de tarefas perceptuais (visuais e auditivas) 
associadas a funções cognitivas como atenção, tomada de decisão, planejamento e inibição de resposta.

O jogo possui 5 modos diferentes intitulados e apresentados aos pacientes na seguinte ordem: Bolha Espacial, Vazamentos, Salão dos Ricochetes, Corredeira e Cume dos Reflexos.

O jogo que simula uma cabine espacial, sem ação da gravidade. Nesta cabine são liberadas bolhas, nas direções horizontais e verticais e elas devem ser capturadas pelo jogador. O processo é simples, o jogador precisa apenas encostarse às bolhas e já é suficiente para pegá-las, no entanto, a cabine é grande e algumas bolhas ficam próximas ao teto necessitando o deslocamento do corpo até o teto para a captura. Para se mover nesta cabine são necessários três movimentos básicos: fazer a adução dos membros superiores partindo de uma abdução completa, simulando um "bater de asas", esse movimento permite que o jogador no espaço virtual flutue e alcance o teto; para descer é necessário apenas que o jogador relaxe os membros superiores e membros inferiores, evitando movimentos por aproximadamente 3 segundos e então o avatar virtual retorna ao chão da cabine; e por fim em alguns casos as bolhas estão à frente (ou atrás caso o jogador já esteja no limite anterior da cabine), longe da área de alcance do jogador, sendo necessário dar um passo à frente (ou para trás quando já estiver à frente) para alcançar todas as bolhas.

O jogo que simula uma cabine no fundo do mar. Nesta cabine o jogador necessita fechar os vazamentos realizados pelos moradores do fundo do mar. O processo é simples, o jogador precisa apenas encostar uma parte do corpo na parede da cabine e segurar até acabar o vazamento. Para se mover o jogador realiza movimento laterais e anteroposterior, movimentando MMSS, MMII e a cabeça, tosos esses movimentos servem para estancar os vazamentos.

O jogo Salão dos Ricochetes, no qual o jogo simula um corredor de vidro fechado, onde em uma ponta estão posicionadas caixas e na outra ponta está o jogador. Neste modo o jogador recebe uma bola, e deve arremessá-la nas caixas com a finalidade de quebrá-las. É necessário apenas um toque para que a caixa seja destruída, e quando ocorre, a bola ricocheteia para o jogador permitindo que ele a mande de volta para destruir outras caixas que estão posicionadas na extremidade oposta do corredor. A bola inicialmente deve ser lançada com as mãos, mas quando ocorre o ricochete ela pode ser defendida com auxílio de todo o corpo (MMSS, MMII, tronco e cabeça). 
O jogo Corredeiras, neste jogo o avatar projetado na tela está dentro de um bote descendo uma corredeira, onde ele deverá arrecadar o máximo de moedas que encontrar no percurso, muitas vezes precisando se desviar de obstáculos para alcança-las. Neste modo o jogador precisa fazer deslocamentos laterais para que o bote se incline para o lado desejado e saltos para pular os obstáculos.

O jogo Cume dos Reflexos, este jogo simula uma trilha, muito semelhante aos trilhos de trem, onde o jogador fica sobre um carrinho de madeira que é conduzido automaticamente. Durante o percurso, obstáculos aparecem à frente do jogador e ele deve se desviar com rapidez e precisão, caso contrário perde moedas ao ser atingido. No geral são três tipos de obstáculos, barras horizontais azuis que são sempre baixas e devem ser puladas, barras horizontais vermelhas que são sempre altas e é necessário abaixar-se para desviar e, por fim, barras verticais rosas, que aparecem tanto à esquerda quanto à direita, e dependendo do lado, é necessário o deslocamento contralateral do jogador.

Após o término do protocolo, foram repetidos exames de neuroimagem (PET-RM), aplicação dos questionários e avaliação neuropsicológica, sendo denominado avaliação pós-teste.

As avaliações clínicas pré e pós-protocolo de RV foram realizadas por 2 fisioterapeutas. Preferencialmente, a fisioterapeuta que fazia a avaliação pré não realizava a avaliação pós.

\subsection{Análise dos dados}

Os dados foram descritos por meio de frequências absolutas e relativas para as variáveis categóricas e por médias, desvio padrão ou medianas e quartis, além de valores mínimos e máximos para as variáveis numéricas.

Foi calculada a variação para cada medida por meio da diferença entre o valor observado no momento pós-intervenção em relação ao valor no momento pré-intervenção. As distribuições das variações foram estudadas por meio de histogramas e boxplots e por testes de normalidade de Shapiro-Wilk.

As medidas pré e pós-intervenção e as variações foram descritas em tabelas por medianas e quartis, valores mínimos e máximos e gráficos de perfis individuais foram apresentados para cada medida. Para comparar as medidas obtidas 
nas avaliações pré e pós-intervenção foram utilizados testes de hipóteses $t$ de Student para dados pareados ou de Wilcoxon para dados relacionados, dependendo da distribuição observada dos dados.

Para cada desfecho do estudo temos diversas medidas relacionadas, a saber, escores dos itens de um instrumento, escores dos domínios de um instrumento, medidas obtidas em lados de um paciente, diferentes medidas obtidas em um exame e essa multiplicidade pode levar a falsas descobertas e conclusões errôneas.

A relação entre as variações observadas nos escores das partes II e III do instrumento UPDRS foi investigada por meio do coeficiente de correlação de Pearson.

As análises foram realizadas com 0 auxílio do programa computacional $R$, versão 3.4.1. O nível de significância global foi fixado em $5 \%$.

\subsection{Aspectos éticos}

O presente projeto foi submetido e aprovado pelo Comitê de Ética do Hospital Israelita Albert Einstein onde todo o trabalho foi realizado, sob o protocolo número: 5169415.7.0000.0071 (SGPP: 2519-15), e nas instituições coparticipantes onde os voluntários foram recrutados: Instituto de Assistência Médica ao Servidor Público (IAMSPE) - CAAE: 51691415.7.3001.5463 e na Universidade Federal de São Paulo (UNIFESP) - CAAE: 51694115.7.3002.5505.

Todos os indivíduos recrutados assinaram um termo de consentimento após receberem informações detalhadas por escrito sobre a natureza e objetivos do estudo. As informações obtidas não foram utilizadas para outros fins que não previstos neste protocolo. Foi garantido o sigilo das informações que possam colocar em risco a privacidade dos sujeitos quanto aos dados confidenciais. 


\section{RESULTADOS}

\subsection{Análise dos dados da avaliação clínica}

A análise dos resultados deste estudo foi composta por 19 voluntários portadores de DP.

\subsubsection{Perfil dos pacientes: dados demográficos e características da doença de} Parkinson

$\mathrm{Na}$ amostra de dezenove participantes do estudo (Tabela 1) a idade variou entre 50 e 71 anos, com média de 63 anos (DP=5,9 anos), sendo nove (47,4\%) mulheres e dez (52,6\%) homens.

Quanto ao Parkinson, o tempo de doença variou entre três e dezessete anos, com mediana de dez anos (primeiro quartil: oito anos e terceiro quartil: doze anos). Utilizando a escala de Hoehn \& Yahr, seis pacientes $(31,6 \%)$ eram estágio 2 e treze $(68,4 \%)$ em estágio 3 e quanto ao hemicorpo afetado, para sete $(36,8 \%)$ o direito e para doze $(63,2 \%)$ o lado esquerdo era o clinicamente mais afetado.

Tabela 1. Características demográficas e da DP dos participantes do estudo

\begin{tabular}{lc}
\hline Características & Medidas \\
\hline Sexo n(\%) & $9(47,4)$ \\
Feminino & $10(52,6)$ \\
Masculino & $63,0(5,9)$ \\
Idade (anos) & $50-71$ \\
$\quad$ Média (DP) & $6(31,6)$ \\
Mínimo - Máximo & $13(68,4)$ \\
Escala de Hoehn \& Yahr (instabilidade postural) n(\%) & $10(8 ; 12)$ \\
2 - sem instabilidade postural & $3-17$ \\
3 - com instabilidade postural & $7(36,8)$ \\
Tempo de doença (anos) & $12(63,2)$ \\
$\quad$ Mediana (Q1; Q3) & \\
Mínimo - Máximo & $52,9(7,7)$ \\
Lado mais afetado n(\%) & $39-66$ \\
$\quad$ Direito & 6
\end{tabular}

DP: desvio padrão; Q1: primeiro quartil; Q3: terceiro quartil. 


\subsubsection{Variação nas avaliações clínicas após a intervenção}

Os pacientes foram avaliados quanto aos sinais e sintomas da DP pela aplicação do instrumento UPDRS nos momentos pré e pós-intervenção e não observamos evidências de variação em nenhum dos itens do instrumento. Na tabela 2 encontramos os escores pré e pós-intervenção em todos os itens do instrumento UPDRS. Encontramos diferenças estatisticamente significantes nos seguintes itens de atividades de vida diária: salivação $(p=0,035)$, escrita manual $(p=0,034)$, corte de alimentos e manipulação de utensílios $(p=0,033)$, quedas $(p=0,008)$, deambulação $(p=0,046)$ e tremor $(p=0,059)$. Quanto a parte de exame motor, encontramos diferença nos itens de movimentação membro superior direito e esquerdo $(p=0,011$ e $p=0,059$ respectivamente), marcha $(p=0,020)$, estabilidade postural $(p=0,014)$ e bradicinesia $(p=0,025)$.

Tabela 2. Escores nos itens da UPDRS dos participantes do estudo nas avaliações pré e pósintervenção

\begin{tabular}{|c|c|c|c|}
\hline \multirow[b]{2}{*}{ UPDRS - Escores dos itens } & \multicolumn{2}{|c|}{ Momento de avaliação } & \multirow[b]{2}{*}{ Valor-p } \\
\hline & $\begin{array}{c}\text { Pré-intervenção } \\
\mathrm{n}(\%)\end{array}$ & $\begin{array}{c}\text { Pós-intervenção } \\
\mathrm{n}(\%)\end{array}$ & \\
\hline \multicolumn{4}{|c|}{ Parte I. Estado Mental, Comportamento e Humor } \\
\hline 1. Comprometimento intelectual & & & 0,180 \\
\hline 0 & $11(57,9)$ & $14(73,7)$ & \\
\hline 1 & $8(42,1)$ & $5(26,3)$ & \\
\hline 2. Transtorno do pensamento & & & 0,102 \\
\hline 0 & $11(57,9)$ & $13(68,4)$ & \\
\hline 1 & $2(10,5)$ & $4(21,1)$ & \\
\hline 2 & $4(21,1)$ & $2(10,5)$ & \\
\hline 3 & $2(10,5)$ & $0(0,0)$ & \\
\hline 3. Depressão & & & 0,257 \\
\hline 0 & $11(57,9)$ & $14(73,7)$ & \\
\hline 1 & $8(42,1)$ & $5(26,3)$ & \\
\hline 4. Motivação/Iniciativa & & & 0,102 \\
\hline 0 & $11(57,9)$ & $15(78,9)$ & \\
\hline 1 & $8(42,1)$ & $4(21,1)$ & \\
\hline Parte II. Atividades da Vida Diária & Pré & Pós & \\
\hline 5. Fala & & & 0,058 \\
\hline 0 & $4(21,1)$ & $5(26,3)$ & \\
\hline 1 & $5(26,3)$ & $9(47,4)$ & \\
\hline 2 & $9(47,4)$ & $4(21,1)$ & \\
\hline 3 & $1(5,3)$ & $1(5,3)$ & \\
\hline 6. Salivação & & & 0,035 \\
\hline 0 & $8(42,1)$ & $11(57,9)$ & \\
\hline 1 & $4(21,1)$ & $4(21,1)$ & \\
\hline 2 & $6(31,6)$ & $3(15,8)$ & \\
\hline 3 & $0(0,0)$ & $1(5,3)$ & \\
\hline 4 & $1(5,3)$ & $0(0,0)$ & \\
\hline
\end{tabular}




\begin{tabular}{|c|c|c|c|}
\hline 7. Deglutição & & & 0,084 \\
\hline 0 & $12(63,2)$ & $15(78,9)$ & \\
\hline 1 & $4(21,1)$ & $3(15,8)$ & \\
\hline 2 & $2(10,5)$ & $1(5,3)$ & \\
\hline 3 & $1(5,3)$ & $0(0,0)$ & \\
\hline 8. Escrita manual & & & 0,034 \\
\hline 0 & $3(15,8)$ & $2(10,5)$ & \\
\hline 1 & $4(21,1)$ & $8(42,1)$ & \\
\hline 2 & $5(26,3)$ & $6(31,6)$ & \\
\hline 3 & $7(36,8)$ & $3(15,8)$ & \\
\hline 9. Corte de alimentos e manipulação de utensílios & & & 0,033 \\
\hline 0 & $2(10,5)$ & $4(21,1)$ & \\
\hline 1 & $10(52,6)$ & $11(57,9)$ & \\
\hline 2 & $3(15,8)$ & $3(15,8)$ & \\
\hline 3 & $4(21,1)$ & $1(5,3)$ & \\
\hline 10. Vestir & & & 0,102 \\
\hline 0 & $0(0,0)$ & $1(5,3)$ & \\
\hline 1 & $10(52,6)$ & $12(63,2)$ & \\
\hline 2 & $9(47,4)$ & $6(31,6)$ & \\
\hline 11. Higiene & & & 0,102 \\
\hline 0 & $1(5,3)$ & $3(15,8)$ & \\
\hline 1 & $15(78,9)$ & $15(78,9)$ & \\
\hline 2 & $3(15,8)$ & $1(5,3)$ & \\
\hline 12. Girar no leito e ajustar roupas de cama & & & 0,102 \\
\hline 0 & $1(5,3)$ & $2(10,5)$ & \\
\hline 1 & $10(52,6)$ & $10(52,6)$ & \\
\hline 2 & $6(31,6)$ & $7(36,8)$ & \\
\hline 3 & $2(10,5)$ & $0(0,0)$ & \\
\hline 13. Quedas & & & 0,008 \\
\hline 0 & $9(47,4)$ & $15(78,9)$ & \\
\hline 1 & $9(47,4)$ & $4(21,1)$ & \\
\hline 2 & $1(5,3)$ & $0(0,0)$ & \\
\hline 14. Freezing quando anda & & & 0,166 \\
\hline 0 & $4(21,1)$ & $4(21,1)$ & \\
\hline 1 & $5(26,3)$ & $9(47,4)$ & \\
\hline 2 & $6(31,6)$ & $3(15,8)$ & \\
\hline 3 & $3(15,8)$ & $2(10,5)$ & \\
\hline 4 & $1(5,3)$ & $1(5,3)$ & \\
\hline 15. Deambulação & & & 0,046 \\
\hline 0 & $1(5,3)$ & $1(5,3)$ & \\
\hline 1 & $7(36,8)$ & $10(52,6)$ & \\
\hline 2 & $9(47,4)$ & $7(36,8)$ & \\
\hline 3 & $2(10,5)$ & $1(5,3)$ & \\
\hline 16. Tremor & & & 0,059 \\
\hline 0 & $1(5,3)$ & $2(10,5)$ & \\
\hline 1 & $7(36,8)$ & $9(47,4)$ & \\
\hline 2 & $9(47,4)$ & $7(36,8)$ & \\
\hline 3 & $2(10,5)$ & $1(5,3)$ & \\
\hline 17. Queixas sensitivas relacionadas ao parkinsonismo & & & 0,331 \\
\hline 0 & $6(31,6)$ & $8(42,1)$ & \\
\hline 1 & $7(36,8)$ & $7(36,8)$ & \\
\hline 2 & $6(31,6)$ & $4(21,1)$ & \\
\hline Parte III. Exame Motor & & & \\
\hline 18. Voz & & & 0,059 \\
\hline 0 & $3(15,8)$ & $5(26,3)$ & \\
\hline 1 & $9(47,4)$ & $10(52,6)$ & \\
\hline 2 & $6(31,6)$ & $3(15,8)$ & \\
\hline 3 & $1(5,3)$ & $1(5,3)$ & \\
\hline
\end{tabular}




\begin{tabular}{|c|c|c|c|}
\hline 19. Expressão facial & & & 0,083 \\
\hline 0 & $3(15,8)$ & $4(21,1)$ & \\
\hline 1 & $7(36,8)$ & $8(42,1)$ & \\
\hline 2 & $8(42,1)$ & $6(31,6)$ & \\
\hline 3 & $1(5,3)$ & $1(5,3)$ & \\
\hline 20. Tremor de repouso - Face, lábios e queixo & & & 0,317 \\
\hline 0 & $12(63,2)$ & $14(73,7)$ & \\
\hline 1 & $4(21,1)$ & $2(10,5)$ & \\
\hline 2 & $3(15,8)$ & $3(15,8)$ & \\
\hline 20. Tremor de repouso - MD & & & 0,608 \\
\hline 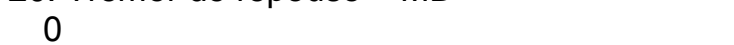 & $8(42,1)$ & $8(42,1)$ & \\
\hline 1 & $6(31,6)$ & $9(47,4)$ & \\
\hline 2 & $5(26,3)$ & $1(5,3)$ & \\
\hline 3 & $0(0,0)$ & $1(5,3)$ & \\
\hline 20. Tremor de repouso - ME & & & 0,132 \\
\hline 0 & $4(21,1)$ & $9(47,4)$ & \\
\hline 1 & $8(42,1)$ & $3(15,8)$ & \\
\hline 2 & $6(31,6)$ & $6(31,6)$ & \\
\hline 3 & $1(5,3)$ & $1(5,3)$ & \\
\hline 20. Tremor de repouso - PD & & & 0,564 \\
\hline 0 & $15(78,9)$ & $17(89,5)$ & \\
\hline 1 & $4(21,1)$ & $1(5,3)$ & \\
\hline 2 & $0(0,0)$ & $1(5,3)$ & \\
\hline 20. Tremor de repouso - PE & & & $>0,999$ \\
\hline 0 & $13(68,4)$ & $13(68,4)$ & \\
\hline 1 & $4(21,1)$ & $4(21,1)$ & \\
\hline 2 & $2(10,5)$ & $2(10,5)$ & \\
\hline 21. Tremor de ação ou postural - MD & & & 0,317 \\
\hline 0 & $14(73,7)$ & $16(84,2)$ & \\
\hline 1 & $5(26,3)$ & $3(15,8)$ & \\
\hline 21. Tremor de ação ou postural - ME & & & 0,763 \\
\hline 0 & $14(73,7)$ & $12(63,2)$ & \\
\hline 1 & $4(21,1)$ & $7(36,8)$ & \\
\hline 2 & $1(5,3)$ & $0(0,0)$ & \\
\hline 22. Rigidez - Pescoço & & & $>0,999$ \\
\hline 0 & $11(57,9)$ & $10(52,6)$ & \\
\hline 1 & $5(26,3)$ & $7(36,8)$ & \\
\hline 2 & $3(15,8)$ & $2(10,5)$ & \\
\hline 22. Rigidez - MSD & & & 0,480 \\
\hline 0 & $8(42,1)$ & $11(57,9)$ & \\
\hline 1 & $10(52,6)$ & $6(31,6)$ & \\
\hline 2 & $1(5,3)$ & $2(10,5)$ & \\
\hline 22. Rigidez - MSE & & & 0,527 \\
\hline 0 & $6(31,6)$ & $7(36,8)$ & \\
\hline 1 & $9(47,4)$ & $9(47,4)$ & \\
\hline 2 & $4(21,1)$ & $3(15,8)$ & \\
\hline 22. Rigidez - MID & & & $>0,999$ \\
\hline 0 & $10(52,6)$ & $10(52,6)$ & \\
\hline 1 & $8(42,1)$ & $8(42,1)$ & \\
\hline 2 & $1(5,3)$ & $1(5,3)$ & \\
\hline 22. Rigidez - MIE & & & 0,739 \\
\hline 0 & $10(52,6)$ & $9(47,4)$ & \\
\hline 1 & $6(31,6)$ & $7(36,8)$ & \\
\hline 2 & $3(15,8)$ & $3(15,8)$ & \\
\hline 23. Bater de dedos - MD & & & 0,763 \\
\hline 0 & $4(21,1)$ & $2(10,5)$ & \\
\hline 1 & $6(31,6)$ & $9(47,4)$ & \\
\hline 2 & $7(36,8)$ & $6(31,6)$ & \\
\hline
\end{tabular}




\begin{tabular}{|c|c|c|c|}
\hline 3 & $1(5,3)$ & $1(53)$ & \\
\hline 4 & $1(5,3)$ & $1(5,3)$ & \\
\hline 23. Bater de dedos - ME & & & 0,206 \\
\hline 0 & $2(10,5)$ & $3(15,8)$ & \\
\hline 1 & $8(42,1)$ & $7(36,8)$ & \\
\hline 2 & $5(26,3)$ & $6(31,6)$ & \\
\hline 3 & $2(10,5)$ & $3(15,8)$ & \\
\hline 4 & $2(10,5)$ & $0(0,0)$ & \\
\hline 24. Movimentos - MD & & & 0,011 \\
\hline 0 & $6(31,6)$ & $12(63,2)$ & \\
\hline 1 & $10(52,6)$ & $5(26,3)$ & \\
\hline 2 & $1(5,3)$ & $1(5,3)$ & \\
\hline 3 & $2(10,5)$ & $1(5,3)$ & \\
\hline 24. Movimentos - ME & & & 0,059 \\
\hline 0 & $5(26,3)$ & $8(42,1)$ & \\
\hline 1 & $9(47,4)$ & $7(36,8)$ & \\
\hline 2 & $3(15,8)$ & $3(15,8)$ & \\
\hline 3 & $1(5,3)$ & $0(0,0)$ & \\
\hline 4 & $1(5,3)$ & $1(5,3)$ & \\
\hline 25. Movimentos rápidos e alternados - MD & & & 0,096 \\
\hline 0 & $10(52,6)$ & $14(73,7)$ & \\
\hline 1 & $6(31,6)$ & $3(15,8)$ & \\
\hline 2 & $3(15,8)$ & $2(10,5)$ & \\
\hline 25. Movimentos rápidos e alternados $-\mathrm{ME}$ & & & 0,248 \\
\hline 0 & $9(47,4)$ & $9(47,4)$ & \\
\hline 1 & $4(21,1)$ & $8(42,1)$ & \\
\hline 2 & $4(21,1)$ & $0(0,0)$ & \\
\hline 3 & $2(10,5)$ & $2(10,5)$ & \\
\hline 26. Agilidade - PD & & & 0,141 \\
\hline 0 & $8(42,1)$ & $11(57,9)$ & \\
\hline 1 & $6(31,6)$ & $6(31,6)$ & \\
\hline 2 & $3(15,8)$ & $0(0,0)$ & \\
\hline 3 & $2(10,5)$ & $2(10,5)$ & \\
\hline 26. Agilidade - PE & & & 0,248 \\
\hline 0 & $7(36,8)$ & $8(42,1)$ & \\
\hline 1 & $5(26,3)$ & $7(36,8)$ & \\
\hline 2 & $3(15,8)$ & $2(10,5)$ & \\
\hline 3 & $3(15,8)$ & $1(5,3)$ & \\
\hline 4 & $1(5,3)$ & $1(5,3)$ & \\
\hline 27. Levantar da cadeira & & & 0,053 \\
\hline 0 & $11(57,9)$ & $14(73,7)$ & \\
\hline 1 & $4(21,1)$ & $5(26,3)$ & \\
\hline 2 & $4(21,1)$ & $0(0,0)$ & \\
\hline 28. Postura & & & 0,739 \\
\hline 0 & $7(36,8)$ & $6(31,6)$ & \\
\hline 1 & $8(42,1)$ & $10(52,6)$ & \\
\hline 2 & $4(21,1)$ & $2(10,5)$ & \\
\hline 3 & $0(0,0)$ & $1(5,3)$ & \\
\hline 29. Marcha & & & 0,020 \\
\hline 0 & $3(15,8)$ & $2(10,5)$ & \\
\hline 1 & $6(31,6)$ & $13(68,4)$ & \\
\hline 2 & $8(42,1)$ & $4(21,1)$ & \\
\hline 3 & $2(10,5)$ & $0(0,0)$ & \\
\hline 30. Estabilidade postural & & & 0,014 \\
\hline 0 & $0(0,0)$ & $3(15,8)$ & \\
\hline 1 & $11(57,9)$ & $12(63,2)$ & \\
\hline 2 & $6(31,6)$ & $4(21,1)$ & \\
\hline 3 & $2(10,5)$ & $0(0,0)$ & \\
\hline
\end{tabular}


...continuação

\begin{tabular}{|c|c|c|c|}
\hline 31. Bradicinesia e hipocinesia corporal & & & 0,025 \\
\hline 0 & $1(5,3)$ & $1(5,3)$ & \\
\hline 1 & $7(36,8)$ & $11(57,9)$ & \\
\hline 2 & $9(47,4)$ & $6(31,6)$ & \\
\hline 3 & $2(10,5)$ & $1(5,3)$ & \\
\hline Parte IV A. Discinesias & & & \\
\hline 32. Duração & & & 0,655 \\
\hline 0 & $13(68,4)$ & $13(68,4)$ & \\
\hline 1 & $4(21,1)$ & $5(26,3)$ & \\
\hline 2 & $2(10,5)$ & $1(5,3)$ & \\
\hline 33. Incapacidade & & & $>0,999$ \\
\hline 0 & $16(84,2)$ & $16(84,2)$ & \\
\hline 1 & $1(5,3)$ & $2(10,5)$ & \\
\hline 2 & $2(10,5)$ & $0(0,0)$ & \\
\hline 3 & $0(0,0)$ & $1(5,3)$ & \\
\hline 34. Discinesias dolorosas & & & $>0,999$ \\
\hline 0 & $17(89,5)$ & $16(84,2)$ & \\
\hline 1 & $1(5,3)$ & $3(15,8)$ & \\
\hline 2 & $1(5,3)$ & $0(0,0)$ & \\
\hline 35. Presença de distonia matutina & & & 0,317 \\
\hline 0 & $18(94,7)$ & $19(100,0)$ & \\
\hline 1 & $1(5,3)$ & $0(0,0)$ & \\
\hline Parte IV B. Flutuações Clínicas & & & \\
\hline 36. Período off previsível & & & $>0,999$ \\
\hline 0 & $12(63,2)$ & $12(63,2)$ & \\
\hline 1 & $7(36,8)$ & $7(36,8)$ & \\
\hline 37. Período off imprevisível & & & 0,655 \\
\hline 0 & $16(84,2)$ & $15(78,9)$ & \\
\hline 1 & $3(15,8)$ & $4(21,1)$ & \\
\hline 38. Período off súbito & & & 0,157 \\
\hline 0 & $18(94,7)$ & $16(84,2)$ & \\
\hline 1 & $1(5,3)$ & $3(15,8)$ & \\
\hline 39. Percentual médio de tempo em off & & & 0,891 \\
\hline 0 & $13(68,4)$ & $11(57,9)$ & \\
\hline 1 & $4(21,1)$ & $7(36,8)$ & \\
\hline 2 & $1(5,3)$ & $1(5,3)$ & \\
\hline 3 & $1(5,3)$ & $0(0,0)$ & \\
\hline Parte IV B. Outras Complicações & & & \\
\hline 40. Anorexia, náuseas ou vômitos & & & 0,317 \\
\hline 0 & $18(94,7)$ & $17(89,5)$ & \\
\hline 1 & $1(5,3)$ & $2(10,5)$ & \\
\hline 41. Transtorno do sono, insônia ou hipersonolência & & & $>0,999$ \\
\hline 0 & $13(68,4)$ & $13(68,4)$ & \\
\hline 1 & $6(31,6)$ & $6(31,6)$ & \\
\hline 42. Hipotensão ortostática sintomática & & & 0,564 \\
\hline 0 & $18(94,7)$ & $17(89,5)$ & \\
\hline 1 & $1(5,3)$ & $2(10,5)$ & \\
\hline
\end{tabular}


Calculamos os escores total e das partes II e III do instrumento UPDRS (Tabela 3 e Figuras 2 a 4) conforme descrito acima na seção 1 e comparando as avaliações pré e pós-intervenção observamos evidências estatisticamente significantes de redução no escore total e das partes II e III, indicando melhora no comprometimento após a intervenção.

Tabela 3. Escores total e das partes II e III da UPDRS dos participantes do estudo nas avaliações pré e pós-intervenção

\begin{tabular}{lccc}
\hline \multirow{2}{*}{ UPDRS - Escores } & \multicolumn{2}{c}{ Momento de avaliação } & \multirow{2}{*}{ Valor-p } \\
\cline { 2 - 3 } & Pré-intervenção & Pós-intervenção & $<0,001$ \\
Parte II. Atividades da Vida Diária & $17(11 ; 19)$ & $12(9 ; 18)$ & \\
$\quad$ Mediana (Q1; Q3) & $8 ; 35$ & $8 ; 23$ & 0,003 \\
Mínimo; Máximo & $23(16 ; 34)$ & $16(13 ; 27)$ & \\
Parte III. Exame Motor & $7 ; 45$ & $2 ; 42$ & \\
$\quad$ Mediana (Q1; Q3) & & & 0,001 \\
Mínimo; Máximo & $43(30 ; 66)$ & $33(25 ; 55)$ & \\
Total & $22 ; 74$ & $16 ; 71$ & \\
$\quad$ Mediana (Q1; Q3) & & & \\
Mínimo; Máximo & &
\end{tabular}

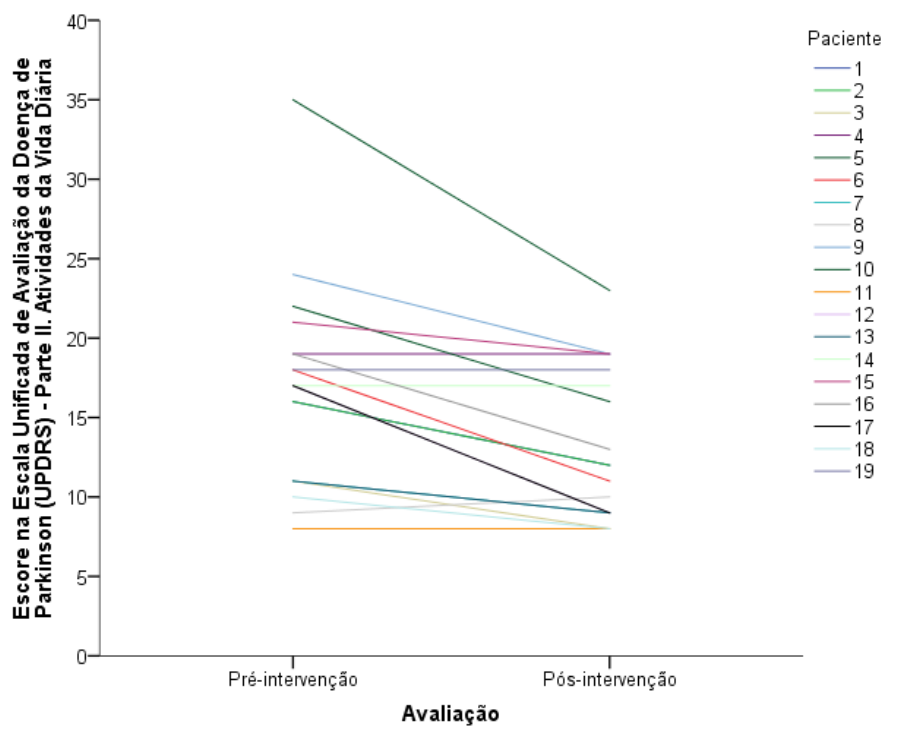

Figura 2. Escore na Parte II. Atividades da Vida Diária do instrumento UPDRS nas avaliações pré e pós-intervenção 


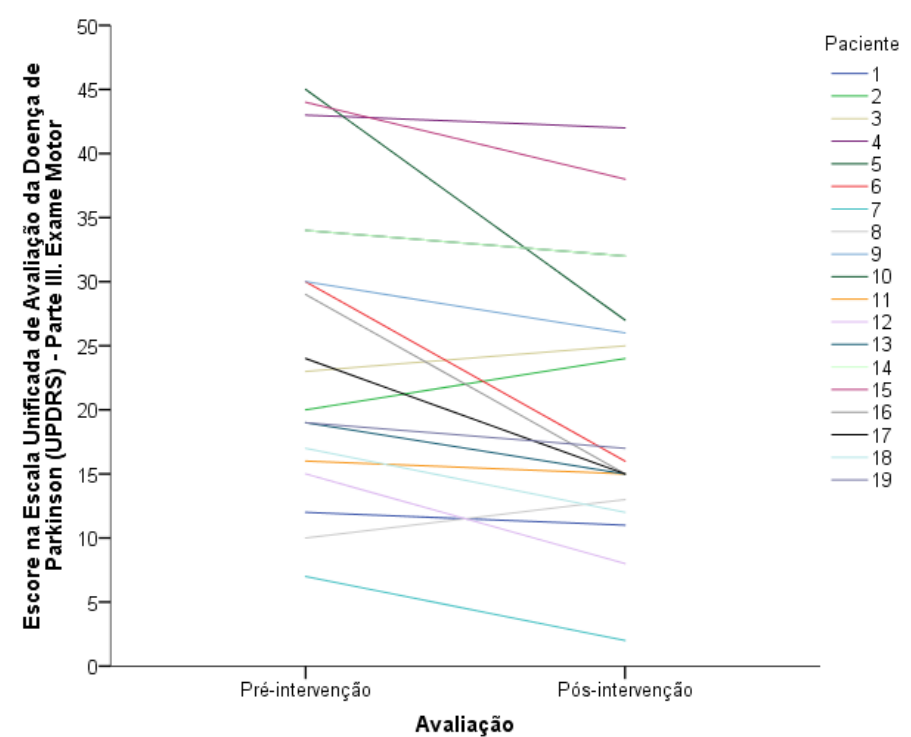

Figura 3. Escore na Parte III. Exame Motor do instrumento UPDRS nas avaliações pré e pósintervenção

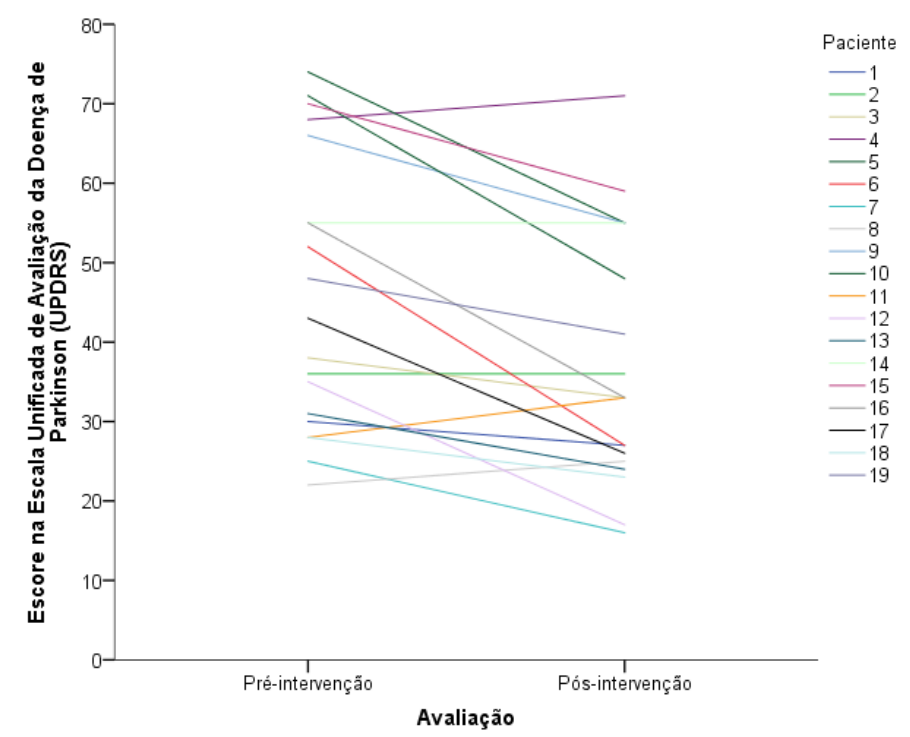

Figura 4. Escore total do instrumento UPDRS nas avaliações pré e pós-intervenção

Os escores dos itens 20 a 26 do instrumento UPDRS que originalmente são subdivididas por lado direito e esquerdo foram ajustados para lado mais afetado e lado menos afetado e os escores do lado mais afetado foram comparados entre as avaliações pré e pós-intervenção (Tabela 4). Foi encontrada diferença estatisticamente significante em movimentos da mão $(p=0,007)$. 
Tabela 4. Escores nos itens da UPDRS no lado mais afetado dos participantes do estudo nas avaliações pré e pós-intervenção

\begin{tabular}{|c|c|c|c|}
\hline \multirow[b]{2}{*}{ UPDRS - Escores no lado mais afetado } & \multicolumn{2}{|c|}{ Momento de avaliação } & \multirow[b]{2}{*}{ Valor-p } \\
\hline & $\begin{array}{c}\text { Pré-intervenção } \\
\mathrm{n}(\%)\end{array}$ & $\begin{array}{c}\text { Pós-intervenção } \\
\mathrm{n}(\%)\end{array}$ & \\
\hline Parte III. Exame Motor & & & \\
\hline 20. Tremor de repouso na mão & & & 0,097 \\
\hline 0 & $1(5,3)$ & $6(31,6)$ & \\
\hline 1 & $9(47,4)$ & $7(36,8)$ & \\
\hline 2 & $8(42,1)$ & $4(21,1)$ & \\
\hline 3 & $1(5,3)$ & $2(10,5)$ & \\
\hline 20. Tremor de repouso no pé & & & 0,317 \\
\hline 0 & $12(63,2)$ & $12(63,2)$ & \\
\hline 1 & $6(31,6)$ & $5(26,3)$ & \\
\hline 2 & $1(5,3)$ & $2(10,5)$ & \\
\hline 21. Tremor de ação ou postural na mão & & & $>0,999$ \\
\hline 0 & $12(63,2)$ & $12(63,2)$ & \\
\hline 1 & $7(36,8)$ & $7(36,8)$ & \\
\hline 22. Rigidez no membro superior & & & 0,405 \\
\hline 0 & $3(15,8)$ & $6(31,6)$ & \\
\hline 1 & $12(63,2)$ & $9(47,4)$ & \\
\hline 2 & $4(21,1)$ & $4(21,1)$ & \\
\hline 22. Rigidez no membro inferior & & & 0,782 \\
\hline 0 & $7(36,8)$ & $7(36,8)$ & \\
\hline 1 & $10(52,6)$ & $9(47,4)$ & \\
\hline 2 & $2(10,5)$ & $3(15,8)$ & \\
\hline 23. Bater de dedos da mão & & & 0,166 \\
\hline 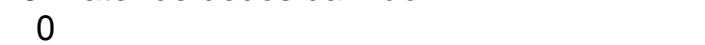 & $1(5,3)$ & $1(5,3)$ & \\
\hline 1 & $7(36,8)$ & $8(42,1)$ & \\
\hline 2 & $7(36,8)$ & $7(36,8)$ & \\
\hline 3 & $1(5,3)$ & $3(15,8)$ & \\
\hline 4 & $3(15,8)$ & $0(0,0)$ & \\
\hline 24. Movimentos da mão & & & 0,007 \\
\hline 0 & $2(10,5)$ & $7(36,8)$ & \\
\hline 1 & $12(63,2)$ & $9(47,4)$ & \\
\hline 2 & $2(10,5)$ & $2(10,5)$ & \\
\hline 3 & $2(10,5)$ & $0(0,0)$ & \\
\hline 4 & $1(5,3)$ & $1(5,3)$ & \\
\hline 25. Movimentos rápidos e alternados da mão & & & 0,564 \\
\hline 0 & $9(47,4)$ & $9(47,4)$ & \\
\hline 1 & $5(26,3)$ & $8(42,1)$ & \\
\hline 2 & $4(21,1)$ & $0(0,0)$ & \\
\hline 3 & $1(5,3)$ & $2(10,5)$ & \\
\hline 26. Agilidade do pé & & & 0,083 \\
\hline 0 & $4(21,1)$ & $6(31,6)$ & \\
\hline 1 & $7(36,8)$ & $9(47,4)$ & \\
\hline 2 & $4(21,1)$ & $2(10,5)$ & \\
\hline 3 & $4(21,1)$ & $1(5,3)$ & \\
\hline 4 & $0(0,0)$ & $1(5,3)$ & \\
\hline
\end{tabular}

Valor-p: teste de Wilcoxon para dados relacionados.

A qualidade de vida dos pacientes foi avaliada pela aplicação do instrumento PDQ-39 nos momentos pré e pós-intervenção e os escores dos itens do instrumento foram apresentados na tabela 5. 
Tabela 5. Escores nos itens do questionário PDQ-39 dos participantes do estudo nas avaliações pré e pós-intervenção

\begin{tabular}{|c|c|c|}
\hline \multirow[b]{2}{*}{ PDQ-39 - Escores dos itens } & \multicolumn{2}{|c|}{ Momento de avaliação } \\
\hline & $\begin{array}{c}\text { Pré- } \\
\text { intervenção } \\
\mathrm{n}(\%)\end{array}$ & $\begin{array}{l}\text { Pós- } \\
\text { intervenção } \\
n(\%)\end{array}$ \\
\hline \multicolumn{3}{|l|}{ Domínio Mobilidade } \\
\hline \multicolumn{3}{|c|}{ 1- Teve dificuldade para realizar atividades de lazer as quais gosta? } \\
\hline Nunca (0) & $12(63,2)$ & $13(68,4)$ \\
\hline Raramente (1) & $5(26,3)$ & $2(10,5)$ \\
\hline Algumas vezes (2) & $1(5,3)$ & $3(15,8)$ \\
\hline Frequentemente (3) & $1(5,3)$ & $0(0,0)$ \\
\hline Sempre (4) & $0(0,0)$ & $1(5,3)$ \\
\hline \multicolumn{3}{|c|}{ 2- Teve dificuldade para cuidar da casa? } \\
\hline Nunca (0) & $6(31,6)$ & $7(36,8)$ \\
\hline Raramente (1) & $3(15,8)$ & $3(15,8)$ \\
\hline Alqumas vezes (2) & $5(26,3)$ & $4(21,1)$ \\
\hline Frequentemente (3) & $3(15,8)$ & $3(15,8)$ \\
\hline Sempre (4) & $2(10,5)$ & $2(10,5)$ \\
\hline \multicolumn{3}{|c|}{ 3- Teve dificuldade para carregar sacolas? } \\
\hline Nunca $(0)$ & $7(36,8)$ & $10(52,6)$ \\
\hline Raramente (1) & $4(21,1)$ & $3(15,8)$ \\
\hline Algumas vezes (2) & $2(10,5)$ & $3(15,8)$ \\
\hline Frequentemente (3) & $4(21,1)$ & $2(10,5)$ \\
\hline Sempre (4) & $2(10,5)$ & $1(5,3)$ \\
\hline \multicolumn{3}{|c|}{ 4- Teve problemas para andar aproximadamente $1 \mathrm{~km}$ ? } \\
\hline Nunca $(0)$ & $5(26,3)$ & $9(47,4)$ \\
\hline Raramente (1) & $4(21,1)$ & $3(15,8)$ \\
\hline Algumas vezes (2) & $4(21,1)$ & $5(26,3)$ \\
\hline Frequentemente (3) & $2(10,5)$ & $1(5,3)$ \\
\hline Sempre (4) & $4(21,1)$ & $1(5,3)$ \\
\hline \multicolumn{3}{|c|}{ 5- Teve problemas para andar aproximadamente $100 \mathrm{~m} ?$} \\
\hline Nunca $(0)$ & $10(52,6)$ & $15(78,9)$ \\
\hline Raramente (1) & $3(15,8)$ & $2(10,5)$ \\
\hline Alqumas vezes (2) & $6(31,6)$ & $2(10,5)$ \\
\hline \multicolumn{3}{|c|}{ 6- Teve problemas para andar pela casa com a facilidade que gostaria? } \\
\hline Nunca $(0)$ & $7(36,8)$ & $12(63,2)$ \\
\hline Raramente (1) & $5(26,3)$ & $5(26,3)$ \\
\hline Algumas vezes (2) & $2(10,5)$ & $1(5,3)$ \\
\hline Frequentemente (3) & $3(15,8)$ & $1(5,3)$ \\
\hline Sempre (4) & $2(10,5)$ & $0(0,0)$ \\
\hline \multicolumn{3}{|c|}{ 7- Teve dificuldade para andar em lugares públicos? } \\
\hline Nunca $(0)$ & $2(10,5)$ & $9(47,4)$ \\
\hline Raramente (1) & $3(15,8)$ & $2(10,5)$ \\
\hline Algumas vezes (2) & $4(21,1)$ & $3(15,8)$ \\
\hline Frequentemente (3) & $6(31,6)$ & $3(15,8)$ \\
\hline Sempre (4) & $4(21,1)$ & $2(10,5)$ \\
\hline \multicolumn{3}{|c|}{ 8- Precisou de alquma pessoa para acompanhá-lo ao sair de casa? } \\
\hline Nunca (0) & $6(31,6)$ & $6(31,6)$ \\
\hline Raramente (1) & $2(10,5)$ & $2(10,5)$ \\
\hline Algumas vezes (2) & $1(5,3)$ & $1(5,3)$ \\
\hline Frequentemente (3) & $2(10,5)$ & $2(10,5)$ \\
\hline Sempre (4) & $8(42,1)$ & $8(42,1)$ \\
\hline \multicolumn{3}{|c|}{ 9- Teve medo ou preocupação de cair em público? } \\
\hline Nunca $(0)$ & $6(31,6)$ & $7(36,8)$ \\
\hline Raramente (1) & $0(0,0)$ & $2(10,5)$ \\
\hline Alqumas vezes (2) & $2(10,5)$ & $3(15,8)$ \\
\hline Frequentemente (3) & $2(10,5)$ & $2(10,5)$ \\
\hline Sempre (4) & $9(47,4)$ & $5(26,3)$ \\
\hline
\end{tabular}


...continuação

\begin{tabular}{|c|c|c|}
\hline \multicolumn{3}{|c|}{ 10- Ficou em casa mais tempo que gostaria? } \\
\hline Nunca (0) & $6(31,6)$ & $7(36,8)$ \\
\hline Raramente (1) & $5(26,3)$ & $2(10,5)$ \\
\hline Algumas vezes (2) & $2(10,5)$ & $6(31,6)$ \\
\hline Frequentemente (3) & $4(21,1)$ & $1(5,3)$ \\
\hline Sempre (4) & $2(10,5)$ & $3(15,8)$ \\
\hline \multicolumn{3}{|c|}{ Domínio Atividade de Vida Diária } \\
\hline \multicolumn{3}{|c|}{ 11- Teve dificuldade para tomar banho? } \\
\hline Nunca (0) & $6(31,6)$ & $11(57,9)$ \\
\hline Raramente (1) & $5(26,3)$ & $2(10,5)$ \\
\hline Algumas vezes (2) & $2(10,5)$ & $3(15,8)$ \\
\hline Frequentemente (3) & $3(15,8)$ & $3(15,8)$ \\
\hline Sempre (4) & $3(15,8)$ & $0(0,0)$ \\
\hline \multicolumn{3}{|c|}{ 12- Teve dificuldade para vestir-se? } \\
\hline Nunca $(0)$ & $0(0,0)$ & $2(10,5)$ \\
\hline Raramente (1) & $4(21,1)$ & $5(26,3)$ \\
\hline Algumas vezes (2) & $7(36,8)$ & $8(42,1)$ \\
\hline Frequentemente (3) & $3(15,8)$ & $3(15,8)$ \\
\hline Sempre (4) & $5(26,3)$ & $1(5,3)$ \\
\hline \multicolumn{3}{|c|}{ 13- Teve dificuldade com botões ou cadarços? } \\
\hline Nunca (0) & $2(10,5)$ & $1(5,3)$ \\
\hline Raramente (1) & $3(15,8)$ & $7(36,8)$ \\
\hline Algumas vezes (2) & $2(10,5)$ & $4(21,1)$ \\
\hline Frequentemente (3) & $2(10,5)$ & $6(31,6)$ \\
\hline Sempre (4) & $10(52,6)$ & $1(5,3)$ \\
\hline \multicolumn{3}{|c|}{ 14- Teve dificuldade para escrever claramente? } \\
\hline Nunca (0) & $2(10,5)$ & $4(21,1)$ \\
\hline Raramente (1) & $4(21,1)$ & $2(10,5)$ \\
\hline Algumas vezes (2) & $2(10,5)$ & $6(31,6)$ \\
\hline Frequentemente (3) & $5(26,3)$ & $1(5,3)$ \\
\hline Sempre (4) & $6(31,6)$ & $6(31,6)$ \\
\hline \multicolumn{3}{|c|}{ 15- Teve dificuldade para cortar a comida? } \\
\hline Nunca $(0)$ & $3(15,8)$ & $5(26,3)$ \\
\hline Raramente (1) & $2(10,5)$ & $4(21,1)$ \\
\hline Algumas vezes (2) & $6(31,6)$ & $5(26,3)$ \\
\hline Frequentemente (3) & $1(5,3)$ & $3(15,8)$ \\
\hline Sempre (4) & $7(36,8)$ & $2(10,5)$ \\
\hline \multicolumn{3}{|c|}{ 16- Teve dificuldade para beber sem derramar? } \\
\hline Nunca (0) & $13(68,4)$ & $14(73,7)$ \\
\hline Raramente (1) & $2(10,5)$ & $2(10,5)$ \\
\hline Algumas vezes (2) & $2(10,5)$ & $1(5,3)$ \\
\hline Frequentemente (3) & $2(10,5)$ & $2(10,5)$ \\
\hline \multicolumn{3}{|c|}{ Domínio Bem-Estar Emocional } \\
\hline \multicolumn{3}{|c|}{ 17- Sentiu-se depressivo? } \\
\hline Nunca (0) & $8(42,1)$ & $11(57,9)$ \\
\hline Raramente (1) & $3(15,8)$ & $4(21,1)$ \\
\hline Algumas vezes (2) & $6(31,6)$ & $3(15,8)$ \\
\hline Frequentemente (3) & $1(5,3)$ & $1(5,3)$ \\
\hline Sempre (4) & $1(5,3)$ & $0(0,0)$ \\
\hline \multicolumn{3}{|c|}{ 18- Sentiu-se isolado e sozinho? } \\
\hline Nunca $(0)$ & $9(47,4)$ & $13(68,4)$ \\
\hline Raramente (1) & $3(15,8)$ & $2(10,5)$ \\
\hline Algumas vezes (2) & $3(15,8)$ & $4(21,1)$ \\
\hline Frequentemente (3) & $2(10,5)$ & $0(0,0)$ \\
\hline Sempre (4) & $2(10,5)$ & $0(0,0)$ \\
\hline \multicolumn{3}{|c|}{ 19- Sentiu-se triste ou chorou? } \\
\hline Nunca (0) & $12(63,2)$ & $9(47,4)$ \\
\hline Raramente (1) & $4(21,1)$ & $5(26,3)$ \\
\hline
\end{tabular}


...continuação

\begin{tabular}{|c|c|c|}
\hline Algumas vezes (2) & $1(5,3)$ & $4(21,1)$ \\
\hline Frequentemente (3) & $2(10,5)$ & $1(5,3)$ \\
\hline \multicolumn{3}{|l|}{ 20- Sentiu-se magoado? } \\
\hline Nunca (0) & $13(68,4)$ & $12(63,2)$ \\
\hline Raramente (1) & $3(15,8)$ & $3(15,8)$ \\
\hline Algumas vezes (2) & $2(10,5)$ & $4(21,1)$ \\
\hline Sempre (4) & $1(5,3)$ & $0(0,0)$ \\
\hline \multicolumn{3}{|l|}{ 21- Sentiu-se ansioso? } \\
\hline Nunca (0) & $3(15,8)$ & $3(15,8)$ \\
\hline Raramente (1) & $2(10,5)$ & $5(26,3)$ \\
\hline Algumas vezes (2) & $8(42,1)$ & $5(26,3)$ \\
\hline Frequentemente (3) & $3(15,8)$ & $2(10,5)$ \\
\hline Sempre (4) & $3(15,8)$ & $4(21,1)$ \\
\hline \multicolumn{3}{|c|}{ 22- Sentiu-se preocupado com o futuro? } \\
\hline Nunca (0) & $2(10,5)$ & $5(26,3)$ \\
\hline Raramente (1) & $2(10,5)$ & $1(5,3)$ \\
\hline Algumas vezes (2) & $5(26,3)$ & $6(31,6)$ \\
\hline Frequentemente (3) & $4(21,1)$ & $3(15,8)$ \\
\hline Sempre (4) & $6(31,6)$ & $4(21,1)$ \\
\hline \multicolumn{3}{|l|}{ Domínio Estigma } \\
\hline \multicolumn{3}{|c|}{ 23- Sentiu que tinha que esconder a doença para outras pessoas? } \\
\hline Nunca (0) & $9(47,4)$ & $11(57,9)$ \\
\hline Raramente (1) & $0(0,0)$ & $2(10,5)$ \\
\hline Algumas vezes (2) & $6(31,6)$ & $3(15,8)$ \\
\hline Sempre (4) & $4(21,1)$ & $3(15,8)$ \\
\hline \multicolumn{3}{|c|}{ 24- Evitou situações que envolviam comer ou beber em público? } \\
\hline Nunca (0) & $9(47,4)$ & $14(73,7)$ \\
\hline Raramente (1) & $3(15,8)$ & $1(5,3)$ \\
\hline Algumas vezes (2) & $3(15,8)$ & $2(10,5)$ \\
\hline Frequentemente (3) & $0(0,0)$ & $1(5,3)$ \\
\hline Sempre (4) & $4(21,1)$ & $1(5,3)$ \\
\hline \multicolumn{3}{|c|}{ 25- Sentiu-se envergonhado em público? } \\
\hline Nunca (0) & $7(36,8)$ & $11(57,9)$ \\
\hline Raramente (1) & $2(10,5)$ & $2(10,5)$ \\
\hline Algumas vezes (2) & $6(31,6)$ & $6(31,6)$ \\
\hline Frequentemente (3) & $2(10,5)$ & $0(0,0)$ \\
\hline Sempre (4) & $2(10,5)$ & $0(0,0)$ \\
\hline \multicolumn{3}{|c|}{$\begin{array}{l}\text { 26- Sentiu-se preocupado com a reação de outras pessoas em relação a } \\
\text { você? }\end{array}$} \\
\hline Nunca (0) & $5(26,3)$ & $10(52,6)$ \\
\hline Raramente (1) & $1(5,3)$ & $0(0,0)$ \\
\hline Algumas vezes (2) & $7(36,8)$ & $6(31,6)$ \\
\hline Frequentemente (3) & $2(10,5)$ & $2(10,5)$ \\
\hline Sempre (4) & $4(21,1)$ & $1(5,3)$ \\
\hline \multicolumn{3}{|c|}{ Domínio Suporte Social } \\
\hline \multicolumn{3}{|c|}{ 27- Teve problemas no relacionamento com pessoas próximas? } \\
\hline Nunca (0) & $16(84,2)$ & $14(73,7)$ \\
\hline Raramente (1) & $0(0,0)$ & $4(21,1)$ \\
\hline Algumas vezes (2) & $1(5,3)$ & $1(5,3)$ \\
\hline Frequentemente (3) & $2(10,5)$ & $0(0,0)$ \\
\hline \multicolumn{3}{|c|}{ 28- Recebeu apoio que precisava do seu conjugue ou parceiro? } \\
\hline Algumas vezes (2) & $2(10,5)$ & $2(10,5)$ \\
\hline Frequentemente (3) & $1(5,3)$ & $0(0,0)$ \\
\hline Sempre (4) & $16(84,2)$ & $17(89,5)$ \\
\hline \multicolumn{3}{|c|}{ 29- Recebeu apoio que precisava da família e amigos íntimos? } \\
\hline Nunca (0) & $1(5,3)$ & $1(5,3)$ \\
\hline Algumas vezes (2) & $1(5,3)$ & $0(0,0)$ \\
\hline Frequentemente (3) & $1(5,3)$ & $1(5,3)$ \\
\hline
\end{tabular}


...continuação

Sempre (4)

Domínio Cognição

30- Adormeceu inesperadamente durante o dia?

Nunca (0)

Raramente (1)

Algumas vezes (2)

Sempre (4)

31- Teve problemas de concentração?

Nunca (0)

Raramente (1)

Algumas vezes (2)

Frequentemente (3)

Sempre (4)

32- Teve falta de memória?

Nunca (0)

Raramente (1)

Algumas vezes (2)

33- Teve pesadelos ou alucinações?

Nunca (0)

Raramente (1)

Algumas vezes (2)

Frequentemente (3)

Domínio Comunicação

34- Teve dificuldade para falar?

Nunca (0)

Raramente (1)

Algumas vezes (2)

Frequentemente (3)

Sempre (4)

35- Sentiu que não podia comunicar-se efetivamente?

Nunca (0)

Raramente (1)

Algumas vezes (2)

Sempre (4)

36- Sentiu-se ignorado pelas pessoas?

Nunca (0)

Raramente (1)

Algumas vezes (2)

Domínio Desconforto Corporal

37- Teve cãibras musculares doloridas ou espasmos?

Nunca (0)

Raramente (1)

Algumas vezes (2)

Frequentemente (3)

Sempre (4)

38- Teve dores nas articulações ou no corpo?

Nunca (0)

Raramente (1)

Algumas vezes (2)

Frequentemente (3)

Sempre (4)

39- Sentiu-se desconfortável no frio ou no calor?

Nunca (0)

Raramente (1)

Algumas vezes (2)

$16(84,2)$

$17(89,5)$

$4(73,7) \quad 12(63,2)$

$1(5,3) \quad 3(15,8)$

$3(15,8) \quad 3(15,8)$

$1(5,3) \quad 1(5,3)$

$15(78,9) \quad 12(63,2)$

$1(5,3) \quad 2(10,5)$

$1(5,3) \quad 4(21,1)$

$1(5,3) \quad 1(5,3)$

$1(5,3) \quad 0(0,0)$

12(63,2) $11(57,9)$

$4(21,1) \quad 3(15,8)$

$3(15,8) \quad 5(26,3)$

$11(57,9) \quad 13(68,4)$

$1(5,3) \quad 1(5,3)$

$6(31,6) \quad 4(21,1)$

$1(5,3) \quad 1(5,3)$

$5(26,3) \quad 5(26,3)$

$2(10,5) \quad 3(15,8)$

$4(21,1) \quad 8(42,1)$

$5(26,3) \quad 1(5,3)$

$3(15,8) \quad 2(10,5)$

$9(47,4) \quad 16(84,2)$

$3(15,8) \quad 0(0,0)$

$6(31,6) \quad 3(15,8)$

$1(5,3) \quad 0(0,0)$

$11(57,9) \quad 16(84,2)$

$2(10,5) \quad 1(5,3)$

$6(31,6) \quad 2(10,5)$

Frequentemente (3)

$5(26,3) \quad 8(42,1)$

$4(21,1) \quad 3(15,8)$

$4(21,1) \quad 4(21,1)$

$4(21,1) \quad 1(5,3)$

$2(10,5) \quad 3(15,8)$

$1(5,3) \quad 2(10,5)$

$1(5,3) \quad 3(15,8)$

$3(15,8) \quad 3(15,8)$

$9(47,4) \quad 7(36,8)$

$5(26,3) \quad 4(21,1)$

$5(26,3) \quad 7(36,8)$

$1(5,3) \quad 4(21,1)$

$6(31,6) \quad 5(26,3)$

$5(26,3) \quad 2(10,5)$

Sempre (4)

$2(10,5) \quad 1(5,3)$


Calculamos os escores total e dos domínios do questionário PDQ-39 (Tabela 6 e Figuras 5 a 10) conforme descrito acima na seção 1 e comparando as avaliações pré e pós-intervenção observamos evidências de redução no escore total (valor-p=0,001) e nos escores dos domínios Mobilidade (valor-p=0,016), atividade de vida diária (valor- $p=0,004$ ), estigma (valor- $p=0,003$ ), comunicação (valor- $p=0,010$ ) e desconforto corporal (valor- $\mathrm{p}=0,001$ ), indicando melhora na percepção do estado de saúde após a intervenção.

Tabela 6. Escores total da escala PDQ-39 dos participantes do estudo nas avaliações pré e pósintervenção

\begin{tabular}{|c|c|c|c|c|}
\hline \multirow{2}{*}{ PDQ-39 - Escores } & \multicolumn{2}{|c|}{ Momento de avaliação } & \multirow{2}{*}{$\begin{array}{l}\text { Variação } \\
\text { (pós - pré) }\end{array}$} & \multirow{2}{*}{ Valor-p } \\
\hline & Pré-intervenção & Pós-intervenção & & \\
\hline Domínio Mobilidade & & & & 0,016 \\
\hline Mediana (Q1; Q3) & $37,5(20,0 ; 57,5)$ & $25,0(12,5 ; 50,0)$ & $-12,5(-27,5 ;-2,5)$ & \\
\hline Mínimo; Máximo & 10,$0 ; 82,5$ & 7,$5 ; 70,0$ & $-32,5 ; 40,0$ & \\
\hline Domínio Atividade de Vida & & & & \\
\hline Diária & & & & 0,004 \\
\hline Mediana (Q1; Q3) & $58,3(25,0 ; 79,2)$ & $33,3(20,8 ; 54,2)$ & $-8,3(-20,8 ;-4,2)$ & \\
\hline Mínimo; Máximo & 8,$3 ; 87,5$ & 8,$3 ; 83,3$ & $-58,3 ; 16,7$ & \\
\hline Domínio Bem-estar Emocional & & & & 0,065 \\
\hline Mediana (Q1; Q3) & $37,5(20,8 ; 50,0)$ & $29,2(16,7 ; 45,8)$ & $-4,2(-16,7 ; 4,2)$ & \\
\hline Mínimo; Máximo & 4,$2 ; 62,5$ & 0,$0 ; 54,2$ & $-33,3 ; 12,5$ & \\
\hline Domínio Estigma & & & & 0,003 \\
\hline Mediana (Q1; Q3) & $43,8(12,5 ; 50,0)$ & $25,0(0,0 ; 37,5)$ & $-6,3(-31,3 ; 0,0)$ & \\
\hline Mínimo; Máximo & 0,$0 ; 100,0$ & 0,$0 ; 50,0$ & $-62,5 ; 6,3$ & \\
\hline Domínio Suporte Social & & & & 0,705 \\
\hline Mediana (Q1; Q3) & $66,7(66,7 ; 66,7)$ & $66,7(66,7 ; 66,7)$ & $0,0(0,0 ; 0,0)$ & \\
\hline Mínimo; Máximo & 33,$3 ; 91,7$ & 33,$3 ; 75,0$ & $-16,7 ; 8,3$ & \\
\hline Domínio Cognição & & & & 0,368 \\
\hline Mediana (Q1; Q3) & $12,5(0,0 ; 25,0)$ & $12,5(6,3 ; 25,0)$ & $6,3(-6,3 ; 12,5)$ & \\
\hline Mínimo; Máximo & 0,$0 ; 37,5$ & 0,$0 ; 43,8$ & $-25,0 ; 12,5$ & \\
\hline Domínio Comunicação & & & & 0,010 \\
\hline Mediana (Q1; Q3) & $33,3(16,7 ; 50,0)$ & $16,7(0,0 ; 33,3)$ & $-8,3(-25,0 ; 0,0)$ & \\
\hline Mínimo; Máximo & 0,$0 ; 66,7$ & 0,$0 ; 50,0$ & $-50,0 ; 16,7$ & \\
\hline Domínio Desconforto Corporal & & & & 0,015 \\
\hline Mediana (Q1; Q3) & $50,0(41,7 ; 66,7)$ & $41,7(33,3 ; 50,0)$ & $-16,7(-25,0 ; 0,0)$ & \\
\hline Mínimo; Máximo & 33,$3 ; 75,0$ & 16,$7 ; 83,3$ & $-41,7 ; 25,0$ & \\
\hline Total & & & & 0,001 \\
\hline Mediana (Q1; Q3) & $42,6(32,3 ; 45,5)$ & $31,3(24,4 ; 38,3)$ & $-9,7(-11,9 ;-1,6)$ & \\
\hline Mínimo; Máximo & 24,$1 ; 61,4$ & 13,$9 ; 59,8$ & $-26,6 ; 2,9$ & \\
\hline
\end{tabular}




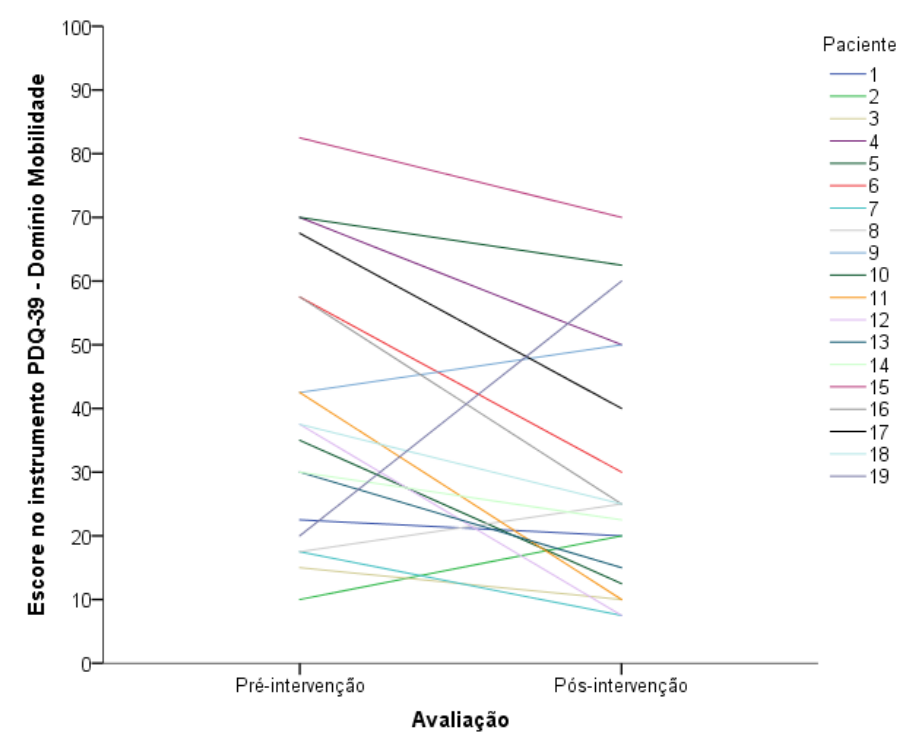

Figura 5. Escore no domínio Mobilidade do questionário PDQ-39 nas avaliações pré e pós-intervenção

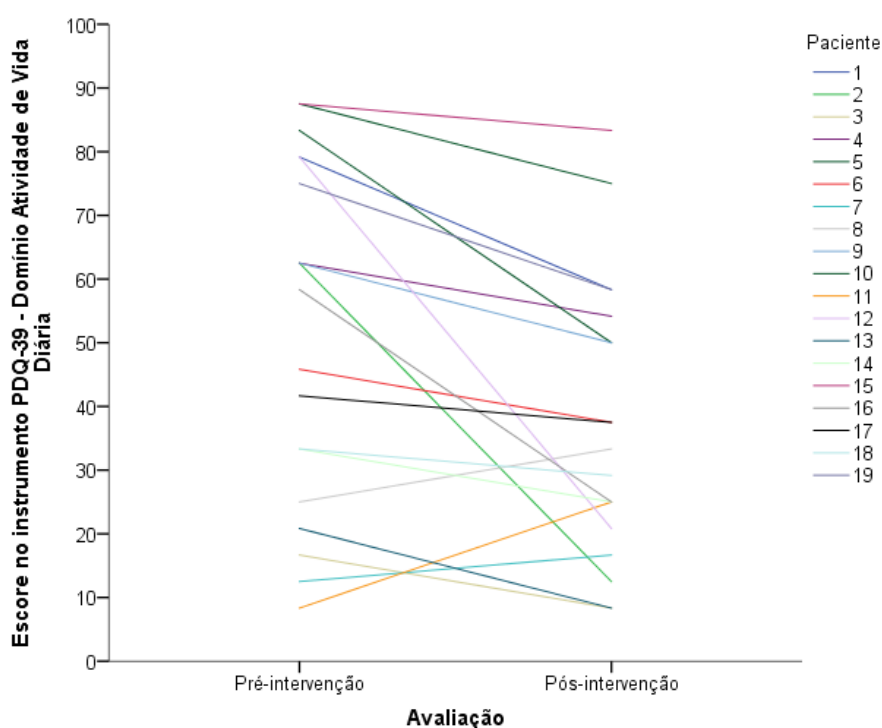

Figura 6. Escore no domínio Atividade de Vida Diária do questionário PDQ-39 nas avaliações pré e pós-intervenção 


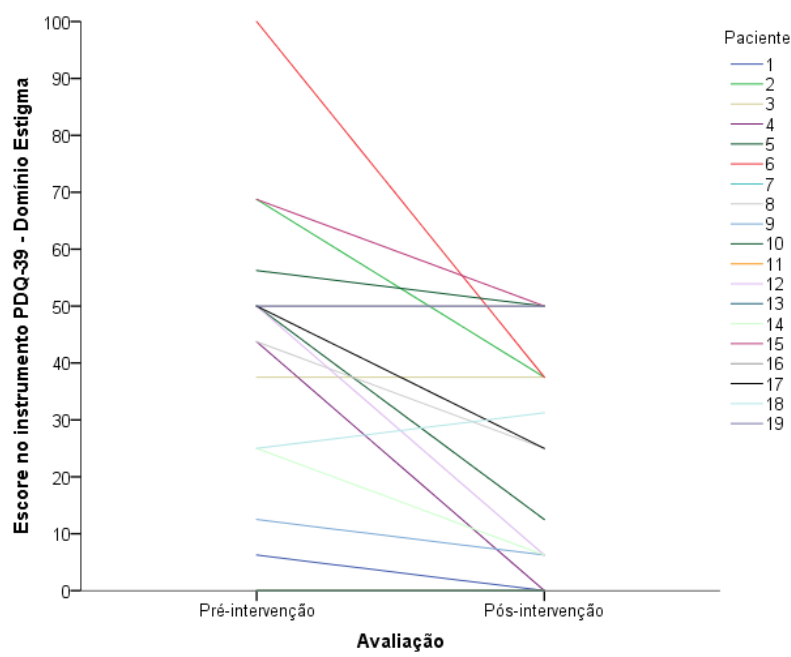

Figura 7. Escore no domínio Estigma do questionário PDQ-39 nas avaliações pré e pósintervenção

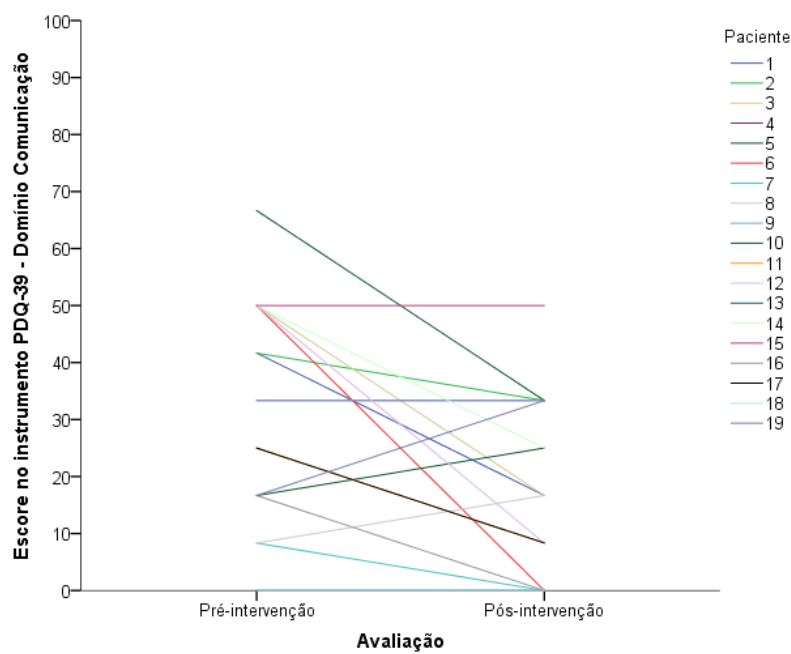

Figura 8. Escore no domínio Comunicação do questionário PDQ-39 nas avaliações pré e pósintervenção 


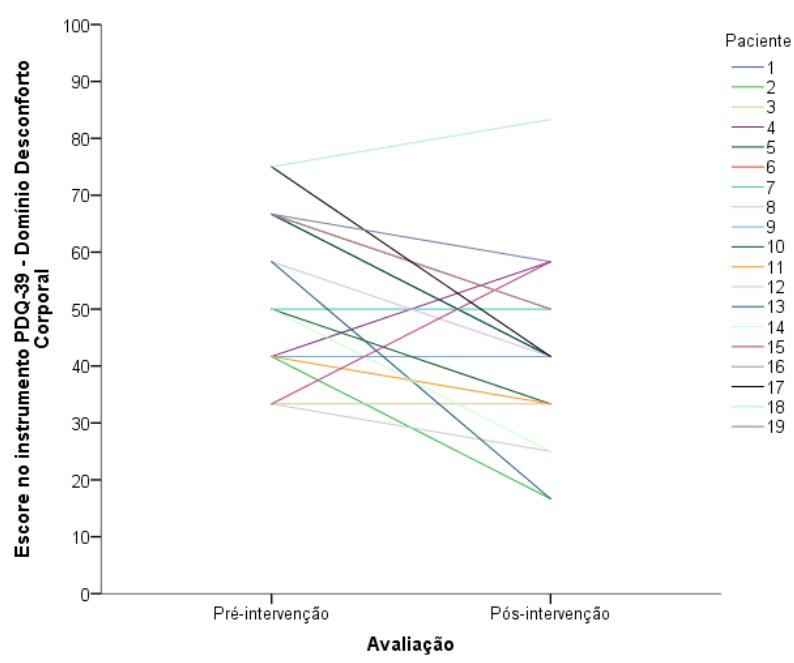

Figura 9. Escore no domínio Desconforto Corporal do questionário PDQ-39 nas avaliações pré e pósintervenção

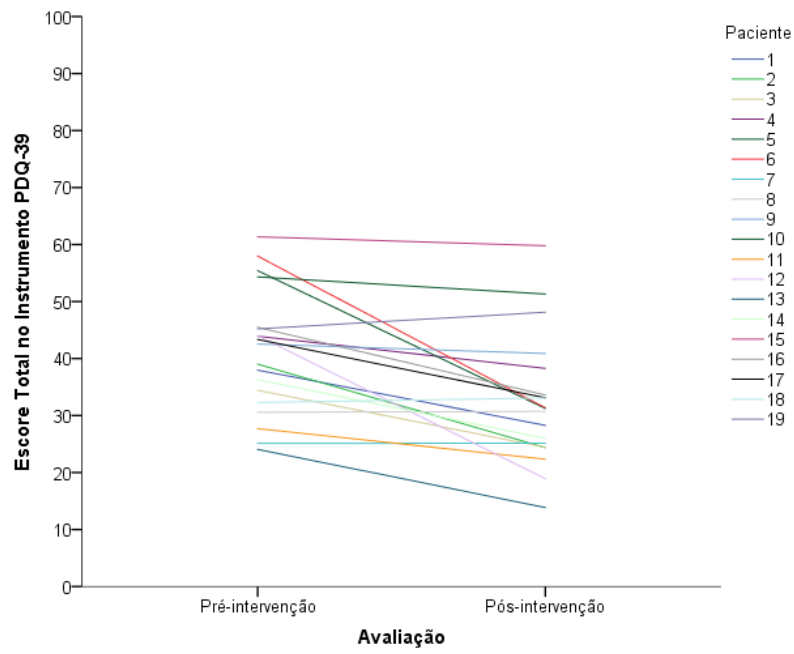

Figura 10. Escore total do questionário PDQ-39 nas avaliações pré e pós-intervenção

Observamos ainda que há evidências de variações após oito semanas de treinamento nos escores dos domínios do instrumento SF36: Capacidade Funcional com diferença estimada de 13,4 pontos $(p=0,001)$, Dor com diferença estimada de 10,1 pontos $(p=0,006)$ e Saúde Mental com diferença estimada de 9,9 pontos $(p<0,001)$ (Tabela 7, Figuras 11 a 13).

Não encontramos evidências de alterações nos escores dos domínios: Limitações por Aspectos Físicos com variação estimada de 5,3 pontos $(p=0,622)$, Estado Geral de Saúde com variação estimada de 0,9 pontos $(p=0,808)$, Vitalidade com variação estimada de 2,9 pontos $(p=0,494)$, Aspectos Sociais com variação estimada de 0,7 pontos $(p=0,494)$ e Limitações por Aspectos Emocionais com 
variação estimada de 0,0 pontos ( $p>0,999)$. Nesta escala, quanto maior a pontuação melhor a percepção de qualidade de vida.

Tabela 7. Escores dos instrumentos de avaliação SF-36 antes e após oito semanas de treinamento

\begin{tabular}{lccc}
\hline \multirow{2}{*}{ Instrumentos } & \multicolumn{2}{c}{ Momento de avaliação } & \multirow{2}{*}{ Valor-p } \\
\cline { 2 - 3 } & Pré-intervenção & Pós-intervenção & \\
\hline SF36 - Capacidade funcional & $54,2(44,2 ; 64,2)$ & $67,6(59,2 ; 76,1)$ & 0,001 \\
SF36 - Limitação por aspectos físicos & $40,8(22,5 ; 59,1)$ & $46,1(26,6 ; 65,5)$ & 0,622 \\
SF36 - Dor & $47,6(39,4 ; 55,8)$ & $57,6(47,9 ; 67,4)$ & 0,006 \\
SF36 - Estado geral de saúde & $64,5(58,2 ; 70,7)$ & $65,4(59,2 ; 71,7)$ & 0,808 \\
SF36 - Vitalidade & $63,4(57,1 ; 69,8)$ & $66,3(59,7 ; 72,9)$ & 0,494 \\
SF36 - Aspectos sociais & $77,0(64,7 ; 89,3)$ & $77,6(69,7 ; 85,5)$ & 0,905 \\
SF36 - Limitação por aspectos & $64,9(45,9 ; 83,9)$ & $64,9(46,7 ; 83,2)$ & $>0,999$ \\
emocionais & $71,8(63,6 ; 80,0)$ & $81,7(75,1 ; 88,3)$ & $<0,001$ \\
SF36 - Saúde mental &
\end{tabular}

Dados expressos por valores médios ajustados e intervalos de confiança de $95 \%$.

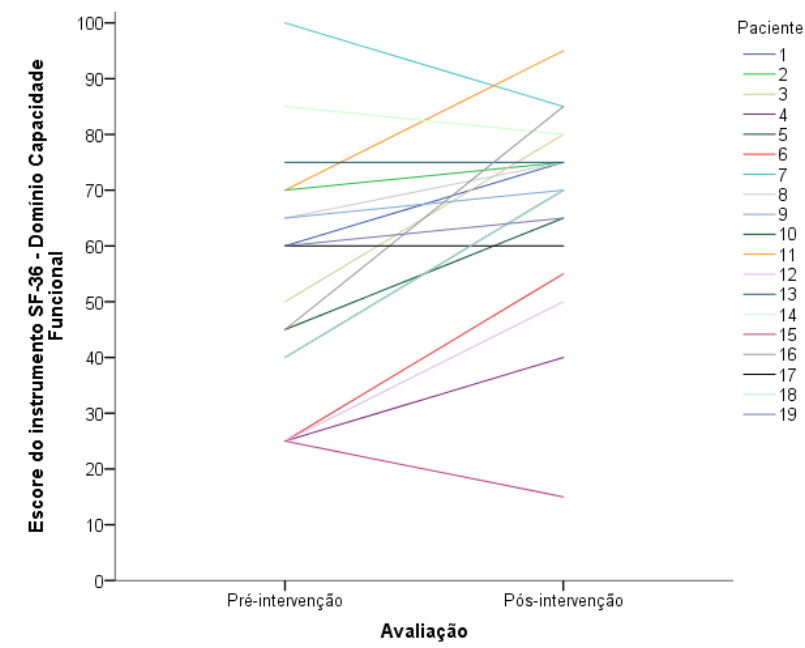

Figura 11. Escore no domínio Capacidade Funcional do instrumento SF-36 nas avaliações pré e pós-intervenção

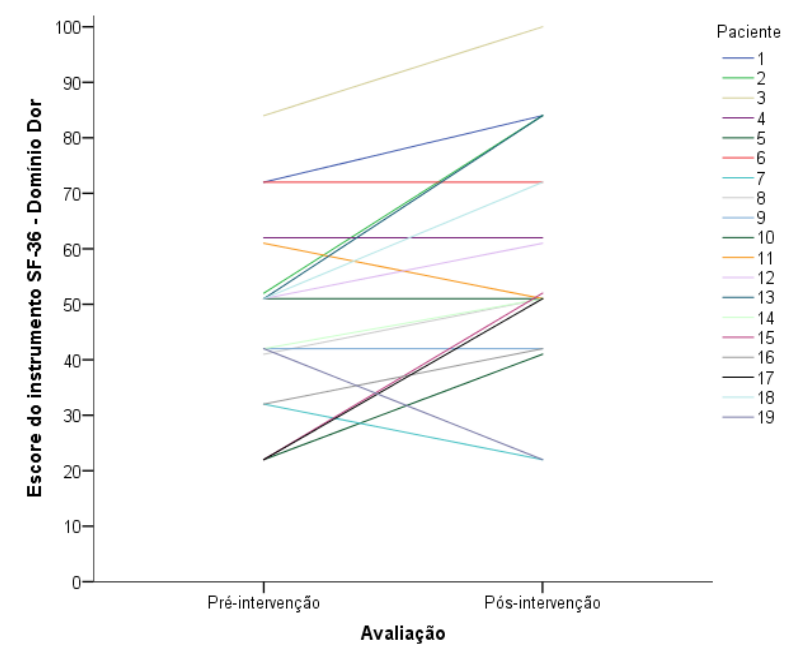

Figura 12. Escore no domínio Dor do instrumento SF-36 nas avaliações pré e pós-intervenção 


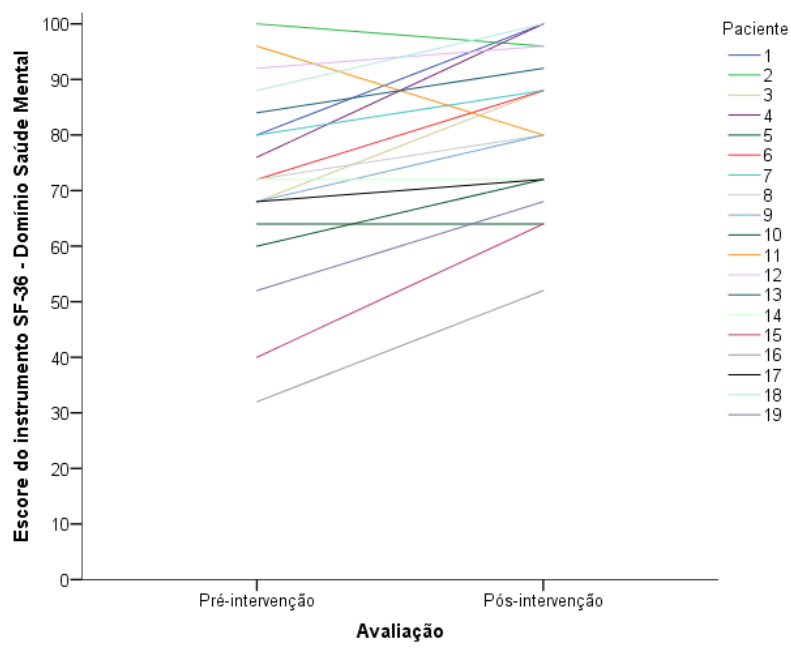

Figura 13. Escore no domínio Saúde Mental do instrumento SF-36 nas avaliações pré e pósintervenção

O equilíbrio dos pacientes foi avaliado pela aplicação do instrumento Escala de Equilíbrio Funcional de Berg nos momentos pré e pós-intervenção e os escores dos itens do instrumento foram apresentados na tabela 8. Calculamos o escore total da Escala de Berg (Tabela 9 e Figura 14) conforme descrito acima na seção 1 e comparando as avaliações pré e pós-intervenção observamos evidências estatisticamente significantes de aumento (valor- $p=0,015)$ do escore, indicando melhora no equilíbrio e redução no risco de queda.

Tabela 8. Escores nos itens do instrumento Escala de Equilíbrio Funcional de Berg dos participantes do estudo nas avaliações pré e pós-intervenção

\begin{tabular}{lcc}
\hline Escala de Berg - Escores dos itens & \multicolumn{2}{c}{ Momento de avaliação } \\
\cline { 2 - 3 } & $\begin{array}{c}\text { Pré-intervenção } \\
\mathbf{n}(\%)\end{array}$ & $\begin{array}{c}\text { Pós-intervenção } \\
\mathbf{n}(\%)\end{array}$ \\
\hline 1. Posição sentada para posição em pé & & \\
2 & $1(5,3)$ & $0(0,0)$ \\
3 & $2(10,5)$ & $1(5,3)$ \\
4 & $16(84,2)$ & $18(94,7)$ \\
2. Permanecer em pé sem apoio & $1(5,3)$ & $0(0,0)$ \\
3 & $18(94,7)$ & $19(100,0)$ \\
4 & & \\
3. Permanecer sentado sem apoio nas costas, mas com os pés & & \\
apoiados no chão ou num banquinho & $19(100,0)$ & $19(100,0)$ \\
4 & & $1(5,3)$ \\
4. Posição em pé para posição sentada & $4(21,1)$ & $18(94,7)$ \\
3 & $15(78,9)$ & \\
4 & & $0(0,0)$ \\
5. Transferências & $1(5,3)$ & $2(10,5)$ \\
2 & $3(15,8)$ & $17(89,5)$ \\
3 & $15(78,9)$ & $0(0,0)$ \\
\hline 4 & & continua...
\end{tabular}


...continuação

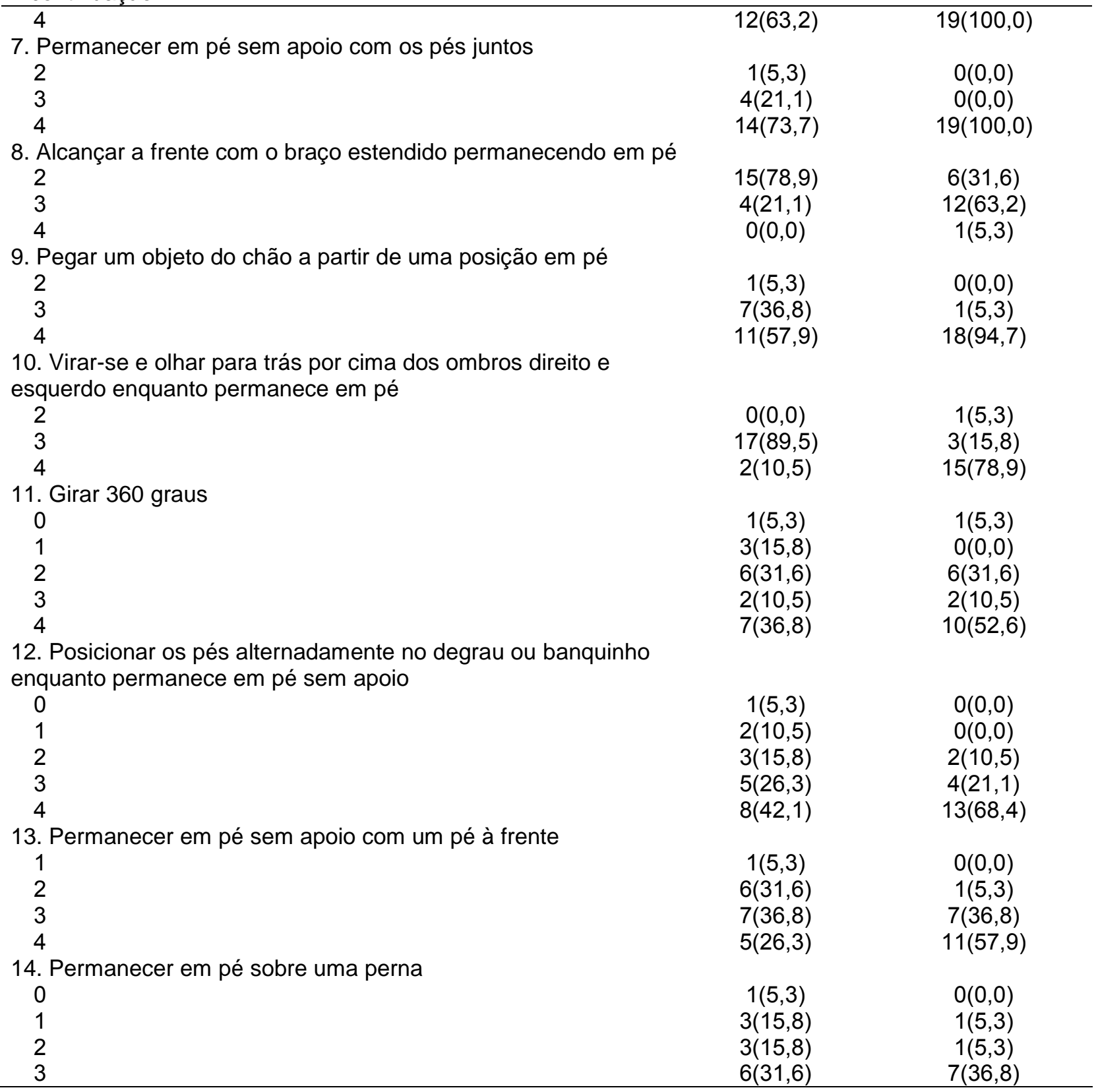

Tabela 9. Escores total da Escala de Equilíbrio Funcional de Berg dos participantes do estudo nas avaliações pré e pós-intervenção

\begin{tabular}{lcccc}
\hline \multirow{2}{*}{ Escala de Berg } & \multicolumn{2}{c}{ Momento de avaliação } & $\begin{array}{c}\text { Variação } \\
\text { (pós - pré) }\end{array}$ & Valor-p \\
\cline { 2 - 3 } & Pré-intervenção & Pós-intervenção & & \\
\hline Escore total & & & & \\
$\quad$ Mediana (Q1; Q3) & $48,0(42,0 ; 51,0)$ & $52,0(51,0 ; 55,0)$ & $4,0(2,0 ; 6,0)$ & \\
$\quad$ Mínimo; Máximo & 32,$0 ; 53,0$ & 42,$0 ; 56,0$ & 0,$0 ; 16,0$ & \\
\hline
\end{tabular}

Q1: primeiro quartil; $\mathrm{Q} 3$ : terceiro quartil; valor $\mathrm{p}$ : teste de Wilcoxon para dados relacionados. 


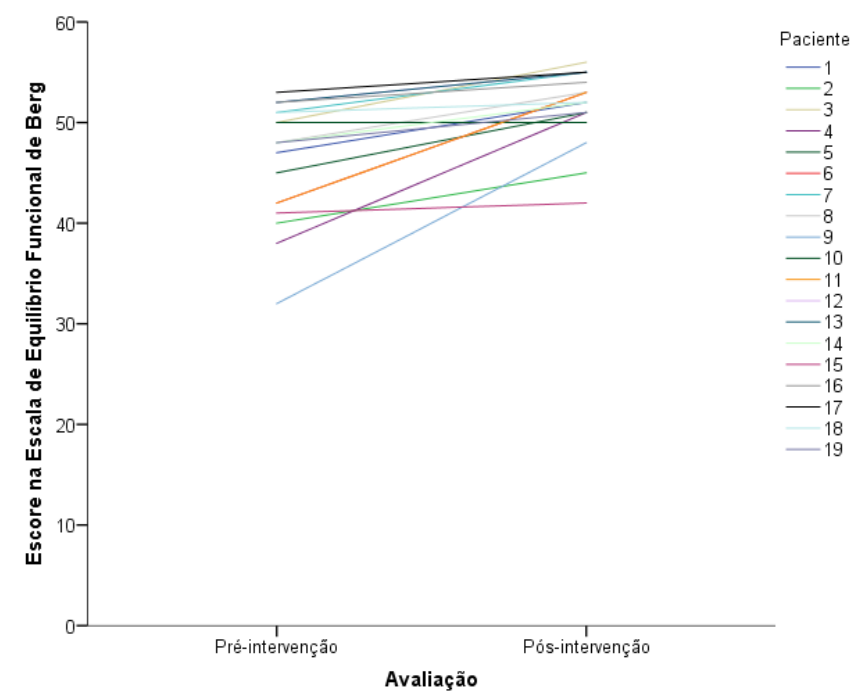

Figura 14. Escore total do instrumento Escala de Equilíbrio Funcional de Berg nas avaliações pré e pós-intervenção

\subsubsection{Variação nos escores dos testes de avaliação neuropsicológica após a intervenção}

A avaliação neuropsicológica foi realizada nos momentos pré e pósintervenção seguindo um protocolo estruturado onde foram explorados campos cognitivos específicos como atenção/funções executivas, memória, linguagem, funções visuais além de avaliação neuropsiquiátrica.

O paciente 1 não foi avaliado por nenhum dos testes neuropsicológicos e o paciente 5 foi avaliado apenas no momento pós-intervenção, reduzindo a amostra de análise para 17 pacientes. No Teste de Interferência de Stroop temos 16 pacientes analisados, uma vez que o paciente 19 não foi avaliado e no Teste das Trilhas parte $B$ os pacientes 10 e 15 não têm resposta, reduzindo para 150 número de pacientes analisados.

Comparando as avaliações pré e pós-intervenção nos Subtestes WAIS-III (Tabela 10 e Figura 15) observamos evidências de aumento no escore do Teste de Vocabulário (valor-p=0,047), indicando melhora na linguagem dos pacientes. 
Tabela 10. Escores nos subtestes WAIS-III (vocabulário, semelhanças, cubos e dígitos) dos participantes do estudo nas avaliações pré e pós-intervenção

\begin{tabular}{|c|c|c|c|c|}
\hline \multirow{2}{*}{ Escores } & \multicolumn{2}{|c|}{ Momento de avaliação } & \multirow{2}{*}{$\begin{array}{c}\text { Variação } \\
\text { (pós - pré) }\end{array}$} & \multirow{2}{*}{ Valor-p } \\
\hline & Pré-intervenção & Pós-intervenção & & \\
\hline Teste de Vocabulário & & & & $0,047^{\$}$ \\
\hline Mediana (Q1; Q3) & $27(24 ; 33)$ & $33(24 ; 38)$ & $5(-1 ; 11)$ & \\
\hline Mínimo; Máximo & $5 ; 56$ & $11 ; 57$ & $-12 ; 23$ & \\
\hline Teste de Semelhanças & & & & $0,496^{\Phi}$ \\
\hline Mediana (Q1; Q3) & $15(13 ; 23)$ & $19(9 ; 25)$ & $2(-1 ; 4)$ & \\
\hline Mínimo; Máximo & $3 ; 33$ & $5 ; 35$ & $-9 ; 8$ & \\
\hline Teste de Desenho com Cubos & & & & $0,597^{\$}$ \\
\hline Mediana (Q1; Q3) & $11(8 ; 20)$ & $12(10 ; 24)$ & $1(-4 ; 3)$ & \\
\hline Mínimo; Máximo & $4 ; 31$ & $0 ; 32$ & $-12 ; 18$ & \\
\hline Teste de Alcance de Dígitos & & & & \\
\hline Escore total & & & & $0,865^{\#}$ \\
\hline Mediana (Q1; Q3) & $10(8 ; 12)$ & $10(8 ; 11)$ & $0(0 ; 1)$ & \\
\hline Mínimo; Máximo & $6 ; 14$ & $6 ; 15$ & $-5 ; 2$ & \\
\hline Escore de Ordem Direta & & & & $0,885^{\#}$ \\
\hline Mediana (Q1; Q3) & $7(6 ; 8)$ & $6(6 ; 8)$ & $0(0 ; 1)$ & \\
\hline Mínimo; Máximo & $4 ; 8$ & $4 ; 10$ & $-2 ; 2$ & \\
\hline Escore de Ordem Inversa & & & & $0,776^{\#}$ \\
\hline Mediana (Q1; Q3) & $3(2 ; 5)$ & $3(2 ; 4)$ & $0(0 ; 0)$ & \\
\hline Mínimo; Máximo & $1 ; 8$ & $2 ; 6$ & $-4 ; 2$ & \\
\hline
\end{tabular}

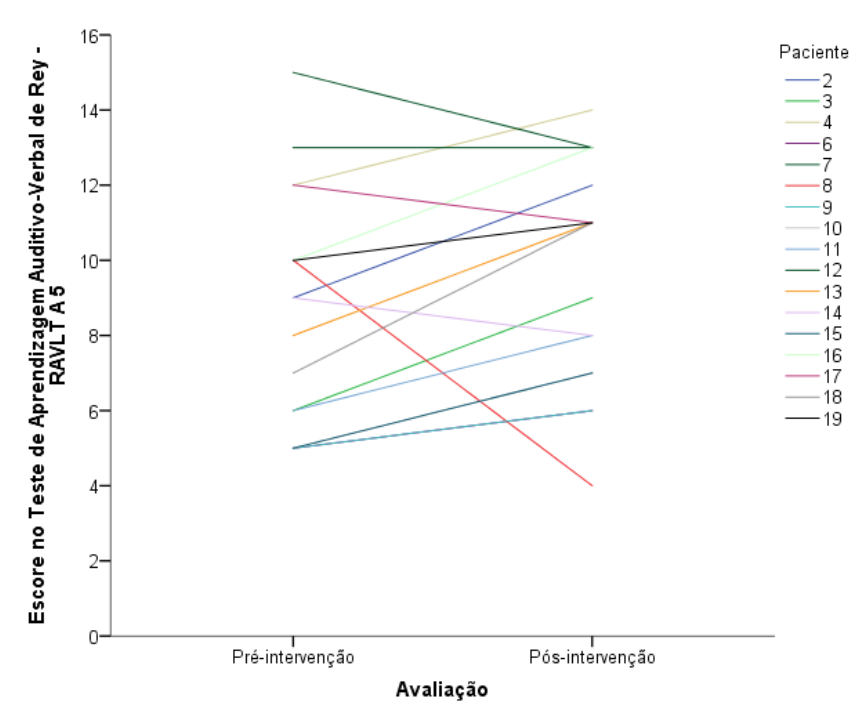

Figura 15. Escore do Teste de Aprendizagem Auditivo-Verbal de Rey - Lista A 5 nas avaliações pré e pós-intervenção

Observamos ainda evidências de variação estatisticamente significantes nos escores das tarefas do Teste de Rey/RAVLT (Tabela 11 e Figura 16). 
Tabela 11. Escores nas tarefas do Teste de Aprendizagem Auditivo-Verbal de Rey (RAVLT) dos participantes do estudo nas avaliações pré e pós-intervenção

\begin{tabular}{|c|c|c|c|c|}
\hline \multirow{2}{*}{ Escores } & \multicolumn{2}{|c|}{ Momento de avaliação } & \multirow{2}{*}{$\begin{array}{c}\text { Variação } \\
\text { (pós - pré) }\end{array}$} & \multirow{2}{*}{ Valor-p } \\
\hline & Pré-intervenção & Pós-intervenção & & \\
\hline \multicolumn{5}{|l|}{ RAVLT } \\
\hline Lista A 1 & & & & 0,163 \\
\hline Mediana (Q1; Q3) & $5(3 ; 5)$ & $5(4 ; 6)$ & $0(0 ; 1)$ & \\
\hline Mínimo; Máximo & $2 ; 7$ & $2 ; 9$ & $-3 ; 5$ & \\
\hline Lista A 2 & & & & 0,189 \\
\hline Mediana (Q1; Q3) & $7(5 ; 8)$ & $7(6 ; 10)$ & $0(0 ; 2)$ & \\
\hline Mínimo; Máximo & $4 ; 11$ & $2 ; 11$ & $-6 ; 3$ & \\
\hline Lista A 3 & & & & 0,5 \\
\hline Mediana (Q1; Q3) & $7(6 ; 9)$ & $8(5 ; 9)$ & $0(0 ; 2)$ & \\
\hline Mínimo; Máximo & $2 ; 12$ & $1 ; 13$ & $-7 ; 3$ & \\
\hline Lista A 4 & & & & 0,234 \\
\hline Mediana (Q1; Q3) & $8(7 ; 10)$ & $9(7 ; 11)$ & $0(0 ; 2)$ & \\
\hline Mínimo; Máximo & $2 ; 14$ & $5 ; 12$ & $-3 ; 4$ & \\
\hline Lista A 5 & & & & 0,048 \\
\hline Mediana (Q1; Q3) & $9(6 ; 10)$ & $11(7 ; 12)$ & $2(0 ; 3)$ & \\
\hline Mínimo; Máximo & $5 ; 15$ & $4 ; 14$ & $-6 ; 4$ & \\
\hline Lista A Total & & & & 0,064 \\
\hline Mediana (Q1; Q3) & $35(27 ; 44)$ & $41(28 ; 48)$ & $3(-1 ; 8)$ & \\
\hline Mínimo; Máximo & $17 ; 57$ & $14 ; 57$ & $-22 ; 14$ & \\
\hline Lista B & & & & 0,819 \\
\hline Mediana (Q1; Q3) & $4(3 ; 4)$ & $4(3 ; 5)$ & $1(-2 ; 1)$ & \\
\hline Mínimo; Máximo & $1 ; 8$ & $0 ; 7$ & $-4 ; 4$ & \\
\hline Lista A 6 & & & & 0,491 \\
\hline Mediana (Q1; Q3) & $6(4 ; 8)$ & $6(3 ; 9)$ & $1(-1 ; 2)$ & \\
\hline Mínimo; Máximo & $0 ; 9$ & $2 ; 11$ & $-6 ; 7$ & \\
\hline Lista A 7 & & & & 0,313 \\
\hline Mediana (Q1; Q3) & $7(4 ; 8)$ & $6(5 ; 8)$ & $1(-1 ; 3)$ & \\
\hline Mínimo; Máximo & $0 ; 10$ & $2 ; 13$ & $-6 ; 6$ & \\
\hline
\end{tabular}

Q1: primeiro quartil; Q3: terceiro quartil; valor $\mathrm{p}$ : teste de Wilcoxon para dados relacionados.

Comparando as avaliações pré e pós-intervenção no Teste de Nomeação de Boston (Tabela 12, Figura 21) observamos evidências de aumento no escore (valor $\mathrm{p}=0,014$ ), indicando melhora na linguagem dos pacientes.

Tabela 12. Escores no Teste de Nomeação de Boston, Teste do Desenho do Relógio e Subteste de Letras Fragmentadas e Análise de Cubos da bateria de Percepção Visual de Objetos e Espeço (VOSP) dos participantes do estudo nas avaliações pré e pós-intervenção

\begin{tabular}{|c|c|c|c|c|}
\hline \multirow{2}{*}{ Escores } & \multicolumn{2}{|c|}{ Momento de avaliação } & \multirow{2}{*}{$\begin{array}{l}\text { Variação } \\
\text { (pós - pré) }\end{array}$} & \multirow{2}{*}{ Valor-p } \\
\hline & Pré-intervenção & Pós-intervenção & & \\
\hline Teste de Nomeação de Boston & & & & $0,014^{\$}$ \\
\hline Mediana (Q1; Q3) & $45(34 ; 52)$ & $49(42 ; 56)$ & $3(-1 ; 6)$ & \\
\hline Mínimo; Máximo & $27 ; 58$ & $26 ; 59$ & $-5 ; 10$ & \\
\hline Teste do Desenho do Relógio & & & & $0,328^{\#}$ \\
\hline Mediana (Q1; Q3) & $12(8 ; 14)$ & $11(8 ; 14)$ & $-1(-2 ; 1)$ & \\
\hline Mínimo; Máximo & $2 ; 15$ & $2 ; 15$ & $-5 ; 12$ & \\
\hline VOSP & & & & \\
\hline Letras Fragmentadas & & & & $0,713^{\$}$ \\
\hline Mediana (Q1; Q3) & $18(14 ; 19)$ & $17(16 ; 20)$ & $0(-1 ; 1)$ & \\
\hline Mínimo; Máximo & $7 ; 20$ & $4 ; 20$ & $-4 ; 3$ & \\
\hline Análise de Cubos & & & & $0,401^{\$}$ \\
\hline Mediana (Q1; Q3) & $5(2 ; 9)$ & $7(2 ; 10)$ & $0(0 ; 1)$ & \\
\hline Mínimo; Máximo & $0 ; 10$ & $0 ; 10$ & $-4 ; 6$ & \\
\hline
\end{tabular}




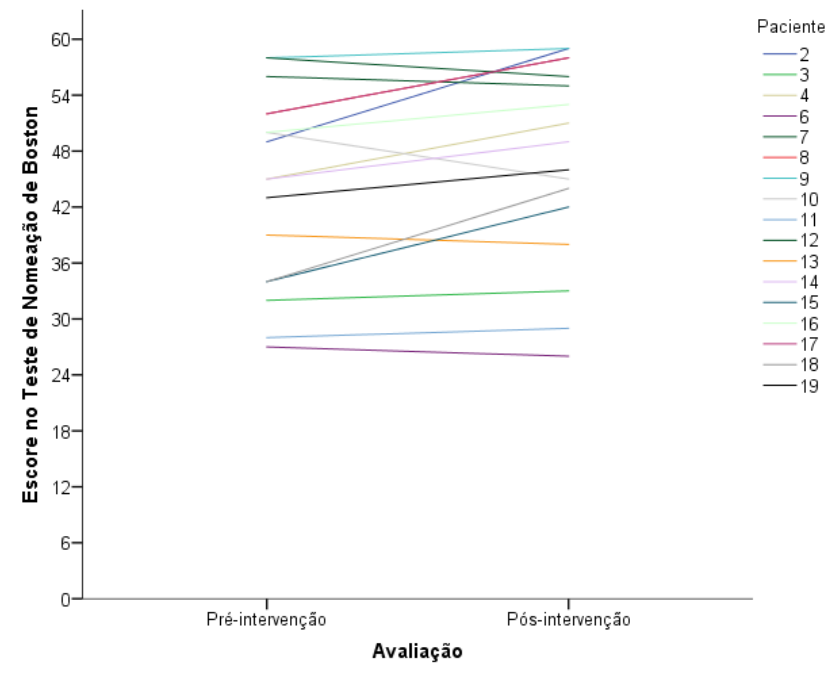

Figura 16. Escore do Teste de Nomeação de Boston nas avaliações pré e pós-intervenção

Não encontramos evidências de variação nos seguintes escores: Teste de Semelhanças (valor $p=0,496$ ), Teste de Desenho com Cubos (valor- $p=0,597$ ), Teste de Alcance de Dígitos, Teste das Trilhas parte A e B, Teste de Interferência de Stroop, Teste de Fluência Verbal, Subteste de Letras Fragmentadas (Tabela 12) e Análises de Cubos da Bateria de Percepção Visual de Objetos e Espaço/VOSP (Tabela 12). Também não encontramos evidências de variação no escore do Teste do Desenho do Relógio (valor $p=0,328 ;$ Tabela 12).

Não encontramos significância estatística nos resultados em relação ao teste de Trilhas A e B, Stroop e Fluência Verbal (Apêndice 1).

$\mathrm{Na}$ comparação entre as avaliações pré e pós-intervenção no Inventário Neuropsiquiátrico (Tabela 13 e Figuras 17 e 18) observamos evidências estatisticamente significantes de redução no escore de Intensidade dos Sintomas e Escore total, indicando melhora nos sintomas dos pacientes. Não encontramos evidências de variação nos escores de Frequência dos Sintomas.

Tabela 13. Inventário neuropsiquiátrico dos participantes do estudo nas avaliações pré e pós-intervenção

\begin{tabular}{lcccc}
\hline \multirow{2}{*}{ Escores } & \multicolumn{2}{c}{ Momento de avaliação } & $\begin{array}{c}\text { Variação } \\
\text { (pós - pré) }\end{array}$ & Valor-p \\
\cline { 2 - 3 } Inventário Neuropsiquiátrico & Pré-intervenção & Pós-intervenção & & \multirow{2}{*}{0,061} \\
Frequência dos Sintomas & & & $-1(-5 ; 0)$ & \\
$\quad$ Mediana (Q1; Q3) & $4(2 ; 8)$ & $3(0 ; 6)$ & $-11 ; 5$ & 0,012 \\
$\quad$ Mínimo; Máximo & $0 ; 16$ & $0 ; 10$ & $-2(-4 ; 0)$ & \\
Intensidade dos Sintomas & $4(2 ; 7)$ & $1(0 ; 5)$ & $-8 ; 3$ & \\
$\quad$ Mediana (Q1; Q3) & $0 ; 14$ & $0 ; 7$ & $-3(-9 ; 0)$ & \\
$\quad$ Mínimo; Máximo & $7(5 ; 15)$ & $3(0 ; 13)$ & $-25 ; 11$ & \\
Total & $0 ; 46$ & $0 ; 21$ &
\end{tabular}




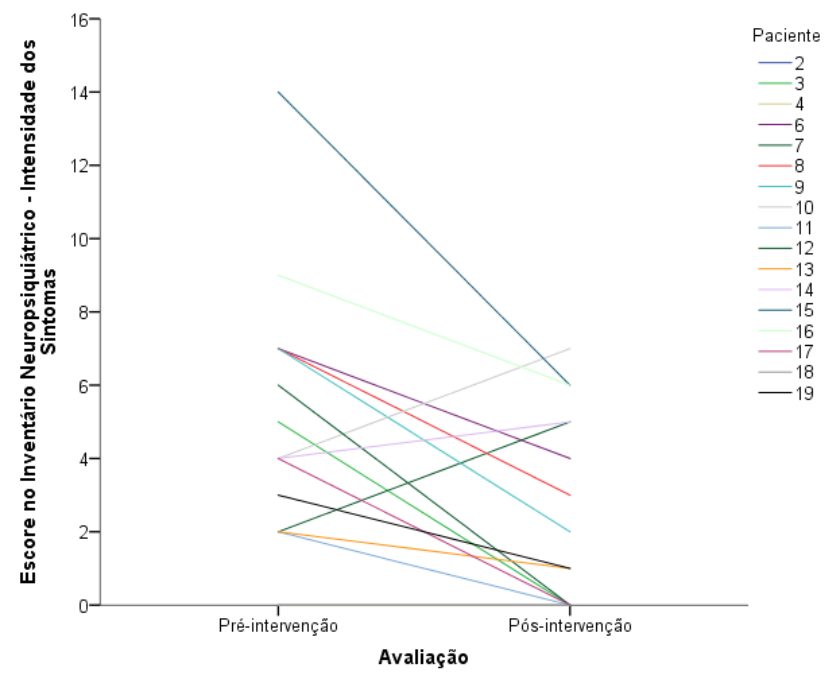

Figura 17. Escore do Inventário Neuropsiquiátrico Intensidade dos Sintomas nas avaliações pré e pósintervenção

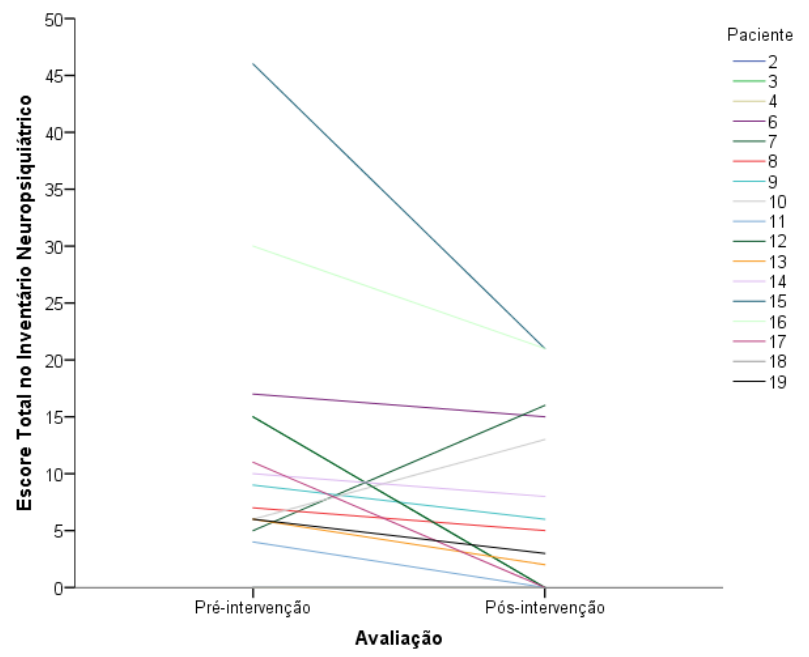

Figura 18. Escore do Inventário Neuropsiquiátrico Total nas avaliações pré e pós-intervenção

4.1.4 Variação nas medidas de neuroimagem funcional obtidas através de PETRM com FDG após a intervenção

O exame de neuroimagem funcional através do PET-RM com injeção do ligante FDG foi realizado nos pacientes nos momentos pré e pósintervenção. As medidas que originalmente foram obtidas para os lados direito e esquerdo foram ajustadas para lados contralateral ao lado mais afetado (lado menos afetado) e ipsilateral ao lado mais afetado (lado mais afetado) de cada paciente. 
As áreas cerebrais avaliadas foram o lobo frontal (giro pré-central, área motora suplementar, giros frontais, dorsolateral), tálamo, núcleo lentiforme (caudado e globo pálido), caudado, putâmen, outras estruturas dos núcleos da base e cerebelo. Estas regiões corticais e/ou subcorticais foram escolhidas porque apresentam uma relação intrínseca direta ou indireta com movimentos automáticos e/ou voluntários.

$\mathrm{Na}$ comparação entre as avaliações pré e pós-intervenção em cada lado não observamos evidências de variação nas medidas SUV de todas as regiões obtidas através do exame PET-RM com FDG (Apêndice 2).

Quando comparado com as medidas de Desvio-Padrão em relação ao banco de controles do Database Comparison (Siemens Medical Solutions) observamos evidencias de variação nas regiões de lobo frontal $p=0,014)$, giro frontal medial $(p=0,031)$, giro frontal superior dorsolateral $(p=0,004)$ e área motora suplementar $(p=0,031)$ contralateral ao hemicorpo clinicamente mais afetado. Em relação às regiões ipsilaterais ao hemicorpo mais afetado observamos variações nas regiões do cuneus $(p=0,036)$, giro frontal superior dorsolateral $(p=0,010)$ e área motora suplementar $(\mathrm{p}=0,012)$ (Tabelas 14 e 15, Figuras 19 a 25). Nas demais áreas analisadas não encontramos diferença estatística (Apêndice 3).

Tabela 14. Medidas de Desvio-Padrão do exame de neuroimagem funcional através do PET-RM com FDG no lado contralateral ao lado mais afetado dos participantes do estudo nas avaliações pré e pósintervenção

\begin{tabular}{|c|c|c|c|c|}
\hline \multirow{2}{*}{$\begin{array}{l}\text { Exame PET-RM com FDG } \\
\text { no Lado Contralateral }\end{array}$} & \multicolumn{2}{|c|}{ Momento de avaliação } & \multirow{2}{*}{$\begin{array}{l}\text { Variação } \\
\text { (pós - pré) }\end{array}$} & \multirow{2}{*}{ Valor-p } \\
\hline & Pré-intervenção & Pós-intervenção & & \\
\hline Lobo frontal & & & & 0,014 \\
\hline Mediana (Q1; Q3) & $-1,60(-3,50 ; 0,10)$ & $-2,60(-5,00 ;-0,10)$ & $-0,80(-1,90 ; 0,40)$ & \\
\hline Mínimo; Máximo & $-4,60 ; 1,90$ & $-5,80 ; 0,90$ & $-4,60 ; 1,30$ & \\
\hline Giro frontal medial & & & & 0,031 \\
\hline Mediana (Q1; Q3) & $-1,70(-3,10 ; 0,40)$ & $-2,40(-3,80 ;-0,90)$ & $-0,40(-1,10 ;-0,10)$ & \\
\hline Mínimo; Máximo & $-5,10 ; 1,30$ & $-5,20 ; 1,30$ & $-4,50 ; 1,60$ & \\
\hline $\begin{array}{l}\text { Giro frontal superior } \\
\text { dorsolateral }\end{array}$ & & & & 0,004 \\
\hline Mediana (Q1; Q3) & $-0,10(-1,20 ; 2,30)$ & $-0,50(-2,30 ; 0,10)$ & $-0,80(-1,80 ; 0,00)$ & \\
\hline Mínimo; Máximo & $-2,90 ; 4,60$ & $-4,00 ; 4,70$ & $-5,00 ; 1,00$ & \\
\hline Área motora suplementar & & & & 0,031 \\
\hline Mediana (Q1; Q3) & $1,20(-0,30 ; 2,70)$ & $1,10(0,00 ; 1,90)$ & $-0,40(-1,40 ; 0,10)$ & \\
\hline Mínimo; Máximo & $-1,90 ; 6,60$ & $-2,40 ; 5,60$ & $-2,30 ; 1,50$ & \\
\hline
\end{tabular}


Tabela 15. Medidas de Desvio-Padrão do exame de neuroimagem funcional através do PET-RM com FDG no lado ipsilateral ao lado mais afetado dos participantes do estudo nas avaliações pré e pósintervenção

\begin{tabular}{|c|c|c|c|c|}
\hline \multirow{2}{*}{$\begin{array}{l}\text { Exame PET-RM com FDG no } \\
\text { Lado Ipsilateral }\end{array}$} & \multicolumn{2}{|c|}{ Momento de avaliação } & \multirow{2}{*}{$\begin{array}{l}\text { Variação } \\
\text { (pós - pré) }\end{array}$} & \multirow[b]{2}{*}{ Valor-p } \\
\hline & Pré-intervencão & Pós-intervencão & & \\
\hline Cuneus & & & & 0,036 \\
\hline Mediana (Q1; Q3) & $0,00(-1,90 ; 0,90)$ & $0,60(-1,10 ; 1,50)$ & $0,40(-0,30 ; 0,90)$ & \\
\hline Mínimo; Máximo & $-4,30 ; 3,40$ & $-3,20 ; 3,10$ & $-1,0$ & \\
\hline $\begin{array}{l}\text { Superior frontal gyrus, } \\
\text { dorsolateral }\end{array}$ & & & & 0,01 \\
\hline Mediana (Q1; Q3) & $0,10(-1,30 ; 1,50)$ & $-0,90(-2,00 ; 1,10)$ & $-0,60(-0,90 ; 0,00)$ & \\
\hline Mínimo; Máximo & $-2,70 ; 7,00$ & $-3,20 ; 4,50$ & $-4,40 ; 1,50$ & \\
\hline Área motora suplementar & & & & 0,012 \\
\hline Mediana (Q1; Q3) & $1,60(0,30 ; 3,10)$ & $0,80(-0,10 ; 3,00)$ & $-0,30(-1,20 ; 0,10)$ & \\
\hline Mínimo; Máximo & $-1,10 ; 7,60$ & $-1,60 ; 4,80$ & $-2,80 ; 0,50$ & \\
\hline
\end{tabular}

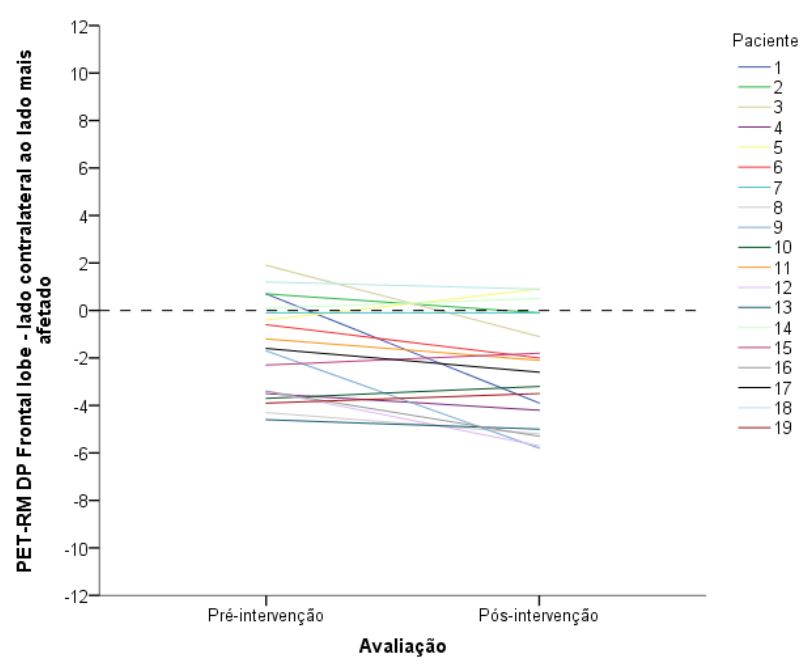

Figura 19. PET-RM Desvio Padrão Lobo frontal no lado contralateral ao lado mais afetado nas avaliações pré e pós-intervenção

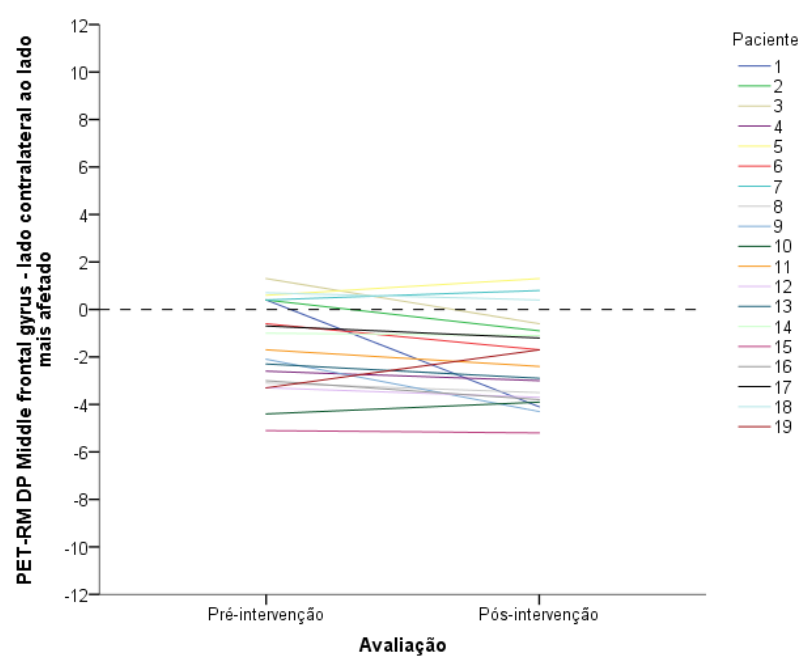

Figura 20. PET-RM Desvio Padrão Giro medial frontal no lado contralateral ao lado mais afetado nas avaliações pré e pós-intervenção 


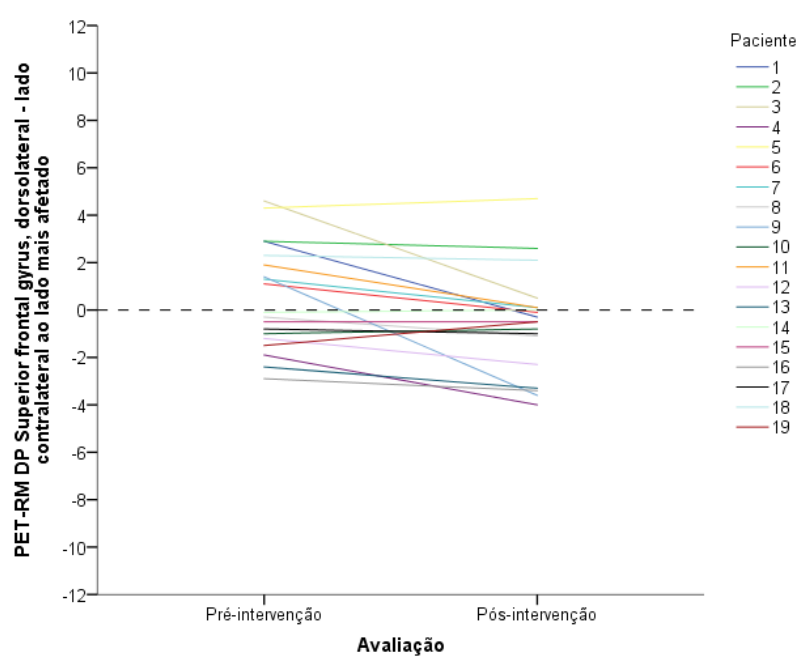

Figura 21. PET-RM Desvio Padrão Giro frontal superior, dorsolateral no lado contralateral ao lado mais afetado nas avaliações pré e pós-intervenção

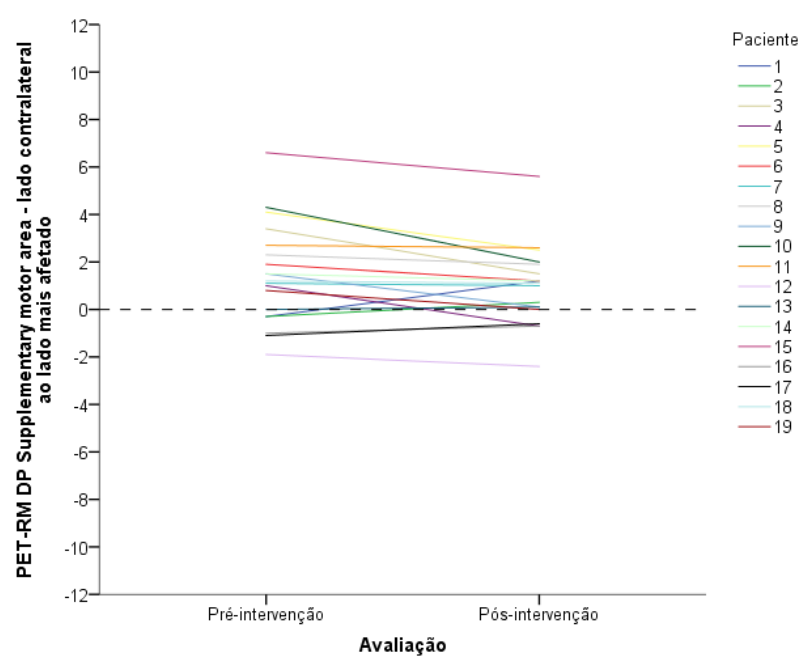

Figura 22. PET-RM Desvio Padrão Área motora suplementar no lado contralateral ao lado mais afetado nas avaliações pré e pós-intervenção 


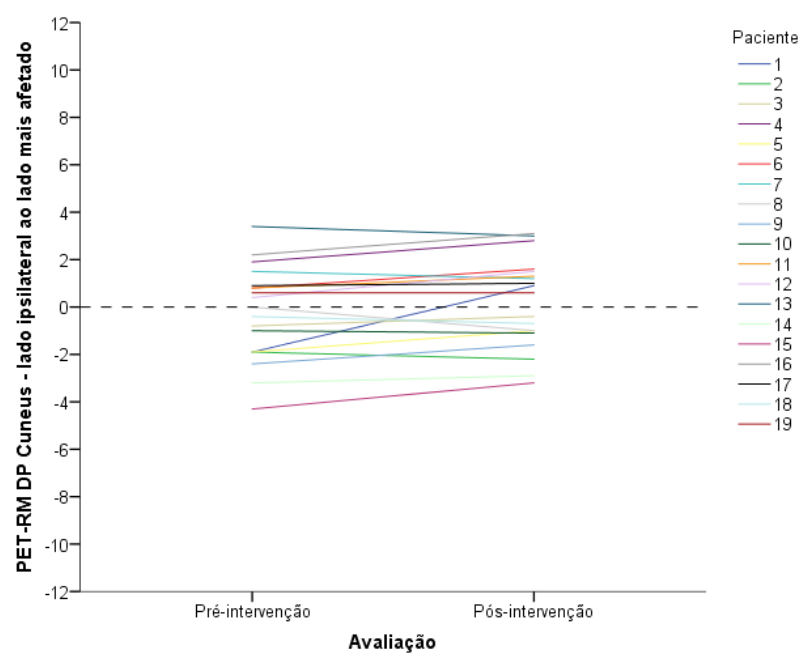

Figura 23. PET-RM Desvio Padrão Cuneus no lado ipsilateral ao lado mais afetado nas avaliações pré e pós-intervenção

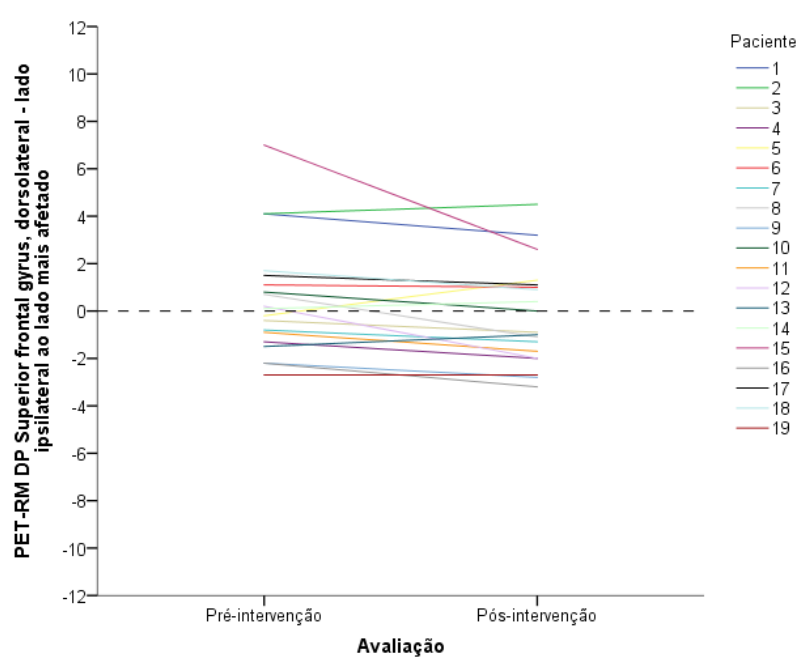

Figura 24. PET-RM Desvio Padrão Giro frontal superior, dorsolateral no lado ipsilateral ao lado mais afetado nas avaliações pré e pós-intervenção

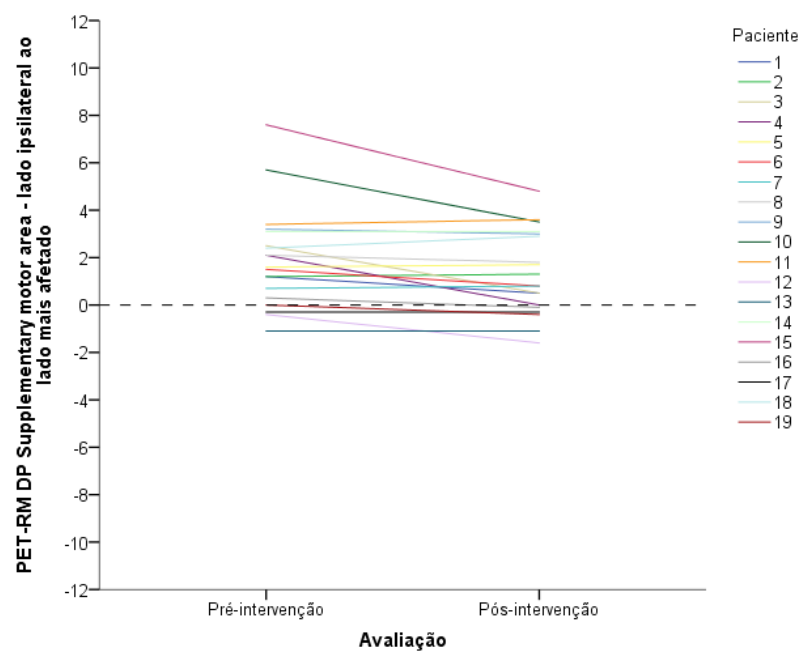

Figura 25. PET-RM Desvio Padrão Área motora suplementar no lado ipsilateral ao lado mais afetado nas avaliações pré e pós-intervenção 


\section{DISCUSSÃO}

Neste estudo, avaliamos um grupo de pacientes com DP submetidos a um protocolo de RV, correlacionando dados clínicos, de qualidade de vida e avaliação neuropsicológica com o metabolismo cerebral de glicose in vivo (PET-FDG). Em síntese, demonstramos uma melhora dos sintomas motores e qualidade de vida, além de identificarmos algumas alterações em testes neuropsicológicos. Além disto, do ponto de vista da neuroimagem funcional, encontramos evidências de alterações metabólicas em regiões corticais notadamente frontais, relacionadas com o controle e planejamento do movimento.

Do ponto de vista motor e da qualidade de vida, pacientes com doenças crônicas, como a DP, necessitam de exercícios desde o momento do diagnóstico, o que leva o paciente a necessitar de um caráter motivacional adicional em seu programa de exercícios. Por outro lado, o medo de cair e a lenta melhora desses pacientes podem ser barreiras importantes que levam à desmotivação e baixo rendimento. ${ }^{(68)}$

A RV estimula os pacientes a se encorajarem durante as terapias, gera um ambiente de competitividade, afetando positivamente a autoestima desses indivíduos, que acabam transferindo as atividades treinadas para as tarefas do dia-adia, o que impacta positivamente a qualidade de vida. ${ }^{(40)}$ Nosso estudo demonstrou essa melhora dos sintomas motores e qualidade de vida após o protocolo de intervenção, assim como nos achados dos estudos de Dockx et al. ${ }^{(69)}$ e Yang et al. ${ }^{(70)}$

Quando avaliamos a escala UPDRS notamos melhora funcional referente a escrita, corte de alimentos, manipulação de objetos e movimentos da mão. No que se refere à locomoção, notamos melhora no item deambulação, marcha, estabilidade postural, bradicinesia e diminuição de quedas. Em relação ao UPDRS III, por exemplo, esta melhora na avaliação do escore refere-se a aproximadamente 7 pontos de decremento na diferença entre as avaliações pré e pós (2 meses), o que pode significar um ganho real para estes pacientes, já que estudos mostram um diferença de cerca de 2 pontos de incremento ${ }^{(71)}$ durante $o$ ano no escore total da escala.

Os jogos de RV podem, do ponto de vista motor, estimular deslocamentos multidirecionais, transferência de peso, movimentos controlados 
próximos aos limites de estabilidade e desempenhadas, ${ }^{(41)}$ gerando assim melhora na movimentação motora desses indivíduos apresentados no estudo.

Em relação a escala PDQ-39, notamos melhora nos itens de mobilidade, atividade de vida diária, desconforto corporal, comunicação e estigma, e a escala SF-36 apresentou melhora em capacidade funcional, dor e saúde mental. Esses achados estão em linha com os benefícios encontrados por Dos Santos Mendes et al. ${ }^{(72)}$ que mostraram em seu estudo que pacientes com DP foram capazes de transferir uma habilidade motora treinada nos jogos para uma tarefa semelhante sem treinamento, melhorando assim sua qualidade de vida.

A DP é clinicamente assimétrica, ou seja, um lado do corpo é usualmente clinicamente mais afetado do que o outro. Assim, separamos nossa análise em lado clinicamente mais afetado e menos afetado, e não entre direito e esquerdo. Ao fazer essa análise comparando as mudanças apresentadas pós-intervenção em lado clinicamente mais afetado visualizamos diferença em relação aos movimentos da mão (Tabela 4), com melhora na movimentação do membro superior clinicamente mais afetado. Sabe-se que ambientes virtuais são simulações do mundo real, fornecendo informações multissensoriais complexas ao usuário em um contexto seguro, envolvente e motivador, podendo melhorar a mobilidade e atividade física de pessoas saudáveis ou com DP. ${ }^{(73)}$

Quando avaliamos o equilíbrio desses indivíduos através da escala de equilíbrio de Berg, observamos melhora no escore total, o que significa melhora do equilíbrio. De acordo com uma revisão sistemática sobre RV em pacientes com DP, ${ }^{(69)}$ o desempenho do equilíbrio neste grupo de pacientes é medido principalmente com medidas clínicas, como a escala de equilíbrio de Berg. Por sua vez, a RV poderia melhorar o equilíbrio destes pacientes através de 4 mecanismos: durante os exercícios em postura ortostática, durante os ajustes posturais reativos, ajustes posturais antecipatórios e durante o equilíbrio dinâmico. ${ }^{(74)}$ De acordo com nossos dados, o equilíbrio dos pacientes em nosso grupo melhorou 11,4\%. Estes dados também já foram observados por outros autores, como nos trabalhos de Silva-Batista et al. ${ }^{(75)} \mathrm{e}$ Yen et al. ${ }^{(76)}$

Cabe aqui ressaltar que o equilíbrio, assim como outros sintomas axiais na DP (freezing de marcha) costumam não responder ao tratamento medicamentoso clássico, sendo as terapias de reabilitação convencional ou virtual ferramentas importantes para minimizar estes sintomas. Além disto, é importante 
destacar o papel de estruturas extra-estriatais, como o cerebelo, no processo de aprendizagem supervisionada, enquanto os núcleos da base seriam importantes para o feedback interno. ${ }^{(77)}$ Finalmente, o cerebelo também parece ser um importante módulo neural para integrar informação sensorial de componentes visuais, vestibulares e somatossensoriais, ajudando no controle postural. ${ }^{(78)}$ Assim, pacientes com DP durante tarefas de RV podem aprender a integrar a informação visual e vestibular de forma mais eficiente através do cerebelo, o que poderia influenciar o tronco cerebral e a medula espinhal no controle postural. ${ }^{(76)}$

No que se refere a avaliação neuropsicológica pré e pósintervenção, encontramos melhora significativa em tarefas envolvendo linguagem, aprendizagem, memória e intensidade dos sintomas neuropsiquiátricos assim como encontrado nos estudos de dos Santos Mendes et al. ${ }^{(72)}$ e Silva et al. ${ }^{(79)}$

A RV fornece como benefícios um alto número de repetições, feedback auditivo e visual, atenção, planejamento, tomada de decisões, concentração sustentada, promoção de motivação e comprometimento nas tarefas. ${ }^{(41)}$ Exige também que o jogador efetue mudanças multidirecionais rápidas e centralizadas de seu centro de gravidade, associadas a demandas cognitivas, como tomada de decisão rápida, divisão de atenção, monitoramento do ambiente, seleção de estímulos visuais e inibição de respostas. A estimulação visual e auditiva intensa pode promover efeitos positivos no controle postural, na marcha e na cognição de indivíduos com distúrbios neurológicos. $^{(69)} \mathrm{O}$ jogo fornece feedback visual e auditivo aos jogadores, o que possibilita que eles conheçam o desempenho em tempo real e os resultados de cada tentativa, fatores que facilitam o aprendizado motor. ${ }^{(72)}$

Em relação aos aspectos cognitivos de pacientes com DP, pode-se acrescentar que os jogos com RV melhoram o planejamento, memória e atenção destes pacientes, em particular aqueles sem demência ${ }^{(80)}$ como observamos em nossos resultados.

Alguns estudos já demonstraram também este benefício sobre a cognição, como o trabalho de Silva et al. ${ }^{(41)}$ e Klinger et al. ${ }^{(81)}$ que mostraram em seus resultados um grande potencial da RV na avaliação e planejamento cognitivo na DP.

Alterações específicas de cada doença devido à disfunção sináptica e degeneração neuronal geram padrões típicos de alterações no metabolismo regional da glicose em pacientes com DP. ${ }^{(16)}$ 
Uma série de estudos estabeleceram associações entre disfunção cognitiva na DP e reduções regionais no metabolismo cortical da glicose, envolvendo principalmente regiões cerebrais posteriores como córtex parieto-occipital e temporal. ${ }^{(51,82,83)}$

Em estudos com diagnóstico de DP com 3 anos de duração dos sintomas, Teune et al. ${ }^{(84)}$ encontraram reduções metabólicas no polo occipital, córtex parietal e pré-frontal inferior, principalmente contralateral ao lado mais afetado dos indivíduos. Na DP mais avançada, Garcia-Garcia et al. ${ }^{(85)}$ mostraram que ocorrem reduções no metabolismo de glicose nas regiões frontal e temporal de pacientes com DP. Reduções no metabolismo de glicose nas regiões parieto-occipitais e temporais têm sido associadas a declínio cognitivo, ou progressão para demência. ${ }^{\left({ }^{(8)}\right.}$

Em nosso estudo, os resultados do PET-FDG revelaram, sobretudo, reduções do metabolismo de glicose em determinadas regiões corticais. Por exemplo, identificamos diminuição do metabolismo de glicose cerebral no lobo frontal, giro frontal superior e medial; e aumento do metabolismo em área motora suplementar ambos no lado contralateral ao hemicorpo clinicamente mais afetado quando comparados a sujeitos saudáveis pareados pela idade (banco de dados do Database Comparison, Siemens Medical Solutions). Identificamos, ainda, redução de metabolismo de glicose em giro frontal dorsolateral superior e área motora suplementar no lado ipsilateral ao lado clinicamente mais afetado.

Os giros frontais superior e médio respondem por diversas funções. A porção mais anterior desses giros é denominada de área pré-frontal, relacionada com funções como atenção, iniciativa e comportamento social. As porções mais posteriores desses giros estão envolvidas com o movimento somático (áreas motoras secundárias), que controlam movimentos posturais e elaboram a programação do movimento, antes que o mesmo ocorra. ${ }^{(86)}$

Uma vez conhecida como área motora suplementar, as áreas motoras frontais mediais incluem múltiplas regiões dedicadas ao controle do movimento, essas regiões se tornam ativas antes que ocorram movimentos. ${ }^{\left({ }^{(6)}\right.} \mathrm{O}$ início de ações voluntárias envolve um laço de gânglios basais que se origina e termina na área motora suplementar. A atividade nessa região e na alça motora voluntária é facilitada pela dopamina, que diminui o limiar para o início do movimento, isso ajuda a determinar se uma intenção de agir é traduzida em um movimento real. ${ }^{(87,88)} \mathrm{A}$ redução da atividade na área motora suplementar (devido à deficiência de dopamina no 
estriado) é responsável pela acinesia na DP. Isso foi explorado com a criação de óculos de RV que fornecem dicas visuais artificiais para pacientes parkinsonianos, levando a melhora na iniciação da marcha, no comprimento da passada e no ritmo, com menos quedas. ${ }^{(89)}$

Logo, os dados de imagem deste estudo sugerem uma possível atividade compensatória da RV sobre o metabolismo cerebral de glicose, talvez com diminuição do hipermetabolismo encontrado na condição patológica, e trazendo o funcionamento da atividade neuronal mais próximo da normalidade (semelhante aos controles do banco de dados), gerando uma menor sobrecarga desse metabolismo. Alterações compensatórias também podem estar relacionados ao aumento do metabolismo com objetivo de manter ativa a atividade naquela região.

Algumas limitações deste estudo não poderiam deixar de ser citadas. Uma delas foi a ausência de um grupo controle, fosse um grupo controle de portadores de DP que não fizessem o protocolo de $\mathrm{RV}$, mas sim reabilitação convencional, fosse um grupo de voluntários saudáveis. Eticamente, não conseguiríamos em nossa instituição submeter voluntários saudáveis a exames que envolvessem radiação, e a opção de não incluir um grupo que fizesse um protocolo de fisioterapia convencional foi uma decisão logística, uma vez que este trabalho tinha, em si, um objetivo de provar um conceito (proof of concept) de que a RV poderia impactar positivamente estes pacientes, através de modificações in vivo do metabolismo de glicose. Finalmente, o fato de o mesmo paciente ser o controle de si próprio seguido de avaliações cegas dos dados pode fornecer informações que permitem fazer as suposições discutidas acima. De qualquer forma, mais estudos são necessários para compreender melhor os efeitos in vivo no cérebro de pacientes com DP submetidos a protocolos de RV.

Em resumo, nosso estudo sugere que após a realização de um protocolo de RV, os voluntários com DP apresentaram benefícios motores, de qualidade de vida e cognitivos, seguido de alterações compensatórias no metabolismo cerebral. 


\section{CONCLUSÕES}

As conclusões são limitadas devido à ausência de um grupo controle. Em pacientes com DP um estudo proof of concept demostra:

1. A reabilitação virtual promove alterações compensatórias no metabolismo de glicose em indivíduos com doença de Parkinson.

2. A reabilitação virtual melhora sinais motores, qualidade de vida e alguns aspectos da função cognitiva de pacientes com doença de Parkinson. 


\section{REFERÊNCIAS}

1. Brasil. Ministério da Saúde. Pacientes com Parkinson contarão com novos medicamentos no SUS [Internet]. Brasília (DF): Ministério da Saúde; 2017 [citado 2018 Set 15]. Disponível em: http://portalms.saude.gov.br/noticias/agencia-saude/41873-pacientes-com-parkinson-contaraocom-novos-medicamentos-no-sus

2. Connolly BS, Lang AE. Pharmacological treatment of Parkinson disease: a review. JAMA. 2014;311(16):1670-83.

3. Miocinovic S, Somayajula S, Chitnis S, Vitek JL. History, applications, and mechanisms of deep brain stimulation. JAMA Neurol. 2013;70(2):163-71.

4. Salat D, Tolosa E. Levodopa in the treatment of Parkinson's disease: current status and new developments. J Parkinsons Dis. 2013;3(3):255-69.

5. Tintner R, Jankovic J. Treatment options for Parkinson's disease. Curr Opin Neurol. 2002;15(4):467-76.

6. Rascol O, Payoux P, Ory F, Ferreira JJ, Brefel-Courbon C, Montastruc JL. Limitations of current Parkinson's disease therapy. Ann Neurol. 2003;53 Suppl 3:S3-12.

7. Okuma Y, Yanagisawa N. The clinical spectrum of freezing of gait in Parkinson's disease. Mov Disord. 2008;23 Suppl 2:S426-30.

8. Capato TT, Domingos JM, Almeida LR. Versão em português da Diretriz Europeia de Fisioterapia para a Doença de Parkinson. São Paulo: Omnifarma; 2015.

9. Kim A, Darakjian N, Finley JM. Walking in fully immersive virtual environments: an evaluation of potential adverse effects in older adults and individuals with Parkinson's disease. J Neuroeng Rehabil. 2017;14(1):16.

10. Felicio AC, Shih MC, Godeiro-Junior C, Andrade LA, Bressan RA, Ferraz HB. Molecular imaging studies in Parkinson disease: reducing diagnostic uncertainty. Neurologist. 2009;15(1):6-16. Review.

11. Gerasimou GP, Aggelopoulou TC, Costa DC, Gotzamani-Psarrakou A. Molecular imaging (SPECT and PET) in the evaluation of patients with movement disorders. Nucl Med Rev Cent East Eur. 2006;9(2):147-53.

12. Gomperts SN. Lewy body dementias: dementia with lewy bodies and Parkinson disease dementia. Continuum (Minneap Minn). 2016;22(2 Dementia):435-63.

13. Singhal T, Alavi A, Kim CK. Brain: positron emission tomography tracers beyond $\left[{ }^{18} \mathrm{~F}\right]$ fluorodeoxyglucose. PET Clin. 2014;9(3):267-76.

14. Broski SM, Hunt CH, Johnson GB, Morreale RF, Lowe VJ, Peller PJ. Structural and functional imaging in parkinsonian syndromes. Radiographics. 2014;34(5):1273-92.

15. Ge J, Wu P, Zuo C. The metabolic brain network in patients with Parkinson's disease based on (18)F-FDG PET imaging: evaluation of neuronal injury and regeneration. Neural Regen Res. 2014;9(7):763-5. 
16. Teune LK, Renken RJ, de Jong BM, Willemsen AT, van Osch MJ, Roerdink JB, et al. Parkinson's disease-related perfusion and glucose metabolic brain patterns identified with PCASL-MRI and FDG-PET imaging. Neuroimage Clin. 2014;5:240-4.

17. Abdullah R, Basak I, Patil KS, Alves G, Larsen JP, Møller SG. Parkinson's disease and age: the obvious but largely unexplored link. Exp Gerontol. 2015;68:33-8. Review.

18. Gaig C, Tolosa E. When does Parkinson's disease begin? Mov Disord. 2009;24 Suppl 2:S656-64. Review.

19. Bovolenta TM, de Azevedo Silva SM, Saba RA, Borges V, Ferraz HB, Felicio AC. Average annual cost of Parkinson's disease in São Paulo, Brazil, with a focus on disease-related motor symptoms. Clin Interv Aging. 2017;12:2095-108.

20. Bovolenta TM, Felicio AC. How do demographic transitions and public health policies affect patients with Parkinson's disease in Brazil? Clin Interv Aging. 2017;12:197-205. Review.

21. Cohen H. Neurociência para fisioterapeutas: incluindo correlações clínicas. São Paulo: Manole; 2001.

22. Guyton AC, Hall JE. Tratado de fisiologia médica. 10 ed. Rio de Janeiro: Guanabara Koogan; 2002.

23. Wüllner U, Fuchs G, Reketat N, Randerath O, Kassubek J. Requirements for Parkinson's disease pharmacotherapy from the patients' perspective: a questionnaire-based survey. Curr Med Res Opin. 2012;28(7):1239-46.

24. Aerts MB, Esselink RA, Post B, van de Warrenburg BP, Bloem BR. Improving the diagnostic accuracy in parkinsonism: a three-pronged approach. Pract Neurol. 2012;12(2):77-87.

25. Crosiers D, Theuns J, Cras P, Van Broeckhoven C. Parkinson disease: insights in clinical, genetic and pathological features of monogenic disease subtypes. J Chem Neuroanat. 2011;42(2):131-41.

26. Fearnley JM, Lees AJ. Ageing and Parkinson's disease: substantia nigra regional selectivity. Brain. 1991;114(Pt 5):2283-301.

27. Jankovic J. Parkinson's disease: clinical features and diagnosis. J Neurol Neurosurg Psychiatry. 2008;79(4):368-76.

28. van der Eijk M, Nijhuis FA, Faber MJ, Bloem BR. Moving from physician-centered care towards patient-centered care for Parkinson's disease patients. Parkinsonism Relat Disord. 2013;19(11):923-7.

29. van Uem JM, Marinus J, Canning C, van Lummel R, Dodel R, Liepelt-Scarfone I, et al. Health-related quality of life in patients with Parkinson's disease--a systematic review based on the ICF model. Neurosci Biobehav Rev. 2016;61:26-34. Review.

30. van Uem JM, Cerff B, Kampmeyer M, Prinzen J, Zuidema M, Hobert MA, et al. The association between objectively measured physical activity, depression, cognition, and healthrelated quality of life in Parkinson's disease. Parkinsonism Relat Disord. 2018;48:74-81.

31. Leung $\mathrm{IH}$, Walton $\mathrm{CC}$, Hallock $\mathrm{H}$, Lewis SJ, Valenzuela M, Lampit A. Cognitive training in Parkinson disease: a systematic review and meta-analysis. Neurology. 2015;85(21):1843-51. 
32. Galvin JE. Cognitive change in Parkinson disease. Alzheimer Dis Assoc Disord. 2006;20(4):302-10.

33. Chekani F, Bali V, Aparasu RR. Quality of life of patients with Parkinson's disease and neurodegenerative dementia: a nationally representative study. Res Social Adm Pharm. 2016;12(4):604-13.

34. Cools R. Dopaminergic modulation of cognitive function-implications for L-DOPA treatment in Parkinson's disease. Neurosci Biobehav Rev. 2006;30(1):1-23.

35. Edelstyn NM, Shepherd TA, Mayes AR, Sherman SM, Ellis SJ. Effect of disease severity and dopaminergic medication on recollection and familiarity in patients with idiopathic nondementing Parkinson's. Neuropsychologia. 2010;48(5):1367-75.

36. Meyer PT, Frings L, Rücker G, Hellwig S. 18F-FDG PET in Parkinsonism: differential diagnosis and evaluation of cognitive impairment. J Nucl Med. 2017;58(12):1888-98.

37. Foerde K, Braun EK, Higgins ET, Shohamy D. Motivational modes and learning in Parkinson's disease. Soc Cogn Affect Neurosci. 2015;10(8):1066-73.

38. Riva G. Applications of virtual environments in medicine. Methods Inf Med. 2003;42(5):52434.

39. Robles-García V, Arias P, Sanmartín G, Espinosa N, Flores J, Grieve KL, et al. Motor facilitation during real-time movement imitation in Parkinson's disease: a virtual reality study. Parkinsonism Relat Disord. 2013;19(12):1123-9.

40. Pompeu JE, Arduini LA, Botelho AR, Fonseca MB, Pompeu SM, Torriani-Pasin C, et al. Feasibility, safety and outcomes of playing Kinect Adventures! ${ }^{\mathrm{TM}}$ for people with Parkinson's disease: a pilot study. Physiotherapy. 2014;100(2):162-8.

41. Silva KG, De Freitas TB, Doná F, Ganança FF, Ferraz HB, Torriani-Pasin C, et al. Effects of virtual rehabilitation versus conventional physical therapy on postural control, gait, and cognition of patients with Parkinson's disease: study protocol for a randomized controlled feasibility trial. Pilot Feasibility Stud. 2017;3:68.

42. Galna B, Barry G, Jackson D, Mhiripiri D, Olivier P, Rochester L. Accuracy of the Microsoft Kinect sensor for measuring movement in people with Parkinson's disease. Gait Posture. 2014;39(4):1062-8.

43. Pourmand A, Davis S, Lee D, Barber S, Sikka N. Emerging utility of virtual reality as a multidisciplinary tool in clinical medicine. Games Health J. 2017;6(5):263-70.

44. StoessI AJ, Mckeown MJ. Movement disorders. Handb Clin Neurol. 2016;136:957-69.

45. Berti V, Pupi A, Mosconi L. PET/CT in diagnosis of movement disorders. Ann N Y Acad Sci. 2011;1228:93-108.

46. Bohnen NI, Djang DS, Herholz K, Anzai Y, Minoshima S. Effectiveness and safety of $18 \mathrm{~F}$ FDG PET in the evaluation of dementia: a review of the recent literature. J Nucl Med. 2012;53(1):59-71.

47. Poston KL, Eidelberg D. FDG PET in the evaluation of Parkinson's disease. PET Clin. 2010;5(1):55-64. 
48. Vitor T, Martins KM, lonescu TM, Cunha ML, Baroni RH, Garcia MR, et al. PET/MRI: a novel hybrid imaging technique. Major clinical indications and preliminary experience in Brazil. Einstein (Sao Paulo). 2017;15(1):115-8.

49. Liu ZY, Liu FT, Zuo CT, Koprich JB, Wang J. Update on molecular imaging in Parkinson's disease. Neurosci Bull; 2018;34(2):330-40.

50. Meles SK, Teune LK, de Jong BM, Dierckx RA, Leenders KL. Metabolic imaging in Parkinson disease. J Nucl Med. 2017;58(1):23-8.

51. Bohnen NI, Koeppe RA, Minoshima S, Giordani B, Albin RL, Frey KA, et al. Cerebral glucose metabolic features of Parkinson disease and incident dementia: longitudinal study. J Nucl Med. 2011;52(6):848-55.

52. Hoehn MM, Yahr MD. Parkinsonism: onset, progression and mortality. Neurology. 1967;17(5):427-42.

53. Guo Y, Logan HL, Glueck DH, Muller KE. Selecting a sample size for studies with repeated measures. BMC Med Res Methodol. 2013;13(1):100.

54. Bohnen NI, Frey KA, Studenski S, Kotagal V, Koeppe RA, Constantine GM, et al. Extranigral pathological conditions are common in Parkinson's disease with freezing of gait: an in vivo positron emission tomography study. Mov Disord. 2014;29(9):1118-24.

55. Gibb WR, Lees AJ. The relevance of the Lewy body to the pathogenesis of idiopathic Parkinson's disease. J Neurol Neurosurg Psychiatry. 1988;51(6):745-52.

56. Movement Disorder Society Task Force on Rating Scales for Parkinson's Disease. The Unified Parkinson's Disease Rating Scale (UPDRS): status and recommendations. Mov Disord. 2003;18(7):738-50.

57. Carod-Artal FJ, Martinez-Martin P, Vargas AP. Independent validation of SCOPApsychosocial and metric properties of the PDQ-39 Brazilian version. Mov Disord. 2007;22(1):91-8.

58. Jenkinson C, Peto V, Fitzpatrick R, Greenhall R, Hyman N. Self-reported functioning and well-being in patients with Parkinson's disease: comparison of the short-form health survey (SF36) and the Parkinson's Disease Questionnaire (PDQ-39). Age Ageing. 1995;24(6):505-9.

59. Gorenstein C, Andrade L. Validation of a Portuguese version of the Beck Depression Inventory and the State-Trait Anxiety Inventory in Brazilian subjects. Braz J Med Biol Res. 1996;29(4):453-7.

60. Berg KO, Wood-Dauphinee SL, Williams JI, Maki B. Measuring balance in the elderly: validation of an instrument. Can J Public Health. 1992;83 Suppl 2:S7-11.

61. Nasreddine ZS, Phillips NA, Bédirian V, Charbonneau S, Whitehead V, Collin I, et al. The Montreal Cognitive Assessment, MoCA: a brief screening tool for mild cognitive impairment. J Am Geriatr Soc. 2005;53(4):695-9.

62. Wechsler D. WAIS-III. Escala de inteligência Wechsler para adultos: manual. São Paulo: Casa do Psicólogo; 2004.

63. Kaplan E, Goodglass H, Weintraub S. The Boston Naming Test. Philadelphia: Lippincott Williams \& Wilkins; 2001. 
64. Spreen O, Strauss E. A compendium of neuropsychological tests: administration, norms, and commentary. New York: Oxford University Press; 1998.

65. Rey A. L'examen clinique en psychologie. Paris: Presse Universitaire de France; 1958.

66. Schmidt M. Rey auditory and verbal learnig test: a handbook. Los Angeles: Western Psychological Services; 1996.

67. Warrington EK. The visual object and spacial perception battery. Bury St Edmunds: Thames Valley Test Company; 1991.

68. Ellis T, Boudreau JK, DeAngelis TR, Brown LE, Cavanaugh JT, Earhart GM, et al. Barriers to exercise in people with Parkinson disease. Phys Ther. 2013;93(5):628-36.

69. Dockx K, Bekkers EM, Van den Bergh V, Ginis P, Rochester L, Hausdorff JM, et al. Virtual reality for rehabilitation in Parkinson's disease. Cochrane Database Syst Rev. 2016;12:CD010760.

70. Yang WC, Wang HK, Wu RM, Lo CS, Lin KH. Home-based virtual reality balance training and conventional balance training in Parkinson's disease: A randomized controlled trial. $\mathrm{J}$ Formos Med Assoc. 2016;115(9):734-43.

71. Evans JR, Mason SL, Williams-Gray CH, Foltynie T, Brayne C, Robbins TW, et al. The natural history of treated Parkinson's disease in an incident, community based cohort. J Neurol Neurosurg Psychiatry. 2011;82(10):1112-8.

72. dos Santos Mendes FA, Pompeu JE, Modenesi Lobo A, Guedes da Silva K, Oliveira TP, Peterson Zomignani A, et al. Motor learning, retention and transfer after virtual-reality-based training in Parkinson's disease-effect of motor and cognitive demands of games: a longitudinal, controlled clinical study. Physiotherapy. 2012;98(3):217-23.

73. Gallagher R, Damodaran H, Werner WG, Powell W, Deutsch JE. Auditory and visual cueing modulate cycling speed of older adults and persons with Parkinson's disease in a Virtual Cycling (V-Cycle) system. J Neuroeng Rehabil. 2016;13(1):77.

74. Schoneburg B, Mancini M, Horak F, Nutt JG. Framework for understanding balance dysfunction in Parkinson's disease. Mov Disord. 2013;28(11):1474-82.

75. Silva-Batista C, Corcos DM, Kanegusuku H, Piemonte ME, Gobbi LT, de Lima-Pardini AC, et al. Balance and fear of falling in subjects with Parkinson's disease is improved after exercises with motor complexity. Gait Posture. 2018;61:90-7.

76. Yen $\mathrm{CY}$, Lin $\mathrm{KH}$, Hu MH, Wu RM, Lu TW, Lin CH. Effects of virtual reality-augmented balance training on sensory organization and attentional demand for postural control in people with Parkinson disease: a randomized controlled trial. Phys Ther. 2011;91(6):862-74.

77. loffe ME, Ustinova KI, Chernikova LA, Kulikov MA. Supervised learning of postural tasks in patients with poststroke hemiparesis, Parkinson's disease or cerebellar ataxia. Exp Brain Res. 2006;168(3):384-94.

78. loffe ME, Chernikova LA, Ustinova KI. Role of cerebellum in learning postural tasks. Cerebellum. 2007;6(1):87-94. 
79. Silva KG, De Freitas TB, Doná F, Ganança FF, Ferraz HB, et al. Effects of virtual rehabilitation versus conventional physical therapy on postural control, gait, and cognition of patients with Parkinson's disease: study protocol for a randomized controlled feasibility trial. Pilot Feasibility Stud. 2017;3:68.

80. Bang YS, Son $\mathrm{KH}$, Kim HJ. Effects of virtual reality training using Nintendo Wii and treadmill walking exercise on balance and walking for stroke patients. J Phys Ther Sci. 2016;28(11):3112-5.

81. Klinger E, Chemin I, Lebreton S, Marié RM. Virtual action planning in Parkinson's disease: a control study. Cyberpsychol Behav. 2006;9(3):342-7.

82. González-Redondo R, García-García D, Clavero P, Gasca-Salas C, García-Eulate R, Zubieta JL, et al. Grey matter hypometabolism and atrophy in Parkinson's disease with cognitive impairment: a two-step process. Brain. 2014;137(Pt 8):2356-67.

83. Firbank MJ, Yarnall AJ, Lawson RA, Duncan GW, Khoo TK, Petrides GS, et al. Cerebral glucose metabolism and cognition in newly diagnosed Parkinson's disease: ICICLE-PD study. J Neurol Neurosurg Psychiatry. 2017;88(4):310-6.

84. Teune LK, Bartels AL, de Jong BM, Willemsen AT, Eshuis SA, de Vries JJ, et al. Typical cerebral metabolic patterns in neurodegenerative brain diseases. Mov Disord.

2010;25(14):2395-404.

85. Garcia-Garcia D, Clavero P, Gasca Salas C, Lamet I, Arbizu J, Gonzalez-Redondo R, et al. Posterior parietooccipital hypometabolism may differentiate mild cognitive impairment from dementia in Parkinson's disease. Eur J Nucl Med Mol Imaging. 2012;39(11):1767-77.

86. Shumway-Cook A, Woollacott MH. Controle motor: teorias e aplicações práticas. 3a ed. São Paulo: Manole; 2010.

87. Kim SJ, Paeng SH, Kang SY. Stimulation in supplementary motor area versus motor cortex for freezing of gait in Parkinson's disease. J Clin Neurol. 2018;14(3):320-6.

88. Nachev P, Kennard C, Husain M. Functional role of the supplementary and presupplementary motor areas. Nat Rev Neurosci. 2008;9(11):856-69.

89. Johns P. Parkinson's disease. In: Johns P. Clinical neuroscience: an illustrated colour text. London: Churchill Livingstone; 2014. p.163-79. 


\section{Abstract}

Introduction: Parkinson's disease is the second most common neurodegenerative disease. In countries such as Brazil, its prevalence is expected to increase with population aging. Standard therapy for Parkinson's disease consists of medications that increase dopamine (levodopa) associated with conventional physical therapy. Virtual reality, however, can offer a more dynamic and interactive rehabilitation environment than conventional physiotherapy. In addition, virtual rehabilitation has the possibility of promoting motor learning (feedback) and providing sensorial cues for treatment of patients with Parkinson's disease. Studies have reported that virtual reality improves motor symptoms of Parkinson's disease, including symptoms resistant to levodopa therapy such as balance, and cognitive functions as attention, memory and planning. However, so far, little information exists about in vivo brain mechanisms that promote these benefits. Purpose: We evaluated effects of a virtual reality protocol on motor symptoms, quality of life and cognition of patients with Parkinson's disease, and correlated these data with cerebral metabolism of glucose through $18 \mathrm{~F}$ fluorodeoxyglucose positron emission tomography. Methods: A total of 20 patients with Parkinson's disease were selected. Patients had no dementia, depression diagnosis, and/or decompensated clinical manifestations. Participants underwent a virtual reality protocol using the $\mathrm{Xbox} 360 \mathrm{~S}^{\circledR}$ console and Kinect ${ }^{\circledR}$ sensor with the Kinect ${ }^{\circledR}$ Adventures games for 8 weeks of supervised training, 2 times a week. Motor and non-motor outcomes were assessed before and after the intervention, using the following scales: Unified Parkinson's disease rating scale part III, Berg balance scale, Parkinson's disease questionnaire, Short-Form Health Status Survey, and neuropsychological assessment structured. The brain images were acquired using a Positron Emission Tomography -18F-fluorodeoxyglucose (PET-FDG) and quantified in in striate and extrastriate areas. Results: We observed after evaluating the periods before and after the virtual reality protocol, statistically significant changes with improvement in motor signs, balance, quality of life and in some cognitive functions: vocabulary test $(p=0.047)$, auditory-verbal learning test of Rey / $(p=0.049)$, Boston naming test $(p=0.014)$, and reduction in symptom severity score $(p=0.0120$ and total score $(p=0.043)$ of the Neuropsychiatric Inventory test). Changes in cerebral metabolism of glucose were seen in frontal regions: frontal lobe regions $(p=0.014)$, medial frontal gyrus $(p=0.031)$, 
dorsolateral superior frontal gyrus $(p=0.004)$, and supplemental motor area $(p=0.031)$ contralateral to the most clinically affected-hemibody. In relation to ipsilateral regions to the most affected-hemobody, we observed changes in cuneus $(p=0.036)$, dorsolateral superior frontal gyrus $(p=0.010)$ and supplementary motor area $(p=0.012)$. Conclusions: Virtual reality improved motor signs, some cognitive functions and quality of life of patients with Parkinson's disease. In parallel, there was possible compensatory activity in the cerebral metabolism of glucose. 


\section{Apêndices}

Apêndice 1. Resultados avaliação neuropsicológica

Tabela 1. Escores nas tarefas do Teste das Trilhas parte $A$ e $B$ dos participantes do estudo ( $n=17$ na parte $A$ e $n=15$ na parte $B$ ) nas avaliações pré e pós-intervenção

\begin{tabular}{|c|c|c|c|c|}
\hline \multirow{2}{*}{ Escores } & \multicolumn{2}{|c|}{ Momento de avaliação } & \multirow{2}{*}{$\begin{array}{l}\text { Variação } \\
\text { (pós - pré) }\end{array}$} & \multirow{2}{*}{ Valor-p } \\
\hline & Pré-intervenção & Pós-intervenção & & \\
\hline \multicolumn{5}{|l|}{ Teste das Trilhas } \\
\hline Parte A & & & & 0,486 \\
\hline Mediana (Q1; Q3) & $90(61 ; 191)$ & $86(63 ; 140)$ & $0(-16 ; 23)$ & \\
\hline Mínimo; Máximo & $44 ; 300$ & $38 ; 300$ & $-126 ; 50$ & \\
\hline Parte B & & & & 0,791 \\
\hline Mediana (Q1; Q3) & $215(138 ; 300)$ & $210(146 ; 300)$ & $0(-37 ; 43)$ & \\
\hline Mínimo; Máximo & $66 ; 300$ & $53 ; 300$ & $-124 ; 104$ & \\
\hline
\end{tabular}

Tabela 2. Escores nas tarefas do Teste de Interferência de Stroop dos participantes do estudo $(n=16)$ nas avaliações pré e pós-intervenção

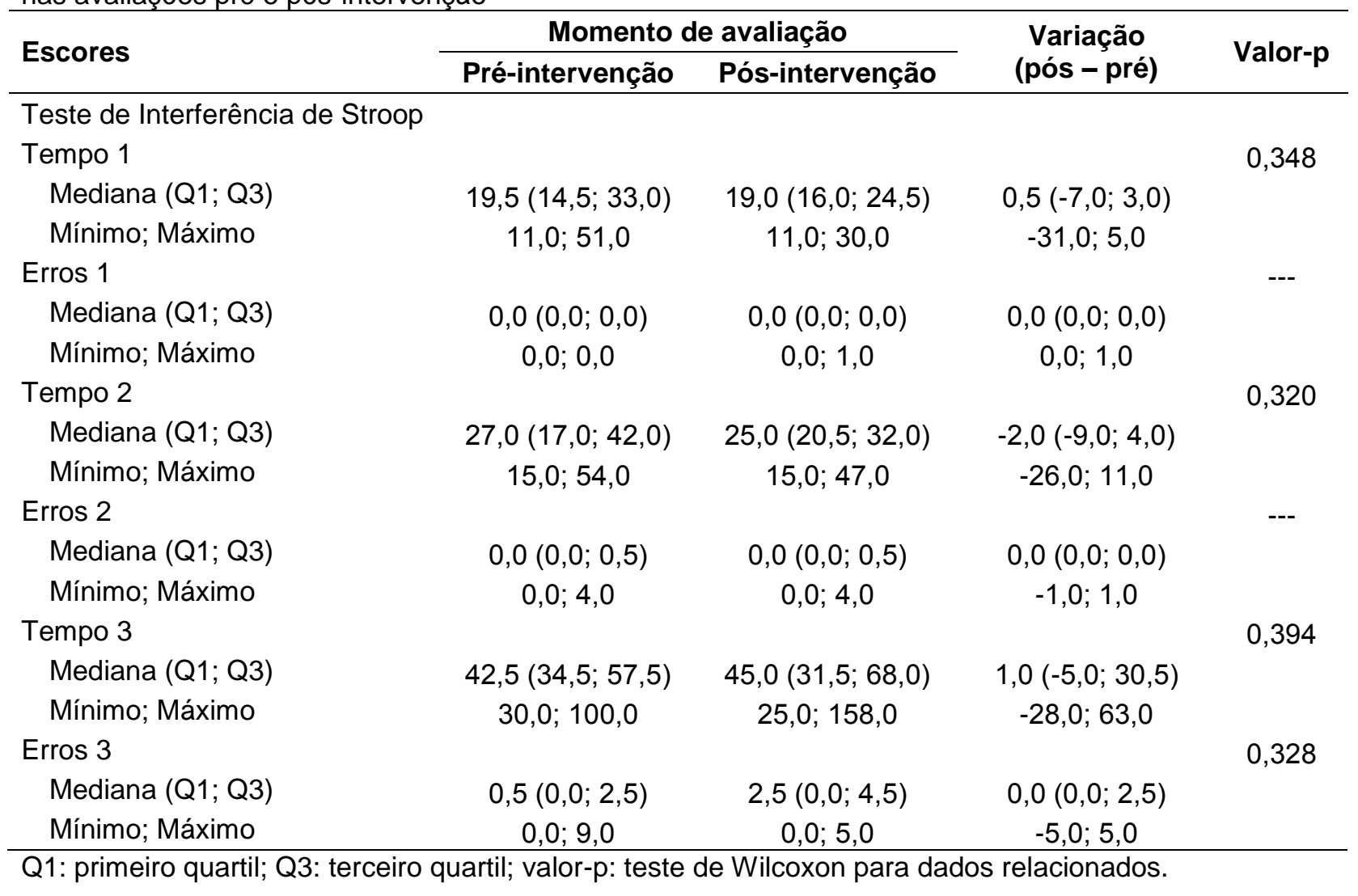


Tabela 3. Escores nas tarefas do Teste de Fluência Verbal dos participantes do estudo $(n=17)$ nas avaliações pré e pós-intervenção

\begin{tabular}{|c|c|c|c|c|}
\hline \multirow{2}{*}{ Escores } & \multicolumn{2}{|c|}{ Momento de avaliação } & \multirow{2}{*}{$\begin{array}{c}\text { Variação } \\
\text { (pós - pré) }\end{array}$} & \multirow{2}{*}{ Valor-p } \\
\hline & Pré-intervenção & Pós-intervenção & & \\
\hline \multicolumn{5}{|l|}{ Teste de Fluência Verbal } \\
\hline Letra F & & & & $>0,999$ \\
\hline Mediana (Q1; Q3) & $11(8 ; 14)$ & $11(8 ; 15)$ & $0(-2 ; 1)$ & \\
\hline Mínimo; Máximo & $4 ; 20$ & $4 ; 18$ & $-6 ; 8$ & \\
\hline Letra A & & & & 0,603 \\
\hline Mediana (Q1; Q3) & $9(5 ; 13)$ & $8(5 ; 12)$ & $0(-3 ; 1)$ & \\
\hline Mínimo; Máximo & $4 ; 15$ & $1 ; 18$ & $-10 ; 10$ & \\
\hline Letra S & & & & 0,862 \\
\hline Mediana (Q1; Q3) & $10(7 ; 13)$ & $9(6 ; 12)$ & $-1(-2 ; 2)$ & \\
\hline Mínimo; Máximo & $0 ; 15$ & $3 ; 16$ & $-4 ; 4$ & \\
\hline Total & & & & 0,701 \\
\hline Mediana (Q1; Q3) & $32(22 ; 40)$ & $30(19 ; 38)$ & $-1(-5 ; 1)$ & \\
\hline Mínimo; Máximo & $9 ; 46$ & $11 ; 50$ & $-16 ; 16$ & \\
\hline Semântica & & & & 0,963 \\
\hline Mediana (Q1; Q3) & $11(10 ; 15)$ & $12(9 ; 15)$ & $0(-3 ; 1)$ & \\
\hline Mínimo; Máximo & $2 ; 21$ & $5 ; 20$ & $-10 ; 12$ & \\
\hline
\end{tabular}


Tabela 4. Medidas do exame de neuroimagem funcional através do PET-RM com FDG SUV no lado contralateral ao lado mais afetado dos participantes do estudo $(n=19)$ nas avaliações pré e pósintervenção

\begin{tabular}{|c|c|c|c|c|}
\hline \multirow{2}{*}{$\begin{array}{l}\text { Exame PET-RM com FDG } \\
\text { SUV no Lado Contralateral }\end{array}$} & \multicolumn{2}{|c|}{ Momento de avaliação } & \multirow{2}{*}{$\begin{array}{l}\text { Variação } \\
\text { (pós-pré) }\end{array}$} & \multirow{2}{*}{ Valor-p } \\
\hline & Pré-intervenção & Pós-intervenção & & \\
\hline Angular gyrus & & & & 0,764 \\
\hline Mediana (Q1; Q3) & $5,40(4,41 ; 6,52)$ & $5,40(4,36 ; 8,09)$ & $0,29(-0,57 ; 0,83)$ & \\
\hline Mínimo; Máximo & 2,$49 ; 11,02$ & 3,$11 ; 9,52$ & $-2,49 ; 1,66$ & \\
\hline Anterior cingulate and & & & & 0,797 \\
\hline paracingulate gyri & & & & 0,191 \\
\hline Mediana (Q1; Q3) & $5,41(3,98 ; 6,14)$ & $5,21(4,15 ; 6,59)$ & $0,14(-0,44 ; 0,90)$ & \\
\hline Mínimo; Máximo & 2,$56 ; 8,81$ & 3,$72 ; 7,03$ & $-1,96 ; 1,80$ & \\
\hline Basal ganglia & & & & 0,392 \\
\hline Mediana (Q1; Q3) & $6,12(4,69 ; 7,66)$ & $6,02(5,17 ; 8,22)$ & $0,07(-0,36 ; 1,32)$ & \\
\hline Mínimo; Máximo & 3,$10 ; 11,78$ & 4,$33 ; 9,66$ & $-2,12 ; 1,99$ & \\
\hline Caudate nucleus & & & & 0,806 \\
\hline Mediana (Q1; Q3) & $5,43(3,99 ; 6,37)$ & $5,10(4,39 ; 6,63)$ & $0,03(-0,32 ; 0,69)$ & \\
\hline Mínimo; Máximo & 2,$55 ; 11,50$ & 3,$03 ; 9,40$ & $-2,10 ; 1,72$ & \\
\hline Central region & & & & 0,443 \\
\hline Mediana (Q1; Q3) & $5,68(4,96 ; 6,87)$ & $5,58(5,01 ; 7,62)$ & $0,38(-0,69 ; 1,09)$ & \\
\hline Mínimo; Máximo & 2,$87 ; 10,06$ & 4,$08 ; 8,59$ & $-2,00 ; 1,78$ & \\
\hline Cerebellum & & & & 0,473 \\
\hline Mediana (Q1; Q3) & $4,54(3,74 ; 6,05)$ & $4,45(3,84 ; 6,35)$ & $0,36(-0,27 ; 0,91)$ & \\
\hline Mínimo; Máximo & 2,$57 ; 8,20$ & 2,$97 ; 7,40$ & $-2,03 ; 1,72$ & \\
\hline $\begin{array}{l}\text { Cingulate and paracingulate } \\
\text { gyri }\end{array}$ & & & & 0,641 \\
\hline Mediana (Q1; Q3) & $5,74(4,78 ; 7,10)$ & $5,87(4,88 ; 7,69)$ & $0,35(-0,46 ; 1,21)$ & \\
\hline Mínimo; Máximo & 2,$88 ; 11,27$ & 4,$25 ; 8,88$ & $-2,39 ; 1,93$ & \\
\hline Cuneus & & & & 0,301 \\
\hline Mediana (Q1; Q3) & $5,79(4,83 ; 7,83)$ & $5,92(4,93 ; 8,71)$ & $0,51(-0,63 ; 1,16)$ & \\
\hline Mínimo; Máximo & 2,$97 ; 10,98$ & 3,$83 ; 9,89$ & $-2,27 ; 2,20$ & \\
\hline Frontal lobe & & & & 0,671 \\
\hline Mediana (Q1; Q3) & $5,74(4,89 ; 6,77)$ & $5,58(4,80 ; 7,52)$ & $0,21(-0,50 ; 1,04)$ & \\
\hline Mínimo; Máximo & 2,$81 ; 10,66$ & 3,$65 ; 8,50$ & $-2,33 ; 1,81$ & \\
\hline Hippocampus & & & & 0,739 \\
\hline Mediana (Q1; Q3) & $4,34(3,65 ; 5,41)$ & $4,04(3,71 ; 5,61)$ & $0,19(-0,37 ; 0,72)$ & \\
\hline Mínimo; Máximo & 2,$33 ; 7,56$ & 2,$88 ; 6,30$ & $-1,52 ; 1,45$ & \\
\hline $\begin{array}{l}\text { Inferior frontal gyrus, opercular } \\
\text { part }\end{array}$ & & & & 0,575 \\
\hline Mediana (Q1; Q3) & $5,69(4,74 ; 7,10)$ & $5,71(4,91 ; 7,59)$ & $0,31(-0,43 ; 1,18)$ & \\
\hline Mínimo; Máximo & 2,$58 ; 11,37$ & 3,$64 ; 8,84$ & $-2,53 ; 1,80$ & \\
\hline Inferior frontal gyrus & & & & 0,442 \\
\hline Mediana (Q1; Q3) & $5,11(3,95 ; 6,86)$ & $5,57(4,55 ; 7,66)$ & $0,25(-0,26 ; 1,18)$ & \\
\hline Mínimo; Máximo & 2,$84 ; 10,37$ & 3,$58 ; 8,75$ & $-2,66 ; 1,85$ & \\
\hline $\begin{array}{l}\text { Inferior frontal gyrus, triangular } \\
\text { part }\end{array}$ & & & & 0,510 \\
\hline Mediana (Q1; Q3) & $5,29(4,52 ; 6,72)$ & $5,50(4,64 ; 7,34)$ & $0,26(-0,33 ; 1,25)$ & \\
\hline Mínimo; Máximo & 2,$74 ; 10,86$ & 3,$64 ; 8,48$ & $-2,57 ; 1,84$ & \\
\hline Inferior occipital gyrus & & & & 0,340 \\
\hline Mediana (Q1; Q3) & $4,89(4,65 ; 6,62)$ & $5,22(4,15 ; 7,23)$ & $0,55(-0,54 ; 1,11)$ & \\
\hline Mínimo; Máximo & 2,$52 ; 10,03$ & 3,$13 ; 8,23$ & $-1,84 ; 1,79$ & \\
\hline Inferior parietal, but & & & & \\
\hline supramarginal and angular & & & & 0,650 \\
\hline gyri & & & & \\
\hline Mediana (Q1; Q3) & $5,28(4,34 ; 6,79)$ & $5,28(4,54 ; 7,16)$ & $0,41(-0,67 ; 0,96)$ & \\
\hline
\end{tabular}


...continuação

\begin{tabular}{|c|c|c|c|c|}
\hline Mínimo; Máximo & 2,$54 ; 11,63$ & 2,$95 ; 9,06$ & $-2,57 ; 1,85$ & \\
\hline Inferior temporal gyrus & & & & 0,490 \\
\hline Mediana (Q1; Q3) & $5,46(4,10 ; 6,50)$ & $4,96(4,39 ; 7,09)$ & $0,28(-0,50 ; 1,15)$ & \\
\hline Mínimo; Máximo & 2,$50 ; 10,49$ & 3,$21 ; 9,21$ & $-2,07 ; 1,72$ & \\
\hline Insula & & & & 0,404 \\
\hline Mediana (Q1; Q3) & $5,64(4,65 ; 7,06)$ & $5,66(4,70 ; 7,45)$ & $0,37(-0,22 ; 1,05)$ & \\
\hline Mínimo; Máximo & 2,$81 ; 9,86$ & 4,$00 ; 8,66$ & $-1,82 ; 1,89$ & \\
\hline Lenticular nucleus, pallidum & & & & 0,312 \\
\hline Mediana (Q1; Q3) & $4,78(3,81 ; 5,64)$ & $4,74(4,03 ; 6,13)$ & $0,39(-0,17 ; 0,73)$ & \\
\hline Mínimo; Máximo & 2,$46 ; 7,66$ & 3,$62 ; 7,14$ & $-1,53 ; 1,66$ & \\
\hline Lenticular nucleus, putamen & & & & 0,217 \\
\hline Mediana (Q1; Q3) & $7,33(5,60 ; 8,74)$ & $7,09(6,15 ; 10,07)$ & $0,28(-0,49 ; 1,78)$ & \\
\hline Mínimo; Máximo & 3,$59 ; 13,13$ & 5,$38 ; 12,00$ & $-2,38 ; 2,44$ & \\
\hline Mesial temporal lobe & & & & 0,613 \\
\hline Mediana (Q1; Q3) & $4,41(3,63 ; 5,59)$ & $4,25(3,76 ; 5,80)$ & $0,15(-0,40 ; 0,72)$ & \\
\hline Mínimo; Máximo & 2,$29 ; 7,68$ & 3,$14 ; 6,72$ & $-1,41 ; 1,47$ & \\
\hline $\begin{array}{l}\text { Middle cingulate and } \\
\text { paracingulate gyri }\end{array}$ & & & & 0,602 \\
\hline Mediana (Q1; Q3) & $6,22(5,31 ; 7,57)$ & $6,37(5,14 ; 8,26)$ & $0,46(-0,60 ; 1,32)$ & \\
\hline Mínimo; Máximo & 3,$05 ; 12,51$ & 4,$56 ; 9,94$ & $-2,57 ; 1,99$ & \\
\hline Middle frontal gyrus & & & & 0,761 \\
\hline Mediana (Q1; Q3) & $6,24(5,11 ; 7,35)$ & $5,82(5,14 ; 7,92)$ & $0,16(-0,55 ; 1,09)$ & \\
\hline Mínimo; Máximo & 2,$80 ; 11,54$ & 3,$78 ; 9,03$ & $-2,51 ; 1,82$ & \\
\hline $\begin{array}{l}\text { Middle frontal gyrus, orbital } \\
\text { part }\end{array}$ & & & & 0,536 \\
\hline Mediana (Q1; Q3) & $5,95(4,55 ; 7,19)$ & $5,96(4,92 ; 6,98)$ & $0,26(-0,50 ; 1,11)$ & \\
\hline Mínimo; Máximo & 2,$86 ; 10,46$ & 3,$48 ; 8,80$ & $-2,25 ; 2,06$ & \\
\hline Middle occipital gyrus & & & & 0,505 \\
\hline Mediana (Q1; Q3) & $5,23(4,55 ; 6,41)$ & $4,94(4,17 ; 7,02)$ & $0,38(-0,53 ; 0,96)$ & \\
\hline Mínimo; Máximo & 2,$50 ; 10,09$ & 3,$03 ; 8,38$ & $-1,97 ; 1,80$ & \\
\hline Middle temporal gyrus & & & & 0,560 \\
\hline Mediana (Q1; Q3) & $5,45(4,53 ; 6,76)$ & $5,39(4,59 ; 7,42)$ & $0,31(-0,54 ; 0,97)$ & \\
\hline Mínimo; Máximo & 2,$72 ; 11,19$ & 3,$26 ; 9,59$ & $-2,35 ; 1,79$ & \\
\hline Occipital lobe & & & & 0,360 \\
\hline Mediana (Q1; Q3) & $5,55(4,77 ; 7,12)$ & $5,28(4,63 ; 7,80)$ & $0,51(-0,56 ; 1,18)$ & \\
\hline Mínimo; Máximo & 2,$80 ; 10,29$ & 3,$62 ; 8,97$ & $-1,99 ; 1,85$ & \\
\hline Paracentral lobule & & & & 0,432 \\
\hline Mediana (Q1; Q3) & $5,41(5,08 ; 7,80)$ & $5,60(5,06 ; 7,86)$ & $0,47(-1,04 ; 0,88)$ & \\
\hline Mínimo; Máximo & 3,$14 ; 8,93$ & 3,$86 ; 8,87$ & $-1,87 ; 2,08$ & \\
\hline Parahippocampal gyrus & & & & 0,528 \\
\hline Mediana (Q1; Q3) & $4,55(3,60 ; 5,79)$ & $4,47(3,78 ; 5,96)$ & $0,18(-0,43 ; 0,88)$ & \\
\hline Mínimo; Máximo & 2,$26 ; 7,93$ & 3,$25 ; 7,47$ & $-1,42 ; 1,46$ & \\
\hline Parietal lobe & & & & 0,461 \\
\hline Mediana (Q1; Q3) & $5,30(4,51 ; 6,70)$ & $5,31(4,71 ; 7,46)$ & $0,41(-0,61 ; 1,10)$ & \\
\hline Mínimo; Máximo & 2,$76 ; 10,74$ & 3,$17 ; 8,97$ & $-2,28 ; 1,91$ & \\
\hline Postcentral gyrus & & & & 0,482 \\
\hline Mediana (Q1; Q3) & $5,31(4,58 ; 6,65)$ & $5,37(4,65 ; 7,14)$ & $0,43(-0,68 ; 1,11)$ & \\
\hline Mínimo; Máximo & 2,$88 ; 9,76$ & 3,$99 ; 8,29$ & $-2,01 ; 1,80$ & \\
\hline $\begin{array}{l}\text { Posterior cingulate and } \\
\text { paracinqulate qyri }\end{array}$ & & & & 0,473 \\
\hline Mediana (Q1; Q3) & $5,23(4,43 ; 7,87)$ & $5,50(4,82 ; 8,22)$ & $0,43(-0,35 ; 1,60)$ & \\
\hline Mínimo; Máximo & 3,$16 ; 12,72$ & 3,$58 ; 9,49$ & $-3,42 ; 2,03$ & \\
\hline Precentral gyrus & & & & 0,466 \\
\hline Mediana (Q1; Q3) & $5,73(5,16 ; 6,90)$ & $5,58(5,02 ; 7,61)$ & $0,50(-0,71 ; 1,19)$ & \\
\hline Mínimo; Máximo & 2,$84 ; 10,09$ & 4,$05 ; 8,60$ & $-2,09 ; 1,73$ & \\
\hline Precuneus & & & & 0,387 \\
\hline Mediana (Q1; Q3) & $5,61(5,02 ; 7,43)$ & $5,98(5,33 ; 8,49)$ & $0,41(-0,63 ; 1,23)$ & \\
\hline Mínimo; Máximo & 3,$11 ; 12,21$ & 3,$43 ; 9,92$ & $-2,61 ; 2,17$ & \\
\hline
\end{tabular}


...continuação

\begin{tabular}{|c|c|c|c|c|}
\hline $\begin{array}{l}\text { Superior frontal gyrus, } \\
\text { dorsolateral }\end{array}$ & & & & 0,912 \\
\hline Mediana (Q1; Q3) & $5,80(4,86 ; 6,51)$ & $5,26(4,65 ; 6,93)$ & $0,02(-0,63 ; 0,65)$ & \\
\hline Mínimo; Máximo & 2,$69 ; 9,95$ & 3,$38 ; 7,87$ & $-2,13 ; 1,73$ & \\
\hline Superior frontal gyrus, medial & & & & 0,754 \\
\hline Mediana (Q1; Q3) & $5,95(4,63 ; 6,41)$ & $5,38(4,37 ; 7,41)$ & $0,23(-0,67 ; 1,08)$ & \\
\hline Mínimo; Máximo & 2,$59 ; 10,56$ & 3,$65 ; 8,28$ & $-2,28 ; 1,73$ & \\
\hline $\begin{array}{l}\text { Superior frontal gyrus, medial } \\
\text { orbital }\end{array}$ & & & & 0,727 \\
\hline Mediana (Q1; Q3) & $5,59(4,49 ; 7,32)$ & $5,95(4,58 ; 7,51)$ & $0,07(-0,33 ; 0,83)$ & \\
\hline Mínimo; Máximo & 2,$73 ; 10,91$ & 3,$60 ; 9,89$ & $-2,42 ; 2,07$ & \\
\hline $\begin{array}{l}\text { Superior frontal gyrus, orbital } \\
\text { part }\end{array}$ & & & & 0,698 \\
\hline Mediana (Q1; Q3) & $5,58(4,44 ; 6,42)$ & $5,65(4,64 ; 7,09)$ & $0,17(-0,28 ; 0,95)$ & \\
\hline Mínimo; Máximo & 2,$78 ; 11,20$ & 3,$50 ; 8,52$ & $-2,71 ; 1,98$ & \\
\hline SUV Superior occipital gyrus & & & & 0,355 \\
\hline Mediana (Q1; Q3) & $5,31(4,28 ; 6,51)$ & $5,11(4,47 ; 7,31)$ & $0,58(-0,45 ; 0,90)$ & \\
\hline Mínimo; Máximo & 2,$66 ; 9,41$ & 3,$33 ; 8,41$ & $-1,93 ; 1,81$ & \\
\hline Superior parietal gyrus & & & & 0,344 \\
\hline Mediana (Q1; Q3) & $4,65(3,94 ; 5,60)$ & $4,53(3,92 ; 6,23)$ & $0,40(-0,36 ; 0,86)$ & \\
\hline Mínimo; Máximo & 2,$47 ; 8,07$ & 2,$97 ; 7,25$ & $-1,68 ; 1,69$ & \\
\hline Superior temporal gyrus & & & & 0,331 \\
\hline Mediana (Q1; Q3) & $5,58(5,01 ; 7,19)$ & $5,97(5,08 ; 7,71)$ & $0,43(-0,52 ; 1,09)$ & \\
\hline Mínimo; Máximo & 3,$07 ; 10,59$ & 3,$75 ; 9,24$ & $-1,86 ; 2,04$ & \\
\hline Supplementary motor area & & & & 0,645 \\
\hline Mediana (Q1; Q3) & $6,22(5,09 ; 6,93)$ & $5,75(5,17 ; 7,88)$ & $0,24(-0,80 ; 0,83)$ & \\
\hline Mínimo; Máximo & 3,$33 ; 10,21$ & 3,$93 ; 8,65$ & $-2,32 ; 1,74$ & \\
\hline Supramarginal gyrus & & & & 0,529 \\
\hline Mediana (Q1; Q3) & $5,57(4,58 ; 6,67)$ & $5,53(4,67 ; 7,41)$ & $0,40(-0,58 ; 1,08)$ & \\
\hline Mínimo; Máximo & 2,$75 ; 10,48$ & 3,$19 ; 8,85$ & $-2,07 ; 1,90$ & \\
\hline Temporal lobe & & & & 0,471 \\
\hline Mediana (Q1; Q3) & $5,43(4,59 ; 6,77)$ & $5,48(4,69 ; 7,37)$ & $0,34(-0,57 ; 1,09)$ & \\
\hline Mínimo; Máximo & 2,$74 ; 10,84$ & 3,$42 ; 9,37$ & $-2,12 ; 1,83$ & \\
\hline Thalamus & & & & 0,632 \\
\hline Mediana (Q1; Q3) & $6,18(5,25 ; 7,62)$ & $6,39(5,38 ; 8,46)$ & $0,21(-0,51 ; 0,97)$ & \\
\hline Mínimo; Máximo & 3,$19 ; 11,79$ & 4,$35 ; 9,45$ & $-3,33 ; 2,10$ & \\
\hline
\end{tabular}

Q1: primeiro quartil; Q3: terceiro quartil; valor-p: teste t-pareado.

Tabela 5. Medidas do exame de neuroimagem funcional através do PET-RM com FDG SUV no lado ipsilateral ao lado mais afetado dos participantes do estudo $(n=19)$ nas avaliações pré e pós-intervenção

\begin{tabular}{|c|c|c|c|c|}
\hline \multirow{2}{*}{$\begin{array}{l}\text { Exame PET-RM com FDG SUV } \\
\text { no Lado Ipsilateral }\end{array}$} & \multicolumn{2}{|c|}{ Momento de avaliação } & \multirow{2}{*}{$\begin{array}{l}\text { Variação } \\
\text { (pós - pré) }\end{array}$} & \multirow{2}{*}{ Valor-p } \\
\hline & Pré-intervenção & Pós-intervenção & & \\
\hline Angular gyrus & & & & 0,491 \\
\hline Mediana (Q1; Q3) & $5,14(4,16 ; 6,79)$ & $5,14(4,09 ; 7,19)$ & $0,10(-0,38 ; 1,26)$ & \\
\hline Mínimo; Máximo & 2,$43 ; 10,90$ & 3,$08 ; 9,47$ & $-2,52 ; 1,78$ & \\
\hline $\begin{array}{l}\text { Anterior cingulate and } \\
\text { paracingulate gyri }\end{array}$ & & & & 0,775 \\
\hline Mediana (Q1; Q3) & $5,12(3,86 ; 6,28)$ & $5,23(4,23 ; 6,62)$ & $0,28(-0,71 ; 0,88)$ & \\
\hline Mínimo; Máximo & 2,$69 ; 9,78$ & 3,$70 ; 7,79$ & $-1,99 ; 1,67$ & \\
\hline Basal ganglia & & & & 0,428 \\
\hline Mediana (Q1; Q3) & $6,29(5,07 ; 7,44)$ & $6,03(5,31 ; 8,33)$ & $0,03(-0,40 ; 1,46)$ & \\
\hline Mínimo; Máximo & 2,$96 ; 12,32$ & 4,$27 ; 10,22$ & $-2,46 ; 1,99$ & \\
\hline Caudate nucleus & & & & 0,756 \\
\hline Mediana (Q1; Q3) & $5,80(4,46 ; 6,56)$ & $5,46(4,26 ; 7,41)$ & $0,00(-0,46 ; 1,21)$ & \\
\hline Mínimo; Máximo & 2,$20 ; 11,89$ & 2,$65 ; 9,45$ & $-2,44 ; 1,64$ & \\
\hline Central region & & & & 0,345 \\
\hline Mediana (Q1; Q3) & $5,30(4,72 ; 6,92)$ & $5,33(5,03 ; 7,51)$ & $0,33(-0,50 ; 1,00)$ & \\
\hline
\end{tabular}


...continuação

\begin{tabular}{|c|c|c|c|c|}
\hline Mínimo; Máximo & 3,$19 ; 9,79$ & 4,$06 ; 8,46$ & $-1,90 ; 1,87$ & \\
\hline Cerebellum & & & & 0,508 \\
\hline Mediana (Q1; Q3) & $4,49(3,76 ; 5,56)$ & $4,54(3,98 ; 6,34)$ & $0,40(-0,24 ; 0,89)$ & \\
\hline Mínimo; Máximo & 2,$40 ; 8,40$ & 3,$13 ; 7,58$ & $-2,05 ; 1,58$ & \\
\hline Cingulate and paracingulate gyri & & & & 0,546 \\
\hline Mediana (Q1; Q3) & $5,43(4,69 ; 7,26)$ & $5,76(4,96 ; 7,49)$ & $0,40(-0,34 ; 1,16)$ & \\
\hline Mínimo; Máximo & 3,$05 ; 11,18$ & 4,$30 ; 8,96$ & $-2,22 ; 2,00$ & \\
\hline Cuneus & & & & 0,237 \\
\hline Mediana (Q1; Q3) & $5,53(4,88 ; 8,07)$ & $6,04(4,98 ; 9,20)$ & $0,41(-0,39 ; 1,44)$ & \\
\hline Mínimo; Máximo & 3,$03 ; 11,56$ & 3,$81 ; 10,31$ & $-2,36 ; 2,30$ & \\
\hline Frontal lobe & & & & 0,533 \\
\hline Mediana (Q1; Q3) & $5,48(4,63 ; 6,81)$ & $5,50(4,82 ; 7,49)$ & $0,37(-0,41 ; 1,05)$ & \\
\hline Mínimo; Máximo & 2,$94 ; 10,52$ & 3,$73 ; 8,48$ & $-2,23 ; 1,88$ & \\
\hline Hippocampus & & & & 0,553 \\
\hline Mediana (Q1; Q3) & $4,01(3,52 ; 5,28)$ & $3,98(3,58 ; 5,74)$ & $0,13(-0,38 ; 0,74)$ & \\
\hline Mínimo; Máximo & 2,$29 ; 7,37$ & 2,$89 ; 6,68$ & $-1,60 ; 1,54$ & \\
\hline $\begin{array}{l}\text { Inferior frontal gyrus, opercular } \\
\text { part }\end{array}$ & & & & 0,460 \\
\hline Mediana (Q1; Q3) & $5,34(4,47 ; 6,81)$ & $5,65(4,79 ; 7,40)$ & $0,30(-0,35 ; 1,20)$ & \\
\hline Mínimo; Máximo & 2,$88 ; 11,00$ & 3,$68 ; 8,67$ & $-2,33 ; 1,91$ & \\
\hline Inferior frontal gyrus & & & & 0,455 \\
\hline Mediana (Q1; Q3) & $5,14(4,07 ; 6,86)$ & $5,41(4,55 ; 7,65)$ & $0,37(-0,40 ; 1,05)$ & \\
\hline Mínimo; Máximo & 2,$58 ; 10,60$ & 3,$79 ; 8,44$ & $-2,38 ; 1,97$ & \\
\hline Inferior frontal gyrus, triangular part & & & & 0,456 \\
\hline Mediana (Q1; Q3) & $5,37(4,58 ; 6,85)$ & $5,57(4,68 ; 7,66)$ & $0,35(-0,51 ; 1,22)$ & \\
\hline Mínimo; Máximo & 2,$72 ; 11,08$ & 3,$86 ; 8,63$ & $-2,47 ; 1,83$ & \\
\hline Inferior occipital gyrus & & & & 0,436 \\
\hline Mediana (Q1; Q3) & $5,45(4,06 ; 6,71)$ & $5,15(4,37 ; 7,18)$ & $0,32(-0,50 ; 1,26)$ & \\
\hline Mínimo; Máximo & 2,$31 ; 9,69$ & 3,$26 ; 9,05$ & $-1,84 ; 1,71$ & \\
\hline Inferior parietal, but & & & & 0,458 \\
\hline supramarginal and angular gyri & & & & \\
\hline Mediana (Q1; Q3) & $5,46(4,59 ; 6,87)$ & $5,21(4,71 ; 7,73)$ & $0,34(-0,48 ; 1,08)$ & \\
\hline Mínimo; Máximo & 2,$80 ; 11,39$ & 3,$29 ; 9,26$ & $-2,26 ; 2,07$ & \\
\hline Inferior temporal gyrus & & & & 0,351 \\
\hline Mediana (Q1; Q3) & $5,30(3,99 ; 6,81)$ & $4,84(4,38 ; 7,49)$ & $0,40(-0,61 ; 1,15)$ & \\
\hline Mínimo; Máximo & 2,$63 ; 10,26$ & 3,$34 ; 8,97$ & $-2,16 ; 1,88$ & \\
\hline Insula & & & & 0,392 \\
\hline Mediana (Q1; Q3) & $5,70(4,65 ; 7,05)$ & $5,74(4,76 ; 7,63)$ & $0,46(-0,41 ; 1,12)$ & \\
\hline Mínimo; Máximo & 2,$81 ; 9,85$ & 3,$96 ; 8,52$ & $-1,77 ; 1,94$ & \\
\hline Lenticular nucleus, pallidum & & & & 0,449 \\
\hline Mediana (Q1; Q3) & $4,81(3,78 ; 5,45)$ & $4,75(4,08 ; 5,92)$ & $0,41(-0,18 ; 0,65)$ & \\
\hline Mínimo; Máximo & 2,$33 ; 8,17$ & 3,$44 ; 7,33$ & $-2,09 ; 1,68$ & \\
\hline Lenticular nucleus, putamen & & & & 0,264 \\
\hline Mediana (Q1; Q3) & $7,26(6,04 ; 8,61)$ & $7,14(6,21 ; 9,82)$ & $0,36(-0,47 ; 1,81)$ & \\
\hline Mínimo; Máximo & 3,$45 ; 13,95$ & 5,$57 ; 12,58$ & $-2,61 ; 2,39$ & \\
\hline Mesial temporal lobe & & & & 0,356 \\
\hline Mediana (Q1; Q3) & $4,15(3,40 ; 5,42)$ & $4,17(3,58 ; 5,87)$ & $0,18(-0,33 ; 0,85)$ & \\
\hline Mínimo; Máximo & 2,$36 ; 7,38$ & 3,$19 ; 6,83$ & $-1,38 ; 1,62$ & \\
\hline $\begin{array}{l}\text { Middle cingulate and } \\
\text { paracinqulate gyri }\end{array}$ & & & & 0,472 \\
\hline Mediana (Q1; Q3) & $5,93(5,20 ; 7,77)$ & $6,04(5,36 ; 8,28)$ & $0,39(-0,46 ; 1,31)$ & \\
\hline Mínimo; Máximo & 3,$34 ; 11,73$ & 4,$46 ; 9,48$ & $-2,25 ; 2,26$ & \\
\hline Middle frontal gyrus & & & & 0,462 \\
\hline Mediana (Q1; Q3) & $5,76(4,81 ; 7,03)$ & $5,57(4,91 ; 7,77)$ & $0,31(-0,47 ; 1,26)$ & \\
\hline Mínimo; Máximo & 3,$03 ; 10,87$ & 3,$65 ; 8,72$ & $-2,29 ; 2,01$ & \\
\hline Middle frontal gyrus, orbital part & & & & 0,482 \\
\hline Mediana (Q1; Q3) & $5,73(4,69 ; 6,94)$ & $5,62(4,90 ; 7,35)$ & $0,31(-0,33 ; 1,05)$ & \\
\hline Mínimo; Máximo & 2,$69 ; 11,21$ & 3,$59 ; 9,28$ & $-2,39 ; 2,21$ & \\
\hline
\end{tabular}


...continuação

\begin{tabular}{|c|c|c|c|c|}
\hline \multicolumn{4}{|l|}{ Middle occipital gyrus } & \multirow[t]{3}{*}{0,309} \\
\hline Mediana (Q1; Q3) & $5,02(4,16 ; 6,87)$ & $4,91(4,51 ; 7,06)$ & $0,37(-0,30 ; 0,82)$ & \\
\hline Mínimo; Máximo & 2,$65 ; 9,73$ & 3,$17 ; 8,89$ & $-1,80 ; 1,81$ & \\
\hline Middle temporal gyrus & & & & 0,371 \\
\hline Mediana (Q1; Q3) & $5,35(4,33 ; 7,18)$ & $5,47(4,59 ; 7,55)$ & $0,40(-0,65 ; 1,11)$ & \\
\hline Mínimo; Máximo & 2,$79 ; 10,45$ & 3,$54 ; 9,18$ & $-2,05 ; 1,90$ & \\
\hline Occipital lobe & & & & 0,304 \\
\hline Mediana (Q1; Q3) & $5,54(4,56 ; 7,21)$ & $5,39(4,77 ; 7,93)$ & $0,38(-0,54 ; 1,28)$ & \\
\hline Mínimo; Máximo & 2,$87 ; 10,38$ & 3,$58 ; 9,08$ & $-2,02 ; 1,88$ & \\
\hline Parahippocampal gyrus & & & & 0,246 \\
\hline Mediana (Q1; Q3) & $4,41(3,48 ; 5,58)$ & $4,32(3,62 ; 6,02)$ & $0,32(-0,23 ; 0,97)$ & \\
\hline Mínimo; Máximo & 2,$38 ; 7,51$ & 3,$38 ; 6,99$ & $-1,49 ; 1,65$ & \\
\hline Parietal lobe & & & & 0,383 \\
\hline Mediana (Q1; Q3) & $5,37(4,57 ; 6,79)$ & $5,35(4,64 ; 7,54)$ & $0,46(-0,45 ; 1,14)$ & \\
\hline Mínimo; Máximo & 2,$78 ; 10,89$ & 3,$44 ; 8,97$ & $-2,15 ; 1,86$ & \\
\hline Postcentral gyrus & & & & 0,304 \\
\hline Mediana (Q1; Q3) & $5,22(4,47 ; 6,82)$ & $5,11(4,89 ; 7,41)$ & $0,26(-0,44 ; 1,12)$ & \\
\hline Mínimo; Máximo & 3,$12 ; 9,68$ & 4,$00 ; 8,42$ & $-1,85 ; 1,85$ & \\
\hline Posterior cingulate and & & & & 0,414 \\
\hline $\begin{array}{l}\text { paracingulate gyri } \\
\text { Mediana (Q1: Q3) }\end{array}$ & & & & \\
\hline $\begin{array}{l}\text { Mediana (Q1; Q3) } \\
\text { Mínimo; Máximo }\end{array}$ & $\begin{array}{c}5,70(4,59 ; 7,28) \\
2.51 ; 13,11\end{array}$ & $\begin{array}{c}5,62(4,72 ; 7,27) \\
362 \cdot 1073\end{array}$ & $\begin{array}{c}0,47(-0,33 ; 1,19) \\
-280.191\end{array}$ & \\
\hline Precentral gyrus & & & $-2,0$ & 0,408 \\
\hline Mediana (Q1; Q3) & $5,64(4,97 ; 6,76)$ & $5,39(5,11 ; 7,61)$ & $0,32(-0,57 ; 0,84)$ & \\
\hline Mínimo; Máximo & 3,$32 ; 9,68$ & 3,$98 ; 8,57$ & $-1,92 ; 1,97$ & \\
\hline Precuneus & & & & 0,323 \\
\hline Mediana (Q1; Q3) & $5,82(5,04 ; 7,50)$ & $6,05(5,22 ; 8,45)$ & $0,45(-0,59 ; 1,39)$ & \\
\hline Mínimo; Máximo & 3,$14 ; 11,99$ & 3,$81 ; 9,95$ & $-2,35 ; 2,08$ & \\
\hline Superior frontal gyrus, dorsolateral & & & & 0,652 \\
\hline Mediana (Q1; Q3) & $5,42(4,47 ; 6,61)$ & $5,19(4,48 ; 7,26)$ & $0,30(-0,35 ; 0,88)$ & \\
\hline Mínimo; Máximo & 2,$86 ; 10,61$ & 3,$36 ; 8,31$ & $-2,30 ; 1,71$ & \\
\hline Superior frontal gyrus, medial & & & & 0,556 \\
\hline Mediana (Q1; Q3) & $5,50(4,41 ; 6,76)$ & $5,40(4,55 ; 7,32)$ & $0,30(-0,37 ; 0,91)$ & \\
\hline Mínimo; Máximo & 2,$76 ; 9,57$ & 3,$61 ; 7,94$ & $-2,04 ; 1,66$ & \\
\hline Superior frontal gyrus, medial orbital & & & & 0,659 \\
\hline Mediana (Q1; Q3) & $5,70(4,34 ; 7,39)$ & $5,81(4,70 ; 7,31)$ & $0,09(-0,17 ; 0,75)$ & \\
\hline Mínimo; Máximo & 2,$93 ; 9,91$ & 3,$79 ; 9,39$ & $-2,33 ; 1,81$ & \\
\hline Superior frontal gyrus, orbital part & & & & 0,661 \\
\hline Mediana (Q1; Q3) & $5,60(4,46 ; 6,72)$ & $5,48(4,61 ; 7,34)$ & $0,05(-0,28 ; 1,25)$ & \\
\hline Mínimo; Máximo & 2,$98 ; 10,72$ & 3,$54 ; 9,32$ & $-2,40 ; 2,06$ & \\
\hline SUV Superior occipital gyrus & & & & 0,227 \\
\hline Mediana (Q1; Q3) & $5,29(4,26 ; 7,24)$ & $5,33(4,45 ; 7,33)$ & $0,45(-0,32 ; 0,86)$ & \\
\hline Mínimo; Máximo & 2,$64 ; 9,64$ & 3,$67 ; 9,36$ & $-1,91 ; 2,11$ & \\
\hline Superior parietal gyrus & & & & 0,386 \\
\hline Mediana (Q1; Q3) & $4,81(3,94 ; 5,57)$ & $4,70(3,97 ; 6,25)$ & $0,34(-0,28 ; 0,80)$ & \\
\hline Mínimo; Máximo & 2,$35 ; 8,87$ & 3,$08 ; 7,44$ & $-1,79 ; 1,56$ & \\
\hline Superior temporal gyrus & & & & 0,382 \\
\hline Mediana (Q1; Q3) & $5,52(4,76 ; 7,40)$ & $6,03(4,98 ; 7,75)$ & $0,53(-0,70 ; 0,94)$ & \\
\hline Mínimo; Máximo & 2,$98 ; 11,23$ & 4,$17 ; 9,29$ & $-1,94 ; 2,00$ & \\
\hline Supplementary motor area & & & & 0,643 \\
\hline Mediana (Q1; Q3) & $5,86(5,07 ; 7,09)$ & $5,87(5,42 ; 7,68)$ & $0,39(-0,58 ; 0,65)$ & \\
\hline Mínimo; Máximo & 3,$65 ; 10,52$ & 4,$26 ; 8,81$ & $-2,20 ; 1,86$ & \\
\hline Supramarginal gyrus & & & & 0,330 \\
\hline Mediana (Q1; Q3) & $5,15(4,46 ; 6,86)$ & $5,38(4,71 ; 7,76)$ & $0,35(-0,47 ; 1,12)$ & \\
\hline Mínimo; Máximo & 2,$85 ; 10,16$ & 3,$41 ; 8,71$ & $-2,01 ; 2,00$ & \\
\hline Temporal lobe & & & & 0,357 \\
\hline Mediana (Q1; Q3) & $5,39(4,29 ; 7,11)$ & $5,34(4,72 ; 7,71)$ & $0,43(-0,66 ; 1,11)$ & \\
\hline Mínimo; Máximo & 2,$81 ; 10,60$ & 3,$68 ; 9,09$ & $-2,05 ; 1,92$ & \\
\hline
\end{tabular}


...continuação

\begin{tabular}{lccc}
\hline \multicolumn{2}{l}{ Temporal pole: middle temporal gyrus } & & 0,245 \\
$\quad$ Mediana (Q1; Q3) & $4,33(3,36 ; 5,23)$ & $4,11(3,63 ; 5,76)$ & $0,28(-0,21 ; 0,78)$ \\
$\quad$ Mínimo; Máximo & 2,$25 ; 7,22$ & 3,$04 ; 6,82$ & $-1,24 ; 1,50$ \\
Temporal pole: superior temporal & & & \\
gyrus & & & 0,613 \\
$\quad$ Mediana (Q1; Q3) & $4,08(3,42 ; 4,90)$ & $4,01(3,46 ; 5,26)$ & $-0,01(-0,29 ; 0,48)$ \\
$\quad$ Mínimo; Máximo & 2,$17 ; 7,31$ & 2,$75 ; 6,06$ & $-1,28 ; 1,44$ \\
Thalamus & & & \\
$\quad$ Mediana (Q1; Q3) & $6,41(5,50 ; 7,60)$ & $6,25(5,57 ; 8,23)$ & $0,07(-0,57 ; 1,47)$ \\
$\quad$ Mínimo; Máximo & 3,$11 ; 11,55$ & 4,$27 ; 10,06$ & $-3,04 ; 2,01$ \\
\hline Q1: primeiro quartil; Q3: terceiro quartil; valor-p: teste t-pareado.
\end{tabular}

Q1: primeiro quartil; Q3: terceiro quartil; valor-p: teste t-pareado. 


\section{Apêndice 3. Resultados PET-FDG - Desvio padrão}

Tabela 6. Medidas de Desvio-Padrão do exame de neuroimagem funcional através do PET-RM com FDG no lado contralateral ao lado mais afetado dos participantes do estudo $(n=19)$ nas avaliações pré e pós-intervenção

\begin{tabular}{|c|c|c|c|c|}
\hline \multirow{2}{*}{$\begin{array}{l}\text { Exame PET-RM com FDG no } \\
\text { Lado Contralateral }\end{array}$} & \multicolumn{2}{|c|}{ Momento de avaliação } & \multirow{2}{*}{$\begin{array}{l}\text { Variação } \\
\text { (pós-pré) }\end{array}$} & \multirow{2}{*}{ Valor-p } \\
\hline & Pré-intervenção & Pós-intervenção & & \\
\hline Angular gyrus & & & & 0,198 \\
\hline Mediana (Q1; Q3) & $-2,00(-3,80 ;-1,30)$ & $-2,80(-4,30 ;-1,00)$ & $-0,30(-0,60 ; 0,20)$ & \\
\hline Mínimo; Máximo & $-8,60 ; 0,60$ & $-7,90 ; 0,60$ & $-4,40 ; 1,40$ & \\
\hline Anterior cingulate and & & & & 0,088 \\
\hline $\begin{array}{l}\text { paracingulate gyri } \\
\text { Mediana (Q1; Q3) }\end{array}$ & $-0,40(-1,30 ; 0,40)$ & $-0,70(-1,80 ; 0,30)$ & $-0,30(-0,60 ; 0,00)$ & \\
\hline Mínimo; Máximo & $-2,80 ; 2,10$ & $-3,00 ; 1,80$ & $-2,90 ; 0,90$ & \\
\hline Basal ganglia & & & & 0,277 \\
\hline Mediana (Q1; Q3) & $0,00(-0,50 ; 1,80)$ & $0,20(-0,50 ; 1,70)$ & $0,00(-0,20 ; 0,60)$ & \\
\hline Mínimo; Máximo & $-2,20 ; 2,00$ & $-3,60 ; 2,60$ & $-2,60 ; 1,20$ & \\
\hline Caudate nucleus & & & & 0,648 \\
\hline Mediana (Q1; Q3) & $-0,50(-1,00 ; 0,10)$ & $-0,50(-1,10 ;-0,10)$ & $0,00(-0,20 ; 0,20)$ & \\
\hline Mínimo; Máximo & $-3,70 ; 1,00$ & $-5,10 ; 1,30$ & $-2,80 ; 0,60$ & \\
\hline Central region & & & & 0,663 \\
\hline Mediana (Q1; Q3) & $0,90(-0,10 ; 2,40)$ & $0,70(-1,00 ; 2,20)$ & $-0,20(-0,90 ; 0,70)$ & \\
\hline Mínimo; Máximo & $-2,20 ; 4,80$ & $-2,20 ; 8,00$ & $-3,50 ; 4,40$ & \\
\hline Cerebellum & & & & 0,924 \\
\hline Mediana (Q1; Q3) & $-0,90(-1,40 ;-0,50)$ & $-1,20(-2,40 ;-0,20)$ & $0,00(-0,90 ; 0,40)$ & \\
\hline Mínimo; Máximo & $-3,40 ; 0,00$ & $-3,40 ; 0,50$ & $-1,90 ; 1,20$ & \\
\hline Cingulate and paracingulate gyr & & & & 0,432 \\
\hline Mediana (Q1; Q3) & $-0,30(-0,80 ; 0,60)$ & $-0,70(-1,00 ; 0,20)$ & $-0,20(-0,40 ; 0,50)$ & \\
\hline Mínimo; Máximo & $-2,90 ; 1,80$ & $-3,80 ; 2,10$ & $-3,60 ; 1,00$ & \\
\hline Cuneus & & & & 0,155 \\
\hline Mediana (Q1; Q3) & $-0,80(-2,60 ; 0,40)$ & $-0,40(-2,10 ; 0,50)$ & $0,20(-0,20 ; 0,80)$ & \\
\hline Mínimo; Máximo & $-3,10 ; 2,50$ & $-3,00 ; 3,10$ & $-2,00 ; 2,60$ & \\
\hline Frontal lobe & & & & 0,014 \\
\hline Mediana (Q1; Q3) & $-1,60(-3,50 ; 0,10)$ & $-2,60(-5,00 ;-0,10)$ & $-0,80(-1,90 ; 0,40)$ & \\
\hline Mínimo; Máximo & $-4,60 ; 1,90$ & $-5,80 ; 0,90$ & $-4,60 ; 1,30$ & \\
\hline Hippocampus & & & & 0,177 \\
\hline Mediana (Q1; Q3) & $0,40(-1,00 ; 1,30)$ & $-0,80(-1,40 ; 0,80)$ & $-0,20(-1,40 ; 0,40)$ & \\
\hline Mínimo; Máximo & $-3,90 ; 6,00$ & $-2,40 ; 5,00$ & $-3,70 ; 2,30$ & \\
\hline $\begin{array}{l}\text { Inferior frontal gyrus, opercular } \\
\text { part }\end{array}$ & & & & 0,585 \\
\hline Mediana (Q1; Q3) & $-1,00(-1,80 ;-0,30)$ & $-1,10(-1,70 ;-0,80)$ & $0,00(-0,50 ; 0,20)$ & \\
\hline Mínime & $-3,10 ; 0,7$ & $-2,70 ; 0,20$ & 1,50 & \\
\hline Inferior frontal gyrus & & & & 0,862 \\
\hline Mediana (Q1; Q3) & $-1,20(-2,20 ;-0,50)$ & $-1,60(-2,00 ;-0,80)$ & $0,00(-0,80 ; 0,70)$ & \\
\hline Mínimo; Máximo & $-5,60 ; 1,10$ & $-2,80 ; 3,20$ & $-2,00 ; 3,00$ & \\
\hline $\begin{array}{l}\text { Inferior frontal gyrus, triangular } \\
\text { part }\end{array}$ & & & & 0,758 \\
\hline Mediana (Q1; Q3) & $-2,70(-4,20 ;-1,50)$ & $-2,80(-5,10 ;-1,60)$ & $0,20(-0,90 ; 0,50)$ & \\
\hline Mínin & $-7,90 ;-0,70$ & $-7,50 ;-0,20$ & $-2,50 ; 1,10$ & \\
\hline Inferior occipital gyrus & & & & 0,200 \\
\hline Mediana (Q1; Q3) & $-1,70(-2,90 ;-1,20)$ & $-1,60(-3,10 ;-1,00)$ & $0,30(-0,10 ; 0,50)$ & \\
\hline Mínimo; Máximo & $-6,80 ; 0,40$ & $-6,40 ; 0,80$ & $-1,40 ; 2,30$ & \\
\hline Inferior parietal, but & & & & \\
\hline supramarginal and angular & & & & 0,658 \\
\hline gyri & & & & \\
\hline Mediana (Q1; Q3) & $-2,00(-4,50 ;-0,80)$ & $-2,20(-4,50 ;-1,40)$ & $-0,20(-0,40 ; 0,50)$ & \\
\hline Mínimo; Máximo & $-7,70 ; 0,60$ & $-6,90 ; 0,20$ & $-1,30 ; 0,80$ & \\
\hline
\end{tabular}


...continuação

\begin{tabular}{|c|c|c|c|c|}
\hline Inferior temporal gyrus & & & & 0,983 \\
\hline Mediana (Q1; Q3) & $-1,80(-5,00 ;-0,20)$ & $-2,50(-3,90 ;-1,40)$ & $0,30(-2,10 ; 1,40)$ & \\
\hline Mínimo; Máximo & $-7,90 ; 0,80$ & $-6,50 ; 1,60$ & $-4,70 ; 3,50$ & \\
\hline Insula & & & & 0,862 \\
\hline Mediana (Q1; Q3) & $0,30(-1,00 ; 1,10)$ & $0,00(-0,70 ; 1,00)$ & $-0,10(-0,60 ; 0,50)$ & \\
\hline Mínimo; Máximo & $-2,10 ; 1,80$ & $-2,30 ; 2,10$ & $-3,40 ; 2,00$ & \\
\hline Lenticular nucleus, pallidum & & & & 0,618 \\
\hline Mediana (Q1; Q3) & $0,60(-0,60 ; 1,40)$ & $0,30(-0,60 ; 1,80)$ & $0,10(-0,70 ; 0,60)$ & \\
\hline Mínimo; Máximo & $-2,20 ; 2,90$ & $-3,10 ; 4,00$ & $-1,20 ; 2,10$ & \\
\hline Lenticular nucleus, putamen & & & & 0,107 \\
\hline Mediana (Q1; Q3) & $1,50(0,70 ; 4,30)$ & $2,40(1,20 ; 3,80)$ & $0,70(0,00 ; 1,20)$ & \\
\hline Mínimo; Máximo & $-1,60 ; 6,40$ & $-1,10 ; 6,90$ & $-2,10 ; 2,70$ & \\
\hline Mesial temporal lobe & & & & 0,376 \\
\hline Mediana (Q1; Q3) & $0,80(-1,40 ; 1,70)$ & $-0,40(-1,10 ; 1,10)$ & $-0,10(-1,40 ; 0,70)$ & \\
\hline Mínimo; Máximo & $-3,30 ; 5,20$ & $-2,10 ; 4,20$ & $-4,80 ; 2,50$ & \\
\hline $\begin{array}{l}\text { Middle cingulate and } \\
\text { paracingulate gyri }\end{array}$ & & & & 0,711 \\
\hline Mediana (Q1; Q3) & $0,10(-0,50 ; 1,20)$ & $0,20(-0,60 ; 1,20)$ & $-0,10(-0,60 ; 0,50)$ & \\
\hline Mínimo; Máximo & $-3,40 ; 2,40$ & $-4,30 ; 2,60$ & $-4,50 ; 1,60$ & \\
\hline Middle frontal gyrus & & & & 0,031 \\
\hline Mediana (Q1; Q3) & $-1,70(-3,10 ; 0,40)$ & $-2,40(-3,80 ;-0,90)$ & $-0,40(-1,10 ;-0,10)$ & \\
\hline Mínimo; Máximo & $-5,10 ; 1,30$ & $-5,20 ; 1,30$ & $-4,50 ; 1,60$ & \\
\hline Middle frontal gyrus, orbital part & & & & $>0,999$ \\
\hline Mediana (Q1; Q3) & $-1,30(-2,30 ;-0,80)$ & $-1,40(-2,00 ;-0,50)$ & $-0,10(-0,70 ; 0,90)$ & \\
\hline Mínimo; Máximo & $-3,00 ; 1,20$ & $-4,80 ; 2,00$ & $-2,50 ; 1,30$ & \\
\hline Middle occipital gyrus & & & & 0,904 \\
\hline Mediana (Q1; Q3) & $-1,80(-2,80 ;-1,40)$ & $-2,40(-3,50 ;-1,20)$ & $-0,10(-0,40 ; 0,40)$ & \\
\hline Mínimo; Máximo & $-7,90 ; 0,00$ & $-7,50 ; 0,60$ & $-1,70 ; 2,10$ & \\
\hline Middle temporal gyrus & & & & 0,904 \\
\hline Mediana (Q1; Q3) & $-1,10(-3,70 ;-0,20)$ & $-2,20(-3,60 ;-0,80)$ & $0,30(-1,00 ; 1,00)$ & \\
\hline Mínimo; Máximo & $-8,90 ; 0,80$ & $-7,90 ; 1,80$ & $-5,00 ; 3,40$ & \\
\hline Occipital lobe & & & & 0,277 \\
\hline Mediana (Q1; Q3) & $-1,60(-2,90 ; 0,10)$ & $-1,30(-2,60 ;-0,90)$ & $0,30(-0,20 ; 0,60)$ & \\
\hline Mínimo; Máximo & $-8,80 ; 1,40$ & $-7,00 ; 1,80$ & $-1,90 ; 2,30$ & \\
\hline Paracentral lobule & & & & 0,513 \\
\hline Mediana (Q1; Q3) & $1,60(0,40 ; 2,90)$ & $1,20(0,50 ; 2,70)$ & $-0,10(-1,00 ; 0,30)$ & \\
\hline Mínimo; Máximo & $-1,90 ; 6,30$ & $-2,00 ; 5,90$ & $-1,90 ; 1,80$ & \\
\hline Parahippocampal gyrus & & & & 0,615 \\
\hline Mediana (Q1; Q3) & $1,00(-0,90 ; 1,80)$ & $-0,10(-0,80 ; 1,40)$ & $0,10(-1,50 ; 0,80)$ & \\
\hline Mínimo; Máximo & $-2,80 ; 2,90$ & $-2,30 ; 3,30$ & $-4,90 ; 1,80$ & \\
\hline Parietal lobe & & & & 0,831 \\
\hline Mediana (Q1; Q3) & $-2,20(-4,30 ;-1,70)$ & $-2,30(-4,60 ;-1,60)$ & $0,00(-0,60 ; 0,50)$ & \\
\hline Mínimo; Máximo & $-10,50 ; 0,10$ & $-9,60 ; 0,10$ & $-2,40 ; 2,10$ & \\
\hline Postcentral gyrus & & & & 0,384 \\
\hline Mediana (Q1; Q3) & $0,70(-0,50 ; 1,50)$ & $0,20(-0,70 ; 1,60)$ & $-0,40(-1,00 ; 0,30)$ & \\
\hline Mínimo; Máximo & $-1,70 ; 3,50$ & $-2,30 ; 5,50$ & $-3,80 ; 4,00$ & \\
\hline $\begin{array}{l}\text { Posterior cingulate and } \\
\text { paracingulate gyri }\end{array}$ & & & & 0,570 \\
\hline Mediana (Q1; Q3) & $-0,70(-0,90 ; 0,80)$ & $-0,30(-0,80 ; 0,40)$ & $0,10(-0,30 ; 0,50)$ & \\
\hline Mínimo; Máximo & $-3,40 ; 2,90$ & $-3,70 ; 1,70$ & $-1,20 ; 0,60$ & \\
\hline Precentral gyrus & & & & 0,541 \\
\hline Mediana (Q1; Q3) & $1,30(-1,10 ; 1,80)$ & $0,70(-0,90 ; 2,30)$ & $-0,30(-0,60 ; 0,70)$ & \\
\hline Mínimo; Máximo & $-2,50 ; 5,80$ & $-2,40 ; 7,60$ & $-2,10 ; 3,10$ & \\
\hline Precuneus & & & & 0,630 \\
\hline Mediana (Q1; Q3) & $-0,20(-1,70 ; 0,50)$ & $0,10(-1,10 ; 0,70)$ & $0,10(-0,30 ; 0,40)$ & \\
\hline Mínimo; Máximo & $-5,00 ; 2,10$ & $-5,30 ; 1,80$ & $-1,30 ; 3,60$ & \\
\hline $\begin{array}{l}\text { Superior frontal gyrus, } \\
\text { dorsolateral }\end{array}$ & & & & 0,004 \\
\hline
\end{tabular}


...continuação

\begin{tabular}{|c|c|c|c|c|}
\hline Mediana (Q1; Q3) & $-0,10(-1,20 ; 2,30)$ & $-0,50(-2,30 ; 0,10)$ & $-0,80(-1,80 ; 0,00)$ & \\
\hline Mínimo; Máximo & $-2,90 ; 4,60$ & $-4,00 ; 4,70$ & $-5,00 ; 1,00$ & \\
\hline Superior frontal gyrus, medial & & & & 0,056 \\
\hline Mediana (Q1; Q3) & $-0,90(-2,50 ; 0,40)$ & $-1,40(-2,90 ;-0,20)$ & $-0,50(-1,50 ; 0,30)$ & \\
\hline Mínimo; Máximo & $-5,10 ; 4,60$ & $-4,80 ; 1,90$ & $-3,40 ; 1,50$ & \\
\hline $\begin{array}{l}\text { Superior frontal gyrus, medial } \\
\text { orbital }\end{array}$ & & & & 0,153 \\
\hline Mediana (Q1; Q3) & $-1,10(-3,00 ; 0,50)$ & $-2,30(-3,80 ; 0,40)$ & $-0,50(-1,30 ; 0,50)$ & \\
\hline Mínimo; Máximo & $-5,90 ; 3,10$ & $-7,20 ; 3,40$ & $-3,90 ; 3,00$ & \\
\hline $\begin{array}{l}\text { Superior frontal gyrus, orbital } \\
\text { part }\end{array}$ & & & & 0,519 \\
\hline Mediana (Q1; Q3) & $-2,80(-4,10 ;-1,20)$ & $-2,50(-4,10 ;-1,10)$ & $0,10(-1,30 ; 1,00)$ & \\
\hline Mínimo; Máximo & $-7,20 ;-0,40$ & $-8,70 ;-0,30$ & $-1,60 ; 1,70$ & \\
\hline SUV Superior occipital gyrus & & & & 0,371 \\
\hline Mediana (Q1; Q3) & $-0,70(-2,00 ;-0,10)$ & $-0,90(-2,10 ; 0,20)$ & $0,10(-0,40 ; 0,70)$ & \\
\hline Mínimo; Máximo & $-3,70 ; 1,60$ & $-2,90 ; 1,70$ & $-0,80 ; 1,40$ & \\
\hline Superior parietal gyrus & & & & 0,462 \\
\hline Mediana (Q1; Q3) & $-0,80(-1,70 ;-0,30)$ & $-1,00(-1,60 ;-0,20)$ & $0,00(-0,30 ; 0,60)$ & \\
\hline Mínimo; Máximo & $-3,50 ; 0,90$ & $-2,80 ; 0,70$ & $-0,60 ; 0,80$ & \\
\hline Superior temporal gyrus & & & & 0,845 \\
\hline Mediana (Q1; Q3) & $-0,20(-1,50 ; 1,30)$ & $0,40(-1,20 ; 1,10)$ & $0,00(-0,90 ; 1,00)$ & \\
\hline Mínimo; Máximo & $-3,20 ; 3,10$ & $-4,20 ; 3,10$ & $-2,70 ; 2,50$ & \\
\hline Supplementary motor area & & & & 0,031 \\
\hline Mediana (Q1; Q3) & $1,20(-0,30 ; 2,70)$ & $1,10(0,00 ; 1,90)$ & $-0,40(-1,40 ; 0,10)$ & \\
\hline Mínimo; Máximo & $-1,90 ; 6,60$ & $-2,40 ; 5,60$ & $-2,30 ; 1,50$ & \\
\hline Supramarginal gyrus & & & & 0,932 \\
\hline Mediana (Q1; Q3) & $-1,90(-2,80 ;-0,60)$ & $-1,60(-3,40 ;-1,20)$ & $0,20(-0,60 ; 0,50)$ & \\
\hline Mínimo; Máximo & $-7,90 ; 0,50$ & $-7,00 ;-0,20$ & $-4,70 ; 1,40$ & \\
\hline Temporal lobe & & & & 0,879 \\
\hline Mediana (Q1; Q3) & $-1,10(-3,80 ; 0,00)$ & $-2,60(-3,80 ;-0,50)$ & $0,60(-1,50 ; 1,00)$ & \\
\hline Mínimo; Máximo & $-8,30$ & $-6,90$ & $-5,20$ & \\
\hline Thalamus & & & & 0,233 \\
\hline Mediana (Q1; Q3) & $0,60(0,20 ; 1,90)$ & $0,40(0,00 ; 1,00)$ & $-0,10(-0,50 ; 0,10)$ & \\
\hline Mínimo; Máximo & $-0,80 ; 2,90$ & $-1,30 ; 3,40$ & $-1,90 ; 1,00$ & \\
\hline
\end{tabular}

Q1: primeiro quartil; Q3: terceiro quartil; valor-p: teste t-pareado.

Tabela 7. Medidas do exame de neuroimagem funcional através do PET-RM com FDG Desvio Padrão no lado ipsilateral ao lado mais afetado dos participantes do estudo $(n=19)$ nas avaliações pré e pósintervenção

\begin{tabular}{|c|c|c|c|c|}
\hline \multirow{2}{*}{$\begin{array}{l}\text { Exame PET-RM com FDG no } \\
\text { Lado Ipsilateral }\end{array}$} & \multicolumn{2}{|c|}{ Momento de avaliação } & \multirow{2}{*}{$\begin{array}{l}\text { Variação } \\
\text { (pós - pré) }\end{array}$} & \multirow[b]{2}{*}{ Valor-p } \\
\hline & Pré-intervenção & Pós-intervenção & & \\
\hline Angular gyrus & & & & 0,887 \\
\hline Mediana (Q1; Q3) & $-3,50(-4,80 ;-1,50)$ & $-3,10(-4,60 ;-2,00)$ & $0,20(-0,70 ; 0,70)$ & \\
\hline Mínimo; Máximo & $-8,40 ; 0,20$ & $-8,10 ; 0,20$ & $-2,30 ; 1,40$ & \\
\hline $\begin{array}{l}\text { Anterior cingulate and } \\
\text { paracingulate gyri }\end{array}$ & & & & 0,126 \\
\hline Mediana (Q1; Q3) & $-0,30(-1,30 ; 1,10)$ & $-0,40(-1,80 ; 0,50)$ & $-0,10(-0,60 ; 0,20)$ & \\
\hline Mínimo; Máximo & $-2,00 ; 2,60$ & $-3,00 ; 2,50$ & $-4,00 ; 1,30$ & \\
\hline Basal ganglia & & & & 0,394 \\
\hline Mediana (Q1; Q3) & $0,40(-0,60 ; 1,30)$ & $0,40(-0,80 ; 1,70)$ & $0,20(-0,10 ; 0,70)$ & \\
\hline Mínimo; Máximo & $-1,70 ; 3,10$ & $-1,20 ; 2,60$ & $-1,90 ; 1,20$ & \\
\hline Caudate nucleus & & & & 0,754 \\
\hline Mediana (Q1; Q3) & $-0,60(-0,60 ; 0,10)$ & $-0,60(-0,90 ; 0,30)$ & $0,00(-0,30 ; 0,20)$ & \\
\hline Mínimo; Máximo & $-2,70 ; 1,30$ & $-2,70 ; 1,40$ & $-1,00 ; 0,90$ & \\
\hline Central region & & & & 0,732 \\
\hline Mediana (Q1; Q3) & $0,80(-0,90 ; 2,80)$ & $0,50(-1,10 ; 3,30)$ & $-0,10(-0,80 ; 0,60)$ & \\
\hline Mínimo; Máximo & $-2,70 ; 7,20$ & $-3,10 ; 5,50$ & $-3,90 ; 2,10$ & \\
\hline
\end{tabular}


...continuação

\begin{tabular}{|c|c|c|c|c|}
\hline \multicolumn{4}{|l|}{ Cerebellum } & \multirow[t]{2}{*}{$>0,999$} \\
\hline Mediana (Q1; Q3) & $-1,20(-1,50 ;-0,90)$ & $-1,30(-2,60 ;-0,50)$ & $-0,10(-0,50 ; 0,60)$ & \\
\hline Mínimo; Máximo & $-3,50 ;-0,20$ & $-3,00 ; 0,10$ & $-1,70 ; 1,20$ & \\
\hline Cingulate and paracingulate gyr & & & & 0,559 \\
\hline Mediana (Q1; Q3) & $-0,10(-0,90 ; 1,30)$ & $-0,10(-1,20 ; 1,00)$ & $-0,10(-0,40 ; 0,30)$ & \\
\hline Mínimo; Máximo & $-3,50 ; 2,60$ & $-4,50 ; 2,90$ & $-3,30 ; 1,40$ & \\
\hline Cuneus & & & & 0,036 \\
\hline Mediana (Q1; Q3) & $0,00(-1,90 ; 0,90)$ & $0,60(-1,10 ; 1,50)$ & $0,40(-0,30 ; 0,90)$ & \\
\hline Mínimo; Máximo & $-4,30 ; 3,40$ & $-3,20 ; 3,10$ & $-1,00 ; 2,80$ & \\
\hline Frontal lobe & & & & 0,094 \\
\hline Mediana (Q1; Q3) & $-1,90(-3,50 ;-0,40)$ & $-2,20(-4,70 ;-1,20)$ & $-0,50(-1,90 ; 0,30)$ & \\
\hline Mínimo; Máximo & $-6,10 ; 5,10$ & $-6,00 ; 2,30$ & $-4,80 ; 2,30$ & \\
\hline Hippocampus & & & & 0,334 \\
\hline Mediana (Q1; Q3) & $-0,10(-1,00 ; 0,40)$ & $-0,60(-1,10 ; 0,10)$ & $-0,30(-1,20 ; 0,60)$ & \\
\hline Mínimo; Máximo & $-3,60 ; 3,90$ & $-2,50 ; 2,50$ & $-2,10 ; 1,50$ & \\
\hline $\begin{array}{l}\text { Inferior frontal gyrus, opercular } \\
\text { part }\end{array}$ & & & & 0,824 \\
\hline Mediana (Q1; Q3) & $-1,10(-1,70 ;-0,40)$ & $-1,20(-1,50 ;-0,70)$ & $0,20(-0,40 ; 0,30)$ & \\
\hline Mínimo; Máximo & $-3,10 ; 1,10$ & $-2,50 ; 1,00$ & $-1,10 ; 1,00$ & \\
\hline Inferior frontal gyrus & & & & 0,793 \\
\hline Mediana (Q1; Q3) & $-1,30(-2,50 ;-0,50)$ & $-1,10(-2,10 ;-1,00)$ & $-0,40(-0,90 ; 1,30)$ & \\
\hline Mínimo; Máximo & $-4,30 ; 1,10$ & $-3,20 ; 2,20$ & $-1,90 ; 2,00$ & \\
\hline $\begin{array}{l}\text { Inferior frontal gyrus, triangular } \\
\text { part }\end{array}$ & & & & 0,868 \\
\hline Mediana (Q1; Q3) & $-2,90(-4,60 ;-1,80)$ & $-2,90(-4,40 ;-1,90)$ & $0,30(-0,60 ; 0,50)$ & \\
\hline Mínimo; Máximo & $-6,90 ;-0,80$ & $-5,70 ; 0,10$ & $-1,60 ; 1,50$ & \\
\hline Inferior occipital gyrus & & & & 0,695 \\
\hline Mediana (Q1; Q3) & $-2,10(-2,60 ;-0,30)$ & $-1,70(-2,50 ;-1,20)$ & $0,30(-0,70 ; 0,80)$ & \\
\hline Mínimo; Máximo & $-6,00 ; 0,50$ & $-5,40 ; 0,80$ & $-1,70 ; 1,50$ & \\
\hline Inferior parietal, but & & & & \\
\hline $\begin{array}{l}\text { supramarginal and angular } \\
\text { gyri }\end{array}$ & & & & 0,965 \\
\hline Mediana (Q1; Q3) & $-1,90(-2,90 ;-1,10)$ & $-2,00(-3,20 ;-1,10)$ & $-0,10(-0,20 ; 0,30)$ & \\
\hline Mínimo; Máximo & $-6,30 ; 0,80$ & $-6,10 ; 1,10$ & $-1,20 ; 0,80$ & \\
\hline Inferior temporal gyrus & & & & 0,513 \\
\hline Mediana (Q1; Q3) & $-3,20(-4,70 ;-0,30)$ & $-1,80(-4,80 ;-0,50)$ & $0,10(-0,70 ; 0,80)$ & \\
\hline Mínimo; Máximo & $-8,00 ; 1,30$ & $-7,20 ; 1,60$ & $-4,00 ; 2,70$ & \\
\hline Insula & & & & 0,836 \\
\hline Mediana (Q1; Q3) & $0,10(-0,80 ; 1,60)$ & $-0,20(-0,90 ; 1,40)$ & $0,00(-0,20 ; 0,70)$ & \\
\hline Mínimo; Máximo & $-1,60 ; 2,40$ & $-1,50 ; 2,50$ & $-2,90 ; 0,90$ & \\
\hline Lenticular nucleus, pallidum & & & & 0,984 \\
\hline Mediana (Q1; Q3) & $0,10(-1,30 ; 0,80)$ & $0,00(-0,70 ; 1,20)$ & $-0,10(-0,60 ; 0,50)$ & \\
\hline Mínimo; Máximo & $-2,00 ; 2,10$ & $-2,60 ; 2,10$ & $-2,00 ; 1,80$ & \\
\hline Lenticular nucleus, putamen & & & & 0,081 \\
\hline Mediana (Q1; Q3) & $2,00(0,20 ; 3,50)$ & $2,70(0,60 ; 4,60)$ & $0,70(0,00 ; 1,20)$ & \\
\hline Mínimo; Máximo & $-1,60 ; 5,70$ & $-0,70 ; 5,90$ & $-2,80 ; 2,00$ & \\
\hline Mesial temporal lobe & & & & 0,904 \\
\hline Mediana (Q1; Q3) & $-0,20(-2,00 ; 1,10)$ & $-0,10(-1,40 ; 0,30)$ & $0,20(-0,80 ; 0,70)$ & \\
\hline Mínimo; Máximo & $-2,40 ; 4,00$ & $-3,10 ; 3,20$ & $-2,40 ; 2,40$ & \\
\hline $\begin{array}{l}\text { Middle cingulate and } \\
\text { paracingulate gyri }\end{array}$ & & & & 0,952 \\
\hline Mediana (Q1; Q3) & $0,40(-0,30 ; 1,70)$ & $0,40(-0,60 ; 1,90)$ & $-0,10(-0,60 ; 0,60)$ & \\
\hline Mínimo; Máximo & $-4,10 ; 3,00$ & $-4,80 ; 2,90$ & $-2,80 ; 1,10$ & \\
\hline Middle frontal gyrus & & & & 0,616 \\
\hline Mediana (Q1; Q3) & $-2,50(-3,50 ;-1,20)$ & $-2,20(-3,10 ;-1,90)$ & $-0,10(-0,60 ; 0,60)$ & \\
\hline Mínimo; Máximo & $-4,50 ; 3,20$ & $-5,00 ; 1,70$ & $-3,80 ; 1,30$ & \\
\hline $\begin{array}{l}\text { Middle frontal gyrus, orbital } \\
\text { part }\end{array}$ & & & & 0,793 \\
\hline
\end{tabular}


...continuação

\begin{tabular}{|c|c|c|c|c|}
\hline Mediana (Q1; Q3) & $-1,60(-2,60 ;-0,90)$ & $-1,60(-2,50 ;-1,00)$ & $0,10(-0,60 ; 0,60)$ & \\
\hline Mínimo; Máximo & $-3,10 ;-0,60$ & $-3,60 ; 0,20$ & $-1,40 ; 2,30$ & \\
\hline Middle occipital gyrus & & & & 0,248 \\
\hline Mediana (Q1; Q3) & $-1,80(-2,70 ;-0,90)$ & $-1,50(-2,70 ;-0,50)$ & $0,30(-0,30 ; 0,70)$ & \\
\hline Mínimo; Máximo & $-8,00 ; 0,60$ & $-7,40 ; 0,70$ & $-1,20 ; 1,30$ & \\
\hline Middle temporal gyrus & & & & 0,448 \\
\hline Mediana (Q1; Q3) & $-2,80(-4,20 ; 0,20)$ & $-1,80(-3,50 ;-0,60)$ & $0,30(-0,60 ; 1,00)$ & \\
\hline Mínimo; Máximo & $-8,70 ; 1,30$ & $-8,50 ; 0,70$ & $-5,30 ; 2,40$ & \\
\hline Occipital lobe & & & & 0,141 \\
\hline Mediana (Q1; Q3) & $-1,20(-1,80 ; 0,10)$ & $-0,60(-1,70 ; 0,00)$ & $0,50(-0,10 ; 0,70)$ & \\
\hline Mínimo; Máximo & $-9,30 ; 1,10$ & $-7,80 ; 1,50$ & $-1,50 ; 2,20$ & \\
\hline Paracentral lobule & & & & 0,235 \\
\hline Mediana (Q1; Q3) & $1,60(0,70 ; 2,70)$ & $1,20(0,80 ; 1,90)$ & $-0,40(-1,30 ; 0,40)$ & \\
\hline Mínimo; Máximo & 0,$00 ; 4,90$ & $-1,10 ; 5,20$ & $-3,60 ; 1,40$ & \\
\hline Parahippocampal gyrus & & & & 0,285 \\
\hline Mediana (Q1; Q3) & $-0,30(-2,10 ; 1,20)$ & $0,00(-2,00 ; 0,40)$ & $0,20(-0,20 ; 0,70)$ & \\
\hline Mínimo; Máximo & $-3,70 ; 2,40$ & $-3,10 ; 2,60$ & $-1,90 ; 2,30$ & \\
\hline Parietal lobe & & & & 0,084 \\
\hline Mediana (Q1; Q3) & $-2,70(-3,70 ;-1,80)$ & $-2,30(-3,90 ;-1,50)$ & $0,40(-0,20 ; 0,90)$ & \\
\hline Mínimo; Máximo & $-9,30 ; 0,40$ & $-8,10 ; 1,00$ & $-0,80 ; 1,30$ & \\
\hline Postcentral gyrus & & & & 0,879 \\
\hline Mediana (Q1; Q3) & $0,50(-0,60 ; 1,60)$ & $0,30(-0,70 ; 2,30)$ & $-0,10(-0,60 ; 0,60)$ & \\
\hline Mínimo; Máximo & $-2,40 ; 5,10$ & $-3,00 ; 4,10$ & $-2,90 ; 4,10$ & \\
\hline $\begin{array}{l}\text { Posterior cingulate and } \\
\text { paracingulate gyri }\end{array}$ & & & & 0,226 \\
\hline Mediana (Q1; Q3) & $-0,60(-1,30 ; 0,30)$ & $-0,60(-1,30 ; 0,50)$ & $0,20(-0,20 ; 0,50)$ & \\
\hline Mínimo; Máximo & $-3,30 ; 1,90$ & $-3,50 ; 1,80$ & $-0,70 ; 1,20$ & \\
\hline Precentral gyrus & & & & 0,420 \\
\hline Mediana (Q1; Q3) & $0,40(-0,90 ; 2,30)$ & $0,20(-1,10 ; 2,10)$ & $-0,10(-0,60 ; 0,30)$ & \\
\hline Mínimo; Máximo & $-1,70 ; 11,10$ & $-2,20 ; 7,00$ & $-4,10 ; 1,40$ & \\
\hline Precuneus & & & & 0,111 \\
\hline Mediana (Q1; Q3) & $0,00(-1,50 ; 0,70)$ & $0,20(-0,90 ; 1,10)$ & $0,40(-0,30 ; 0,60)$ & \\
\hline Mínimo; Máximo & $-3,30 ; 2,00$ & $-3,00 ; 2,40$ & $-0,90 ; 3,20$ & \\
\hline $\begin{array}{l}\text { Superior frontal gyrus, } \\
\text { dorsolateral }\end{array}$ & & & & 0,010 \\
\hline Mediana (Q1; Q3) & $0,10(-1,30 ; 1,50)$ & $-0,90(-2,00 ; 1,10)$ & $-0,60(-0,90 ; 0,00)$ & \\
\hline Mínimo; Máximo & $-2,70 ; 7,00$ & $-3,20 ; 4,50$ & $-4,40 ; 1,50$ & \\
\hline Superior frontal gyrus, medial & & & & 0,063 \\
\hline Mediana (Q1; Q3) & $-2,00(-2,50 ; 0,00)$ & $-1,90(-2,80 ;-0,20)$ & $-0,40(-1,00 ; 0,30)$ & \\
\hline Mínimo; Máximo & $-4,50 ; 5,50$ & $-6,10 ; 1,50$ & $-4,00 ; 1,90$ & \\
\hline $\begin{array}{l}\text { Superior frontal gyrus, medial } \\
\text { orbital }\end{array}$ & & & & 0,199 \\
\hline Mediana (Q1; Q3) & $-1,00(-3,00 ; 0,60)$ & $-1,80(-3,90 ; 0,60)$ & $-0,20(-1,90 ; 0,50)$ & \\
\hline Mínimo; Máximo & $-4,70 ; 1,90$ & $-7,00 ; 1,80$ & $-2,80 ; 2,10$ & \\
\hline $\begin{array}{l}\text { Superior frontal gyrus, orbital } \\
\text { part }\end{array}$ & & & & 0,234 \\
\hline Mediana (Q1; Q3) & $-1,50(-3,30 ;-1,10)$ & $-2,20(-3,60 ;-0,90)$ & $-0,40(-1,10 ; 0,60)$ & \\
\hline Mínimo; Máximo & $-6,70 ;-0,50$ & $-8,60 ;-0,20$ & $-2,50 ; 1,50$ & \\
\hline SUV Superior occipital gyrus & & & & 0,050 \\
\hline Mediana (Q1; Q3) & $-0,40(-1,30 ; 0,30)$ & $-0,10(-0,70 ; 0,40)$ & $0,30(-0,20 ; 1,10)$ & \\
\hline Mínimo; Máximo & $-3,80 ; 2,10$ & $-2,30 ; 2,90$ & $-0,70 ; 2,60$ & \\
\hline Superior parietal gyrus & & & & 0,374 \\
\hline Mediana (Q1; Q3) & $-0,80(-1,50 ; 0,00)$ & $-0,50(-2,00 ;-0,20)$ & $0,30(-0,50 ; 0,50)$ & \\
\hline Mínimo; Máximo & $-3,50 ; 1,50$ & $-3,60 ; 1,90$ & $-0,90 ; 1,40$ & \\
\hline Superior temporal gyrus & & & & 0,663 \\
\hline Mediana (Q1; Q3) & $0,70(-1,20 ; 1,80)$ & $1,00(-1,00 ; 1,90)$ & $0,20(-0,80 ; 0,80)$ & \\
\hline Mínimo; Máximo & $-2,50 ; 2,60$ & $-4,50 ; 2,70$ & $-3,30 ; 1,40$ & \\
\hline Supplementary motor area & & & & 0,012 \\
\hline
\end{tabular}




\begin{tabular}{|c|c|c|c|c|}
\hline Mediana (Q1; Q3) & $1,60(0,30 ; 3,10)$ & $0,80(-0,10 ; 3,00)$ & $-0,30(-1,20 ; 0,10)$ & \\
\hline Mínimo; Máximo & $-1,10 ; 7,60$ & $-1,60 ; 4,80$ & $-2,80 ; 0,50$ & \\
\hline Supramarginal gyrus & & & & 0,275 \\
\hline Mediana (Q1; Q3) & $-2,00(-3,10 ;-1,30)$ & $-1,60(-3,20 ;-0,80)$ & $0,20(-0,30 ; 0,80)$ & \\
\hline Mínimo; Máximo & $-5,90 ;-0,50$ & $-5,50 ; 0,10$ & $-1,80 ; 1,30$ & \\
\hline Temporal lobe & & & & 0,257 \\
\hline Mediana (Q1; Q3) & $-2,60(-3,40 ; 0,70)$ & $-2,00(-3,20 ; 0,10)$ & $0,50(-0,60 ; 1,10)$ & \\
\hline Mínimo; Máximo & $-7,40 ; 1,40$ & $-8,10 ; 0,90$ & $-5,70 ; 2,80$ & \\
\hline $\begin{array}{l}\text { Temporal pole: middle } \\
\text { temporal gyrus }\end{array}$ & & & & 0,586 \\
\hline $\begin{array}{l}\text { Mediana (Q1; Q3) } \\
\text { Mínimo; Máximo }\end{array}$ & $\begin{array}{c}-1,80(-3,20 ;-0,40) \\
-8,50 ; 0,40\end{array}$ & $\begin{array}{c}-1,40(-2,70 ;-0,90) \\
-7,60 ; 0,00\end{array}$ & $\begin{array}{c}0,50(-0,80 ; 0,90) \\
-3,60 ; 3,40\end{array}$ & \\
\hline $\begin{array}{l}\text { Temporal pole: superior } \\
\text { temporal gyrus }\end{array}$ & & & & 0,248 \\
\hline Mediana (Q1; Q3) & $-0,10(-1,60 ; 0,20)$ & $-1,20(-2,20 ; 0,70)$ & $-0,30(-1,10 ; 0,50)$ & \\
\hline Mínimo; Máximo & $-4,00 ; 2,10$ & $-3,80 ; 1,80$ & $-2,30 ; 1,50$ & \\
\hline Thalamus & & & & 0,221 \\
\hline Mediana (Q1; Q3) & $1,40(0,30 ; 2,40)$ & $1,10(-0,50 ; 2,00)$ & $-0,20(-0,60 ; 0,30)$ & \\
\hline Mínimo; Máximo & $-1,50 ; 3,10$ & $-1,60 ; 4,60$ & $-2,50 ; 1,50$ & \\
\hline
\end{tabular}

Q1: primeiro quartil; Q3: terceiro quartil; valor-p: teste t-pareado. 